\title{
Evaluation of the effects of aggregate gradation and compaction effort on the voids in mineral aggregate in asphalt concrete
}

\author{
Logan Bessette
}

Follow this and additional works at: https://researchrepository.wvu.edu/etd

\section{Recommended Citation}

Bessette, Logan, "Evaluation of the effects of aggregate gradation and compaction effort on the voids in mineral aggregate in asphalt concrete" (2013). Graduate Theses, Dissertations, and Problem Reports.

7301.

https://researchrepository.wvu.edu/etd/7301

This Thesis is protected by copyright and/or related rights. It has been brought to you by the The Research Repository @WVU with permission from the rights-holder(s). You are free to use this Thesis in any way that is permitted by the copyright and related rights legislation that applies to your use. For other uses you must obtain permission from the rights-holder(s) directly, unless additional rights are indicated by a Creative Commons license in the record and/ or on the work itself. This Thesis has been accepted for inclusion in WVU Graduate Theses, Dissertations, and Problem Reports collection by an authorized administrator of The Research Repository @ WVU. For more information, please contact researchrepository@mail.wvu.edu. 


\title{
EVALUATION OF THE EFFECTS OF AGGREGATE GRADATION AND COMPACTION EFFORT ON THE VOIDS IN MINERAL AGGREGATE IN ASPHALT CONCRETE
}

\author{
Logan Bessette
}

\author{
Thesis submitted to the \\ Benjamin M. Statler College of Engineering and Mineral Resources \\ at West Virginia University \\ in partial fulfillment of the requirements \\ for the degree of
}

Master of Science

in

Civil Engineering
Dr. John P. Zaniewski, Chair
Dr. John Quaranta
Dr. Avinash Unnikrishnan

Department of Civil and Environmental Engineering

Morgantown, West Virginia

2013

Keywords: Voids in Mineral Aggregate (VMA), Fracture Energy, Compaction Effort 


\begin{abstract}
All rights reserved
INFORMATION TO ALL USERS

The quality of this reproduction is dependent upon the quality of the copy submitted.

In the unlikely event that the author did not send a complete manuscript and there are missing pages, these will be noted. Also, if material had to be removed, a note will indicate the deletion.
\end{abstract}

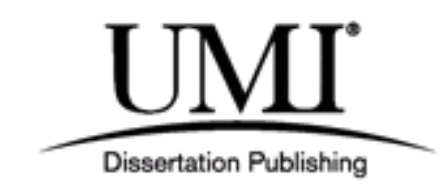

UMI 1549729

Published by ProQuest LLC (2013). Copyright in the Dissertation held by the Author.

Microform Edition (c) ProQuest LLC.

All rights reserved. This work is protected against unauthorized copying under Title 17, United States Code

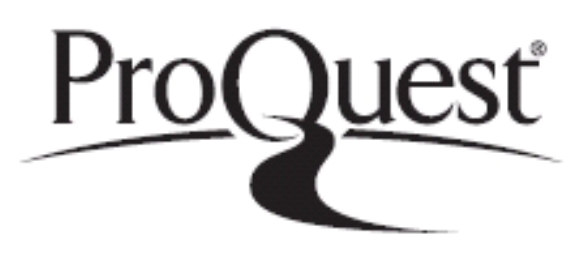

ProQuest LLC.

789 East Eisenhower Parkway

P.O. Box 1346

Ann Arbor, MI 48106 - 1346 


\section{ABSTRACT \\ EVALUATION OF THE EFFECT OF AGGREGATE GRADATION AND COMPACTION EFFORT ON THE VOIDS IN MINERAL AGGREGATE IN ASPHALT CONCRETE}

\section{Logan Bessette}

Asphalt concrete should resist short-term rutting, provide resistance to thermal cracking, and maintain structural integrity through the design life of the structure. Balancing these factors is achieved by ensuring adequate asphalt binder in a strong aggregate structure. The design asphalt content is decreased by applying additional compaction effort in the form of increased gyrations in the Superpave Gyrator Compactor. The mixes that undergo increased compaction effort present decreased fatigue life, although they resist short-term rutting. Mixes that undergo less compaction effort contain more binder and have long fatigue lives, although they are susceptible to rutting.

Two hypotheses were tested to determine the effects of compaction effort, and gradation on the voids in mineral aggregate. Three gradations were tested to simulate the range of aggregate gradations allowed within the West Virginia Department of Highways control points for $9.5 \mathrm{~mm}$ asphalt concrete at compaction levels of 80 , and 100 gyrations. The reduction in the number of design gyrations for asphalt concretes in West Virginia does not create significant differences in the design parameter, voids in mineral aggregate (VMA). At a given compaction level, moving away from the maximum density line, either coarse- or fine-graded, creates statistically different VMA.

Additionally, the bulk specific gravity samples were tested for indirect tensile (IDT) strength, and fracture energy. The 80 gyration mixes presented higher IDT strength than the 100 gyration mixes. Mixes with high compaction slopes presented the lowest IDT strength. Using the load-deflection curves from the IDT test, the fracture energy was calculated. The 80 gyration mixes had fracture energy $32 \%$ greater than the 100 gyration mixes, indicating an increased fatigue life. The coarse graded mix has the largest increase in fracture energy when reducing compaction effort, although it had the lowest IDT strength. 


\section{TABLE OF CONTENTS}

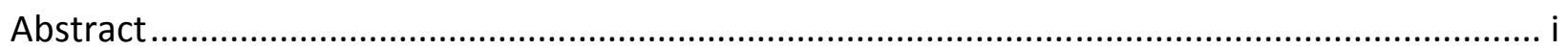

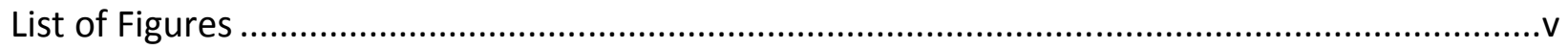

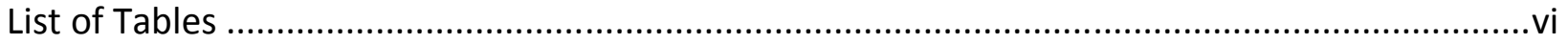

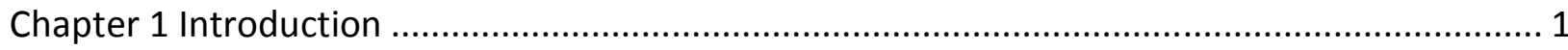

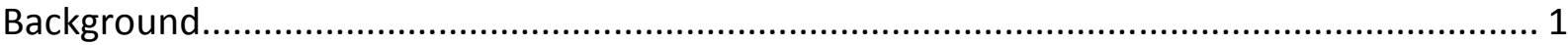

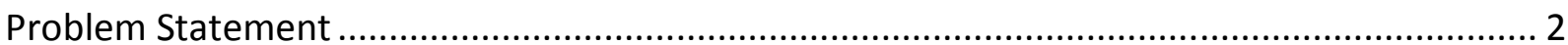

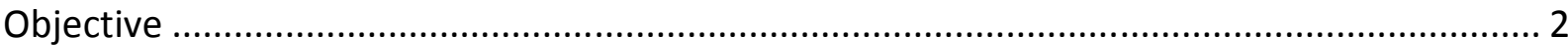

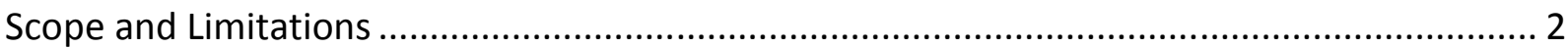

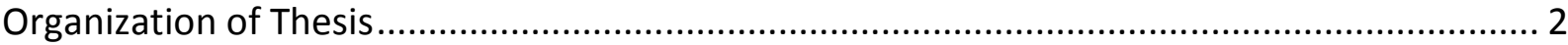

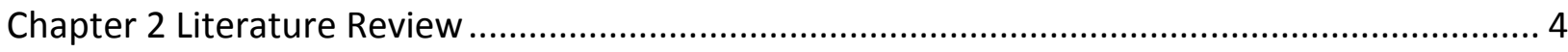

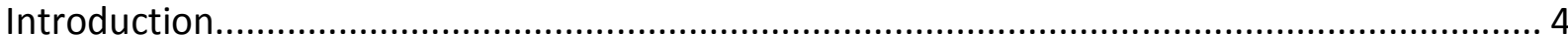

Asphalt Concrete Mixture Design ....................................................................................... 4

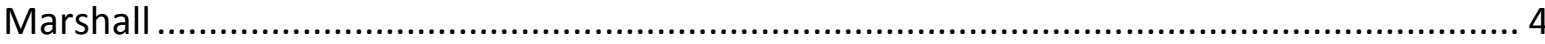

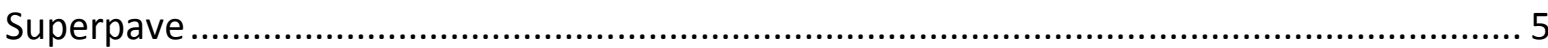

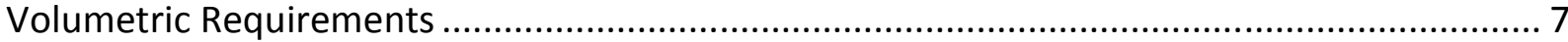

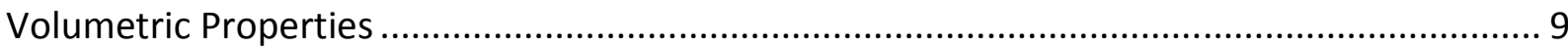

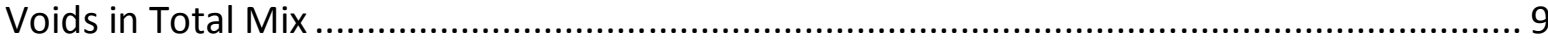

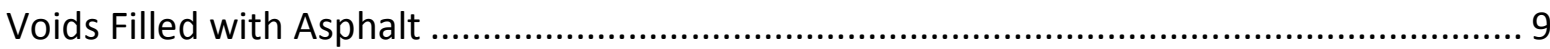

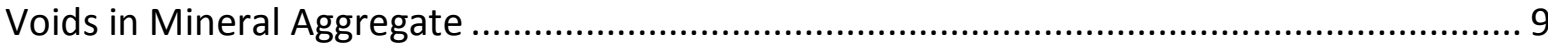

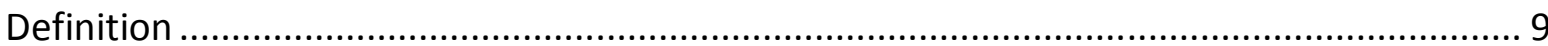

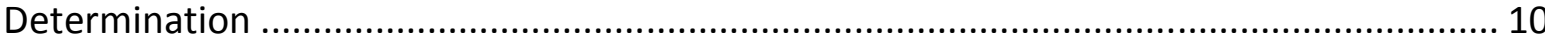

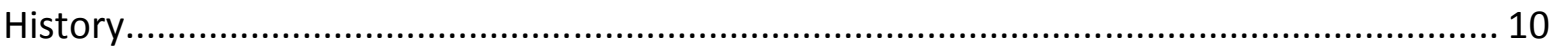

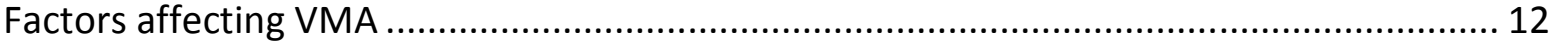

Effect of VMA on Asphalt Concrete Performance ................................................................ 14

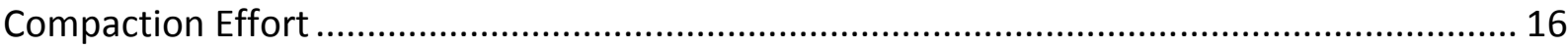

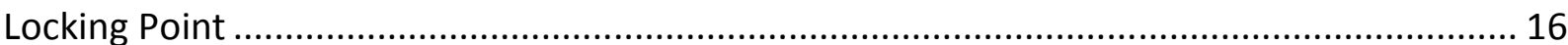

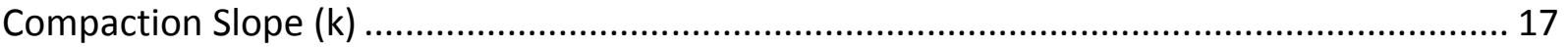

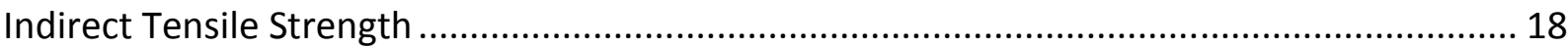




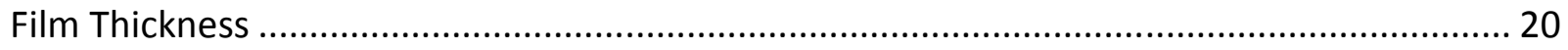

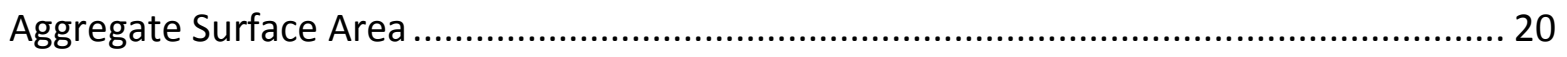

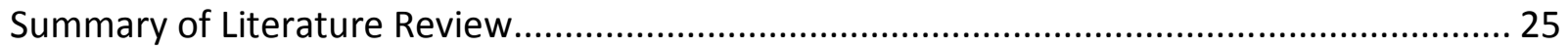

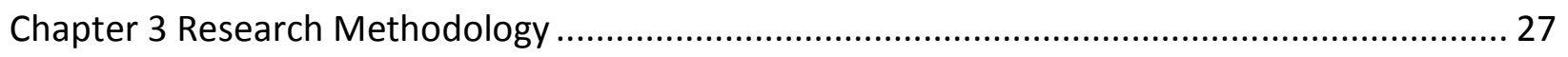

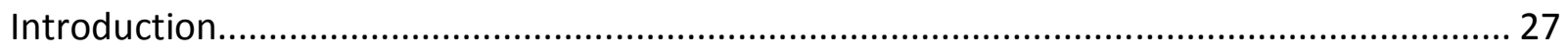

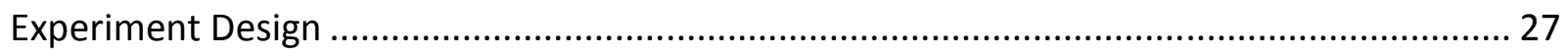

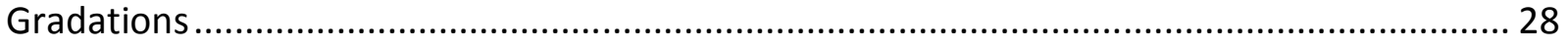

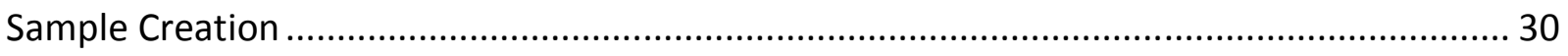

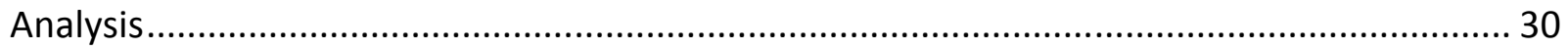

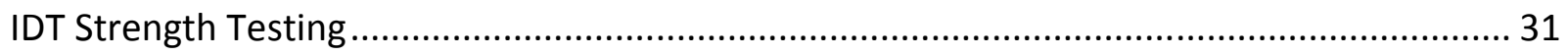

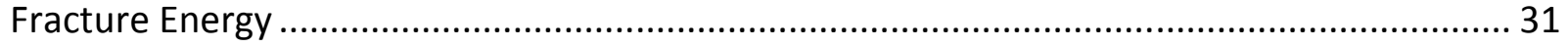

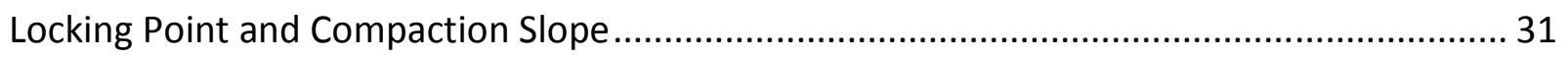

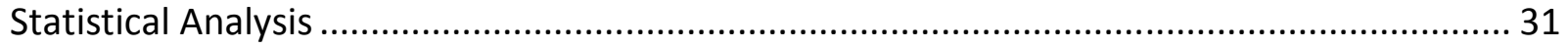

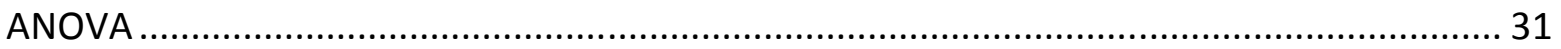

Tukey Kramer Honest Significant Difference (HSD) ................................................... 32

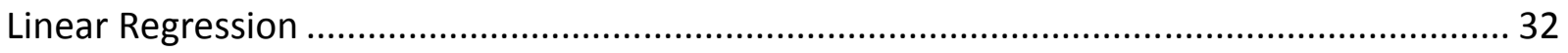

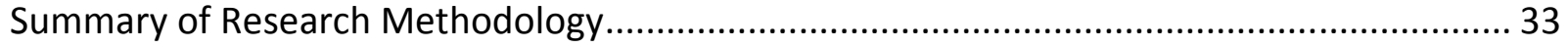

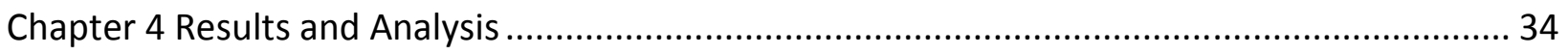

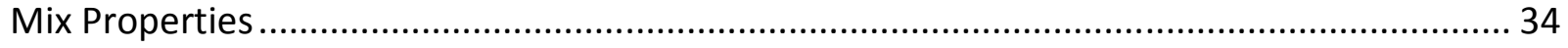

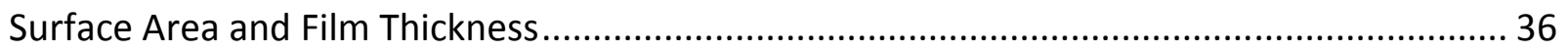

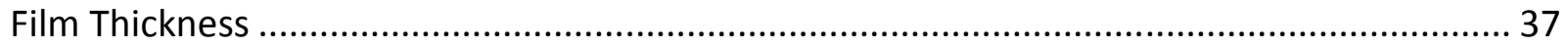

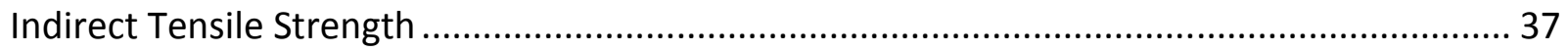

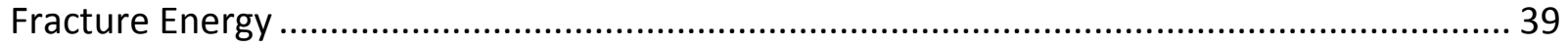

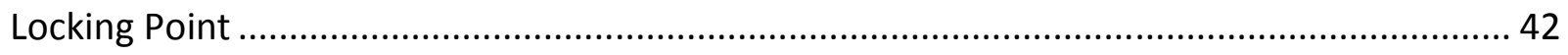

Comparison of IDT Strength and Compaction Effort................................................. 45

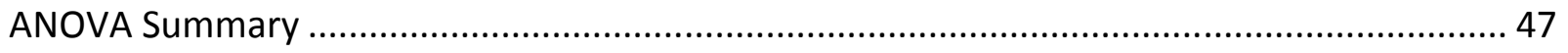

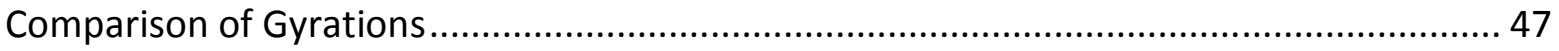

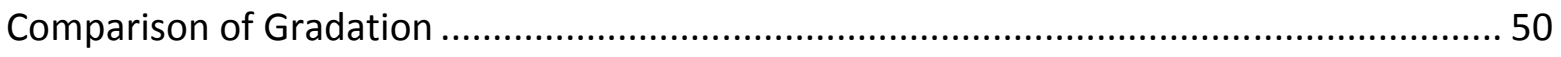

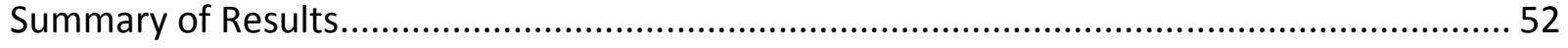




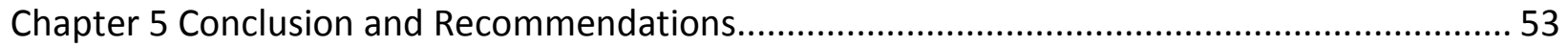

Recommendations for Further Research ....................................................................... 54

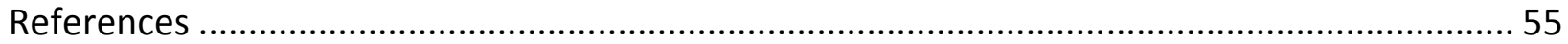

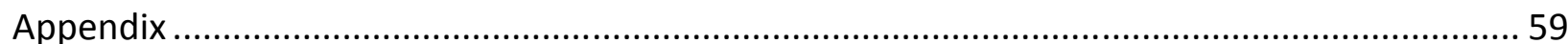




\section{LIST OF FIGURES}

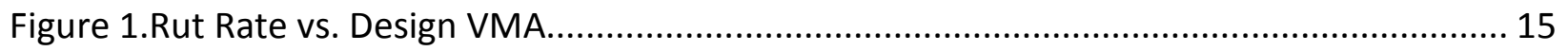

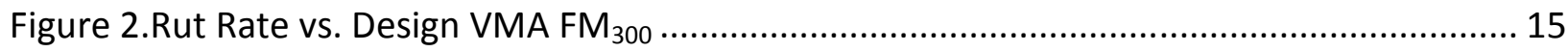

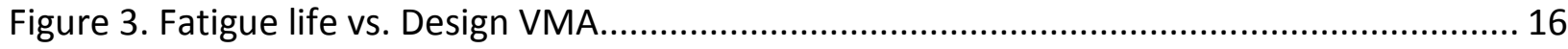

Figure 4. IDT strength test, prior to failure, and failed specimen ......................................... 18

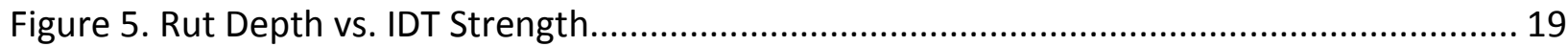

Figure 6. IDT Fracture Energy vs. Fatigue Life (Cycles) ....................................................... 19

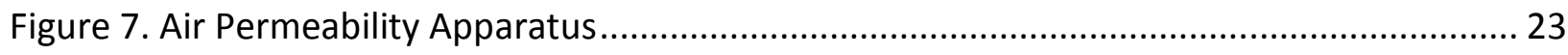

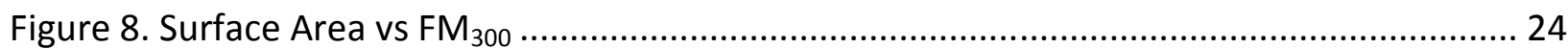

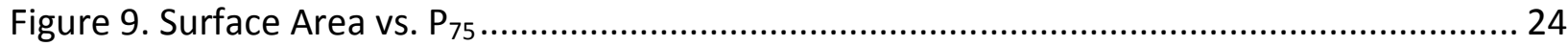

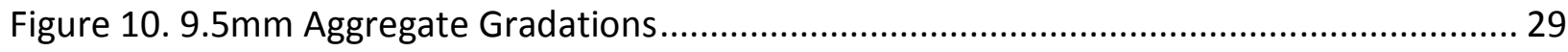

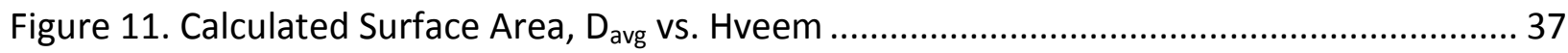

Figure 12. Relationship between IDT strength and film thickness at 80 gyrations.................... 38

Figure 13. Relationship between IDT strength and film thickness at 100 gyrations ................... 38

Figure 14. Example Fracture Energy from IDT Load Diagram.............................................. 39

Figure 15. Fracture Energy vs. IDT Strength ................................................................ 41

Figure 16. Compaction slope vs. Film thickness .............................................................. 44

Figure 17. Dust-to-film thickness ratio vs. dust-to-effective binder ratio................................ 45

Figure 18. IDT Strength vs. percent binder for Coarse gradation........................................... 46

Figure 19. IDT Strength vs. Percent binder, Fine gradation..................................................... 46

Figure 20. IDT Strength vs. Percent binder, Contractor gradation ....................................... 47

Figure 21. Coarse Gradation, VTM (\%) vs. Percent Binder ...................................................... 60

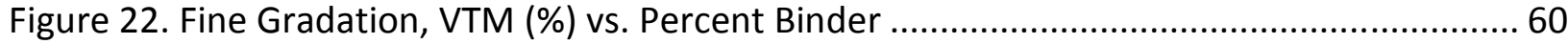

Figure 23. Contractor Gradation, VTM(\%) vs. Percent Binder............................................... 60

Figure 24. Coarse Gradation, VFA vs. Percent Binder ....................................................... 61

Figure 25. Fine Gradation, VFA vs. Percent Binder ........................................................... 61

Figure 26. Contractor Gradation, VFA vs. Percent Binder ................................................. 61

Figure 27. Coarse Gradation, VMA vs. Percent Binder .................................................... 62

Figure 28. Fine Gradation, VMA vs. Percent Binder ............................................................. 62

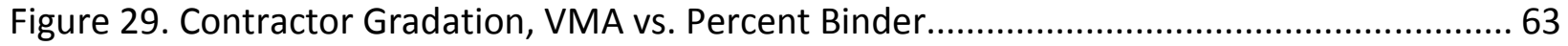




\section{LIST OF TABLES}

Table 1. 1948 Corp of Engineers Limiting Values .................................................................. 5

Table 2. AASHTO Superpave Gyrator Compaction Effort ....................................................... 6

Table 3. WVDOH Gyratory Compaction Levels..................................................................... 7

Table 4. WVDOH Marshall Method Volumetric Criteria........................................................... 7

Table 5. West Virginia Marshall Method VMA Criteria ........................................................... 8

Table 6. WVDOH Superpave Mix Design Criteria .................................................................... 8

Table 7. WVDOH Superpave Method VMA and VFA Criteria ............................................... 8

Table 8. Comparison of VMA for Marshall and Superpave ...................................................... 11

Table 9. Comparison of VFA for Marshall and Superpave ................................................... 12

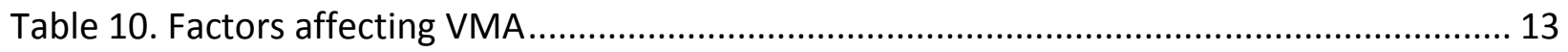

Table 11. VMA related to distance from MDL .................................................................. 13

Table 12. Gradations used by Huber \& Shuler..................................................................... 14

Table 13. Example of Locking Point from SGC height output................................................. 17

Table 14. Surface area for one gram of uniform sand ............................................................ 21

Table 15. Surface Area Factors, based on Percent Passing .................................................... 22

Table 16. Specific area for material less than 75 microns .................................................... 23

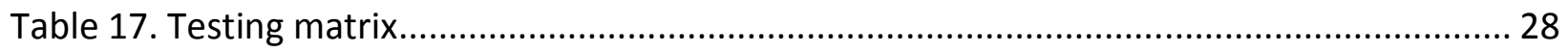

Table 18. Volumetric Properties at 4.0\% VTM, 80 Gyrations .................................................. 34

Table 19. Volumetric Parameters at 4\% VTM, 100 Gyrations ................................................. 35

Table 20. Mix Properties at Design Binder Content* ........................................................... 35

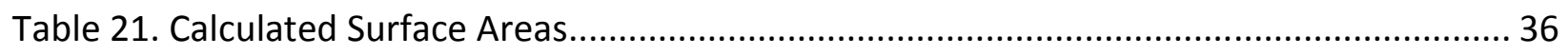

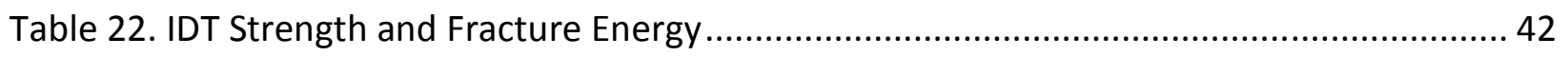

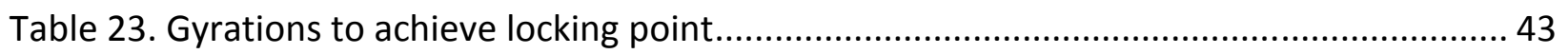

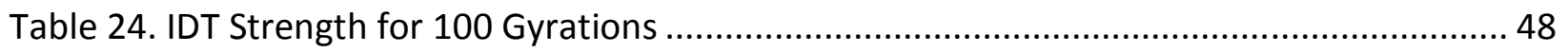

Table 25. Tukey-Kramer Multiple Comparisons, 100 Gyrations.............................................. 48

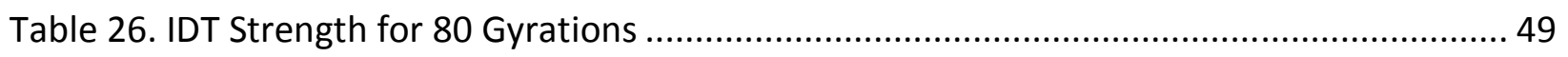

Table 27. Tukey-Kramer Multiple Comparisons 80 Gyrations................................................ 49

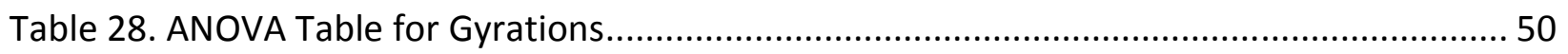

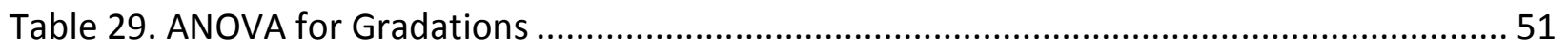

Table 30. Tukey-Kramer Gradation Comparison ............................................................. 51 


\section{CHAPTER 1 INTRODUCTION}

\section{Background}

As of 2005 there were approximately 4 million miles of roads in the United States, 2.4 million miles of these roads are covered with asphalt concrete (Roberts et al., 2009). The abundance of both freight and commuter vehicles on these roads means that it is important that asphalt pavements be designed to provide both long-term durability, and high performance when subjected to environmental and load induced stresses.

Asphalt concrete is comprised of three primary components, asphalt binder, aggregate, and air. Asphalt binder is a bituminous material that is largely produced through petroleum distillation. The material has viscous, elastic, and plastic behavior dependent on temperature. Asphalt binder is heated, and used to coat aggregate particles and bind them together. Asphalt binder can be produced to create desired performance characteristics based on the expected temperature range of the pavement.

Aggregates comprise approximately $95 \%$ of the asphalt concrete by mass ( $85 \%$ by volume). Depending on location, the aggregates used in asphalt concrete vary largely but all are expected to exhibit the same desirable characteristics of mechanical strength, durability, chemical durability, and desirable surface characteristics (Roberts et al., 2009). Aggregates range from natural products collected in river beds, to materials that have been blasted from quarries and mechanically crushed to create the desired qualities and size. In addition to the origin of the aggregates, they are also categorized according to the size of the particles to create design gradations for the aggregate structure in the asphalt concrete.

Air is the final constituent in asphalt concrete. Air voids within the mixture allow space for the thermal expansion and contraction of the asphalt binder. The mixture is mechanically compacted. After compaction, the mixture cools, and the final product is a material that can be subjected to high loads and many repetitions such as those on the interstate highway system.

In 1943 Bruce Marshall and the Army Corps of Engineers worked to create a portable apparatus to test asphalt for airfield pavements. Through development and modifications it would become known as the Marshall Design method. During the 1980's, Congress outlined a plan to develop the United States transportation network through improvements to roads and highways. As a product of the Strategic Highway Research Program (SHRP), the Superpave design method was developed. These two design methods are now the most common methods in the United States and are related through the use of extensive volumetric analysis to create a quality pavement (Roberts et al., 2009). The West Virginia Division of Highways (WVDOH) currently uses both the Marshall and Superpave methods.

Bessette, Logan P. 1 


\section{Problem Statement}

The issue with the current volumetric analysis used by both the Marshall and Superpave design method is that the Voids in Mineral Aggregate (VMA) is often the most difficult design parameter to satisfy (Kandhal et al., 1998). Criteria that are used today were developed in the 1950's under a specific set of assumptions. With the development of new asphalt additives, the increased compaction effort of the Superpave gyratory compactor (SGC), and a wide range of aggregate sources being used for the production of asphalt concrete the current specifications for VMA should be evaluated in ensure durable asphalt pavements.

\section{Objective}

The objective of this research is to evaluate the effects that the parameters of gradation, and compaction effort have on VMA in dense-graded asphalt concrete. This research has primary importance because of a recent reduction in the design number of gyrations for asphalt concretes, and an increase in the minimum VMA requirements by the WVDOH. The purpose of decreasing design gyrations was to add asphalt into the aggregate structure and create mixes that were more resistant to fatigue distress. The increased VMA requirements effectively increase the minimum required binder in the mix by $0.5 \%$ compared to mixes designed prior to the change.

\section{Scope and Limitations}

This research has primary significance to the WVDOH, but also holds value for all states. The research is limited to one aggregate source from a single West Virginia quarry, with a single nominal maximum aggregate size (NMAS).

Evaluation of the mixes was limited to the volumetric parameters used in mix design plus data on the sample compaction rate as measured with the Superpave Gyrator Compactor. Indirect tensile strengths were measured for each sample following the Superpave mix design protocol for the tensile strength ratio evaluation. Tensile strengths was only measured for unconditioned samples. Evaluation of the performance parameters was beyond the scope of this research.

\section{Organization of Thesis}

This thesis is divided into five chapters. Following the introduction, Chapter 2 focuses on the development of the Marshall, and Superpave mix design methods, additionally it reviews the historical developments of VMA criteria, the use of indirect tensile strength as a performance indicator, and the concept of specific area for aggregates and asphalt film thickness. Chapter 3 outlines the research methodology and testing procedures used in the 
laboratory. Chapter 4 contains the results, and the analysis of the results from laboratory testing. Chapter 5 presents conclusions from the testing conducted and proposes recommendations to design economical and high performance asphalt pavements. The appendix contains all results from laboratory testing and mathematical equations 


\section{CHAPTER 2 LITERATURE REVIEW}

\section{Introduction}

The research presented in this thesis builds upon the volumetric properties, and concepts that are well established in both academic literature, and literature from the asphalt paving industry. The use of volumetric criteria by the WVDOH is based around the recommendations of American Association of State Highway and Transportation Officials (AASHTO) and the Asphalt Institute (TAI) for the requirements regarding volumetric properties for Superpave and Marshall methods, respectively.

Prior to the introduction of the Superpave in the early 1990's most states designed asphalt pavements with either the Marshall or Hveem Method. In 1984, approximately $25 \%$ of the states used a variation of the Hveem method, and the remainder used a variation of the Marshall Design method (Asphalt Institute, 2007). With the introduction of the Superpave design method, the primary methods for asphalt pavement design are currently the Marshall and Superpave methods (FHWA, 1995) and are the focus of this literature review.

\section{Asphalt Concrete Mixture Design}

\section{Marshall}

The Marshall mix design method was conceived by Bruce Marshall of the Mississippi Highway Department. Marshall's method was researched by the Corps of Engineers (COE) and in 1943 it was adopted for the design of airfield pavements (Roberts et al., 2009). The COE manipulated the Marshall hammer to apply a variety of compaction efforts to simulate the construction of asphalt pavements in the field. The compaction effort was varied by changing the number of blows from the hammer, the weight of the hammer, and the distance the hammer fell. The final Marshall hammer produced by the COE was a portable apparatus, with a 10-lb hammer falling 18 inches, a 3-7/8" inches diameter foot, a 4-inch diameter mold, and a standard compaction effort of 35 blows per side. With an increase of aircraft size and weight in the 1950's the laboratory compaction efforts were increased to 50 blows on each side of the specimen (Roberts et al., 2009). In May 1948, the COE presented the limiting values of testing 
properties for asphalt concretes designed with the Marshall method, classification was either "Brittle", "Satisfactory," or "Plastic," as presented in Table 1. There were no requirements for VMA in the 1948 COE design criteria (USCOE, 1948). However, there were voids filled with asphalt (VFA) criterion. The WVDOH currently uses 50 and 75 blows for the design of Marshall mixes for medium and heavy traffic, respectively (WVDOH, MP 401.02.22)

Table 1. 1948 Corp of Engineers Limiting Values

\begin{tabular}{|l|c|c|c|}
\hline Test Property & Brittle & Satisfactory & Plastic \\
\hline Flow Value & No Lower Limit & 20 or less & More than 20 \\
\hline Percent Air Voids & More than 5 & $5-3$ & Less than 3 \\
\hline $\begin{array}{l}\text { Percent Voids } \\
\text { filled with Asphalt }\end{array}$ & Less than 70 & 75 to 85 & More than 85 \\
\hline
\end{tabular}

\section{Superpave}

In 1987, Congress authorized a five-year research program, SHRP, to combat the deterioration of the United States highways and to improve safety, performance and overall durability of highway infrastructure (Roberts et al., 2009). The research initiative was undertaken by industry, academia, and government agencies and focus on asphalt pavements, concrete structures, maintenance and work zone safety, and long term pavement performance studies. The scope of this literature review follows the developments only regarding asphalt pavements, and primarily the Superpave design method.

The Superpave design method was developed as a procedure to better predict asphalt concrete field performance (Christensen and Bonaquist, 2006). A major outcome of SHRP was the development of the Superpave Gyrator Compactor (SGC). The SGC uses a constant vertical stress of $600 \mathrm{kPa}$, an internal compaction angle of $1.25^{\circ}$, a gyration speed of 30 gyrations per minute and number of gyrations. The first three parameters are kept constant and the number of gyrations is varied for different mix types and applications. Table 2 presents the AASHTO compaction recommendation and Table 3 presents the compaction levels used by the WVDOH (WVDOH, MP 401.02.28) 
The size of the specimen produced was also increased from 4 inches in diameter under Marshall to $150 \mathrm{~mm}$ in diameter under Superpave. The rationale behind this was to allow larger aggregates to be used without causing compaction problems (Roberts et. al. 2009), although there was a six inch Marshall mold to create base layer specimens.

Table 2and Table 3 shows the WVDOH is using a lower compaction effort than the AASHTO specification for all but the lowest traffic level. Following the performance of field projects in 16 states, Brown and Powell (2007) determined that there could be a reduction in $\mathrm{N}_{\text {design }}$ while maintaining density and mixes that were readily compacted. The WVDOH has also dropped the $\mathrm{N}_{\text {initial }}$ and $\mathrm{N}_{\text {Maximum }}$ requirements, and lowered $\mathrm{N}_{\text {design }}$ for high ESAL, modified binder, and rich bottom mixes.

Table 2. AASHTO Superpave Gyrator Compaction Effort

\begin{tabular}{|c|c|c|c|c|}
\hline \multirow[b]{2}{*}{$\begin{array}{l}\text { Design ESALs } \\
\text { (millions) }\end{array}$} & \multicolumn{3}{|c|}{ Gyrator Compaction Effort } & \multirow[b]{2}{*}{ Typical Application } \\
\hline & $\mathbf{N}_{\text {initial }}$ & $\mathbf{N}_{\text {design }}$ & $\mathbf{N}_{\text {maximum }}$ & \\
\hline$<0.3$ & 6 & 50 & 75 & $\begin{array}{c}\text { Very light volume roads, local } \\
\text { roads, country roads, city } \\
\text { streets. }\end{array}$ \\
\hline 0.3 to 3.0 & 7 & 75 & 115 & $\begin{array}{l}\text { Medium traffic city streets, } \\
\text { majority of country roads. }\end{array}$ \\
\hline 3.0 to $<30$ & 8 & 100 & 160 & $\begin{array}{c}\text { Two lane/multilane divided } \\
\text { highways. State routes and } \\
\text { U.S. highways }\end{array}$ \\
\hline$>30$ & 9 & 125 & 205 & $\begin{array}{l}\text { Vast majority of U.S. Interstate } \\
\text { system. Special application for } \\
\text { truck climbing lanes }\end{array}$ \\
\hline
\end{tabular}


Table 3. WVDOH Gyratory Compaction Levels

\begin{tabular}{|c|c|c|}
\cline { 2 - 3 } \multicolumn{1}{c|}{} & \multicolumn{2}{c|}{ Compaction Parameters } \\
\cline { 2 - 3 } \multicolumn{1}{c|}{$\begin{array}{c}\text { 20 Year } \\
\text { Projected design } \\
\text { ESALs (millions) }\end{array}$} & $\begin{array}{c}\mathbf{N}_{\text {design }} \text { for Binder }< \\
\text { PG 76-XX }\end{array}$ & $\begin{array}{c}\text { Gyration Level-2 } \\
\mathbf{N}_{\text {design }} \text { for Binders } \geq \text { PG } \\
\mathbf{7 6 - X X} \text { or Mixes Placed } \\
\text { Below Top Two Lifts }\end{array}$ \\
\hline$<\mathbf{0 . 3}$ & 50 & 50 \\
\hline $\mathbf{0 . 3}$ to $<\mathbf{3 . 0}$ & 65 & 65 \\
\hline $\mathbf{3 . 0}$ to $<\mathbf{3 0}$ & 80 & 65 \\
\hline $\mathbf{3 0}$ & 100 & 80 \\
\hline
\end{tabular}

\section{Volumetric Requirements}

The current design criteria for Marshall in West Virginia follow the recommendations from both the American Association of State and Highway Transportation Officials (AASHTO). The Superpave gyration levels are based on recommendation by the National Cooperative Highway Research Program (NCHRP). Table 4 and Table 5 present the current criteria in West Virginia for asphalt concrete designed under the Marshall Method:

Table 4. WVDOH Marshall Method Volumetric Criteria

\begin{tabular}{|l|c|c|c|}
\hline \multicolumn{1}{|c|}{ Design Criteria } & $\begin{array}{c}\text { Medium Traffic } \\
\text { Design }\end{array}$ & $\begin{array}{l}\text { Heavy } \\
\text { Traffic } \\
\text { Design }\end{array}$ & $\begin{array}{c}\text { Base-I } \\
\text { Design }\end{array}$ \\
\hline Compaction, number of blows & 50 & 75 & 112 \\
\hline Stability (Newtons) (minimum) & 5,300 & 8,000 & 13,300 \\
\hline Flow (0.25 mm) & 8 to 14 & 8 to 14 & 8 to 14 \\
\hline Percent Air Voids & 4.0 & 4.0 & 4.0 \\
\hline Percent Voids Filled with Asphalt ${ }^{3}$ & 65 to 80 & 65 to 78 & 64 to 73 \\
\hline Fines-to-Asphalt Ratio & \multicolumn{3}{|c|}{0.6 to 1.2} \\
\hline
\end{tabular}

Note $^{1}$ : All Wearing-III mixes shall be designed as a 50 blow mix;

Note $^{2}$.All Base I mixes will be designed and tested with 112 blows and 6 inch specimen; Note $^{3}$ : When using a recording chart to determine the flow value, the flow is normally read at the point of maximum stability just before it begins to decrease. This approach works fine when the stability plot is a reasonably smooth rounded curve. Some mixes comprised of very angular aggregates may exhibit aggregate interlocking which causes the plot to produce a flat line at the peak stability before it begins to drop. This type of 
plot is often difficult to interpret, and sometimes the stability will even start increasing again after the initial flat line peak. When such a stability plot occurs, the stability and flow value shall be read at the initial point of peak stability.

Note $^{4}$ : Wearing I Heavy design will have a VFA range of 73 to 78 percent, a Wearing III mix shall have a VFA range of 75 to 81 percent.

Table 5. West Virginia Marshall Method VMA Criteria

\begin{tabular}{|l|c|c|}
\hline \multicolumn{1}{|c|}{ Mix Type } & $\begin{array}{c}\text { Nominal Maximum } \\
\text { Aggregate Size }\end{array}$ & $\begin{array}{c}\text { Percent Voids in } \\
\text { Mineral Aggregate } \\
\text { (minimum) }\end{array}$ \\
\hline Wearing-III and Scratch-III & $4.75 \mathrm{~mm}$ (No. 4) & 17.0 \\
\hline Wearing-I and Scratch-I & $9.5 \mathrm{~mm}(3 / 8 \mathrm{in})$ & 15.0 \\
\hline Base-II, P\&L and Wearing-IV & $19 \mathrm{~mm}$ (3/4 in) & 13.0 \\
\hline Base-I & $37.5 \mathrm{~mm}(1 \mathrm{1} / 2 \mathrm{in})$ & 11.0 \\
\hline
\end{tabular}

Table 6 and 7 are the current criteria in West Virginia for asphalt concrete designed under the Superpave Method:

Table 6. WVDOH Superpave Mix Design Criteria

\begin{tabular}{|l|c|}
\hline \multicolumn{1}{|c|}{ Design Criteria } & \\
\hline Design Air Void Content & $4.0 \%$ \\
\hline Fines-to-Effective Asphalt Ratio & \\
\hline Tensile strength Ratio, $\%$ & $0.6-1.2$ \\
\hline
\end{tabular}

Note $^{1}$ : For coarse graded mixes the fines to effective asphalt ratio is $0.8-1.6$, all $4.75 \mathrm{~mm}$ mixes will have fines to effective asphalt ratio of 0.9-2.0

Table 7. WVDOH Superpave Method VMA and VFA Criteria

Nominal Maximum Aggregate Size, $\mathrm{mm}$

\begin{tabular}{|l|c|c|c|c|c|l|}
\hline & 37.5 & 25 & 19 & 12.5 & 9.5 & \multicolumn{1}{|c|}{45} \\
\hline Percent VMA & & & & & & \\
\hline Percent VFA & 11.5 & 12.5 & 13.5 & 14.5 & 15.5 & 16.5 \\
\hline
\end{tabular}

Note $^{2}$ : Mixtures exceeding VMA by more than two percent may be susceptible to flushing and rutting. 
The minimum VMA criteria for the Superpave method was increased by $0.5 \%$ in 2011 along with a reduction compaction effort (WVDOH, MP 402.22.28) as recommended by Brown and Powell (2007).

\section{Volumetric Properties}

\section{Voids in Total Mix}

Voids in total mix (VTM) is the volume of all pockets of air between the asphalt coated aggregate particles in a compacted asphalt concrete. VTM is expressed as a percentage of the bulk volume of the mixture (Roberts et al., 2009). The design VTM is $4 \%$ for laboratory specimens, although they are often compacted to a level less than this in the field to allow for densification under loading. VTM is calculated using the maximum and bulk specific gravities in Equation 1

$$
V T M=100\left(1-\frac{G_{m b}}{G_{m m}}\right)
$$

Where:

VTM= Voids in total Mix (\%);

$\mathrm{G}_{\mathrm{mb}}=$ Bulk specific gravity of compacted asphalt specimen; and

$\mathrm{G}_{\mathrm{mm}}=$ Maximum theoretical specific gravity of loose asphalt mixture.

The concept of using VTM was to ensure that there was adequate air voids to allow space for the expansion and contraction of asphalt binder (Roberts et al., 2009). The presence of adequate air voids would decrease the likelihood of rutting. Volumetric analysis based on the principle that not all of the asphalt is within the matrix of aggregate, some of the asphalt is absorbed into the surface voids of the aggregate particles, thus decreasing the total effective volume of asphalt in the mixture.

\section{Voids Filled with Asphalt}

Voids filled with asphalt (VFA) are the percentage of the VMA, in volume, that are filled with asphalt. VFA is calculated in Equation 2

$$
V F A=100\left(\frac{V M A-V T M}{V M A}\right)
$$

\section{Voids in Mineral Aggregate}

\section{Definition}

The Asphalt institute (1962) definition of voids in the mineral aggregate is: 
"VMA consists of the intergranular void spaces between the particles of aggregate in a compacted mixture. It is the bulk volume of the compacted paving mixture minus the volume of the aggregate determined from its bulk specific gravity, or the volume of effective asphalt content plus volume of air voids."

VMA is expressed as a percentage of the bulk volume of the compacted asphalt concrete specimen. The volume of effective asphalt is the amount of asphalt that is not absorbed into the pores of the aggregate particle during mixing, conditioning and compacting. The effective asphalt creates a film that surrounds the aggregate particles.

\section{Determination}

VMA is calculated using Equation 3,

Where:

$$
V M A=100-\left(\frac{G_{m b} P_{s}}{G_{s b}}\right)
$$

$\mathrm{VMA}=$ Voids in the mineral aggregate;

$\mathrm{G}_{\mathrm{mb}}=$ Bulk specific gravity of compacted asphalt specimen;

$\mathrm{P}_{\mathrm{s}}=$ Percent stone in the mixture; and

$\mathrm{G}_{\mathrm{sb}}=$ Bulk specific gravity of the aggregate.

McLeod (1959) emphasized the importance of using the bulk specific gravity of the aggregate when calculating VMA. If apparent specific gravity was used the total volume of surface pores of the aggregate would be included. If the effective specific gravity was used then the volume of the voids within the aggregate particle filled with binder are included. The use of bulk specific gravity removes the voids within the aggregate particle regardless of whether or not they are filled with binder. McLeod numerically demonstrated that VTM and VMA calculations are incorrect if bulk specific gravity is not used.

The VMA requirement proposed by McLeod (1959) is under the assumptions that the bulk specific gravity of the aggregate is 2.65 , and the binder specific gravity is 1.01 . However, Hinrichsen and Heggen (1996) found that the calculated values of VMA are valid for aggregate bulk specific gravities between 2.50 and 2.80, and adjustment can be made for aggregates with specific gravity outside this range.

\section{History}

During the early development of mix design procedures, between approximately 1901 through 1905, there were two approaches to determine the design asphalt content (Hudson and Davis, 1965).The first method, coming from Warren emphasized the minimizing of VMA to ensure stability. An example of this method is the Hubbard-Field mix design, which was primarily for the use of sheet/sand mixes with all material passing the $4.75 \mathrm{~mm}$ sieve. Another 
method, utilized by Richardson was to determine the asphalt content based upon the computed surface area of the aggregates and an optimum film thickness, combining air voids, the products of surface area and optimum film thickness, and experience to determine design asphalt content (Hudson and Davis, 1965). Richardson used "The Pat Test," a way of determining the residual binder in an asphalt mix to determine whether the mix was rich, or deficient in asphalt binder (Roberts et al,. 2009). The Hveem mix design is also based on this method, in 1941 Hveem wrote that knowing the volume of the voids alone could not be used to predict other properties of the mixture. Due to the variety of aggregate gradation and bituminous materials, a universal application of VMA criteria cannot be established (Hveem, 1941). Current VMA criteria attempt to address this by changing minimum VMA according to the nominal maximum aggregate size (NMAS).

The majority of the volumetric criteria for asphalt concrete was developed between 1960 and the 1980's, preceding the Superpave design method for asphalt concrete (Christensen and Bonaquist, 2006). During this period approximately $80 \%$ of the HMA in the United States used aggregate gradations that passed above the maximum density line (MDL), deemed to be fine graded aggregate blends (Christensen and Bonaquist, 2006). The MDL is a straight line connecting the point $(0,0)$ to the maximum aggregate size (MAS) with $100 \%$ passing when plotted on the X-axis raised to the .45, commonly referred to as "power-45," (Roberts et al., 2009). Gradations that lie on the MDL have the lowest VMA, moving away from the MDL increases VMA (Roberts et. al., 2009). VMA and air voids requirements were based on the performance of fine graded Marshall specimen, not Superpave specimen, although upon the introduction of Superpave these same volumetric criteria were adopted, as presented in Table 8 and Table 9 (West Virginia MP 401.02.28 and 401.02.22, 2011, and Asphalt Institute, 2007).

Table 8. Comparison of VMA for Marshall and Superpave

\begin{tabular}{|c|c|c|c|}
\hline $\begin{array}{c}\text { Nominal } \\
\text { Sieve Size, } \\
\mathbf{m m} \text { (in.) }\end{array}$ & Marshall & $\begin{array}{c}\text { Superpave } \\
\text { WVDOH }\end{array}$ & Superpave AASHTO \\
\hline $37.5(11 / 2)$ & 11.0 & 11.5 & 11 \\
\hline $25(1)$ & - & 12.5 & 12 \\
\hline $19(3 / 4)$ & 13.0 & 13.5 & 13 \\
\hline $12.5(1 / 2)$ & - & 14.5 & 14 \\
\hline $9.5(3 / 8)$ & 15.0 & 15.5 & 15 \\
\hline $4.75($ No. 4$)$ & 17.0 & 16.5 & 16 \\
\hline
\end{tabular}


Table 9. Comparison of VFA for Marshall and Superpave

\begin{tabular}{|c|c|c|}
\hline $\begin{array}{c}\text { Nominal } \\
\text { Sieve Size, } \\
\text { mm (in.) }\end{array}$ & Marshall & Superpave \\
\hline $37.5(11 / 2)$ & $64-73$ & $65-75$ \\
\hline $25(1)$ & - & $68-76$ \\
\hline $19(3 / 4)^{\mathrm{H}}$ & $65-78$ & $70-78$ \\
\hline $12.5(1 / 2)$ & - & $72-79$ \\
\hline $9.5(3 / 8)^{\mathrm{H}}$ & $73-78$ & $74-80$ \\
$9.5(3 / 8)^{\mathrm{M}}$ & $65-80$ & \\
\hline $4.75($ No. 4) & $75-81$ & $75-81$ \\
\hline
\end{tabular}

Note:

$19(3 / 4)^{\mathrm{H}}$ indicates a heavy mix; and

$9.5(3 / 8)^{\mathrm{M}}$ indicates medium mix.

\section{Factors affecting VMA}

Abdullah et al. (1998) tested laboratory samples and came to the conclusion that

- Binder acts as a lubricant for aggregate particles, more lubricant allows for tighter compaction and decreased VMA

- Mixtures that have binder content greater than the optimum content will have binder filling intergranual space and increase the distance between aggregate particles, thus increasing the VMA

Chadbourn et al. (1999) produced Table 10 based on an analysis of pavements in Minnesota. 
Table 10. Factors affecting VMA

\begin{tabular}{|c|l|}
\hline Factor & Effect on VMA \\
\hline Aggregate gradation & Dense gradations decrease VMA \\
\hline Aggregate handling & $\begin{array}{l}\text { More handing increases aggregate degradation, increasing fines, } \\
\text { and lower VMA }\end{array}$ \\
\hline Aggregate shape & Rounded aggregate decrease VMA \\
\hline Aggregate texture & Smooth, polished aggregate decrease VMA \\
\hline Asphalt absorption & $\begin{array}{l}\text { Increased absorption decreases effective asphalt and decreases } \\
\text { VMA }\end{array}$ \\
\hline Dust content & $\begin{array}{l}\text { Higher dust content increase surface area, decrease film thickness, } \\
\text { lower VMA }\end{array}$ \\
\hline $\begin{array}{c}\text { Plant production } \\
\text { temperature }\end{array}$ & $\begin{array}{l}\text { Higher temperatures decrease binder viscosity, resulting increase in } \\
\text { absorption, lower VMA }\end{array}$ \\
\hline $\begin{array}{c}\text { Temperature of material } \\
\text { during paving }\end{array}$ & $\begin{array}{l}\text { Higher temperatures during paving create softer mixes, lower air } \\
\text { voids, and lower VMA }\end{array}$ \\
\hline Hauling time & $\begin{array}{l}\text { Longer haul times allow for increased absorption, lower effective } \\
\text { binder content and lower VMA }\end{array}$ \\
\hline
\end{tabular}

Huber and Shuler (1992) investigated the changes in VMA due to aggregate type, and gradation. Huber and Shuler created identical gradations, with constant binder content for all gradations and varied the aggregate between crushed limestone, and uncrushed gravel. The testing demonstrated that the crushed limestone created a higher VMA than the uncrushed gravel. Huber and Shuler also found that by moving gradations farther away from the maximum density line VMA initially decreases, and then began to increase for both aggregate types, this is presented in Table 11. Table 12 presents the gradations used.

Table 11. VMA related to distance from MDL

\begin{tabular}{|c|c|c|}
\cline { 2 - 3 } \multicolumn{1}{c|}{} & \multicolumn{2}{c|}{ VMA, Percent \% } \\
\hline $\begin{array}{c}\text { Increasing Distance } \\
\text { from Maximum } \\
\text { Density Line }\end{array}$ & $\begin{array}{c}\text { Crushed } \\
\text { Aggregate }\end{array}$ & $\begin{array}{c}\text { Uncrushed } \\
\text { Aggregate }\end{array}$ \\
\hline E & 13.9 & 12.8 \\
\hline D & 12.6 & 11.0 \\
\hline C & 11.6 & 10.4 \\
\hline A & 11.5 & 10.8 \\
\hline B & 12.1 & 10.4 \\
\hline F & 14.4 & 12.4 \\
\hline
\end{tabular}


Table 12. Gradations used by Huber \& Shuler

\begin{tabular}{|c|c|c|c|c|c|c|}
\cline { 2 - 7 } \multicolumn{1}{c|}{} & \multicolumn{6}{c|}{ Gradation, Percent Passing } \\
\hline Sieve & A & B & C & D & E & F \\
\hline $\mathbf{1 8 . 7 5} \mathbf{~ m m}$ & 100 & 100 & 100 & 100 & 100 & 100 \\
$\mathbf{1 2 . 5 0} \mathbf{~ m m}$ & 79 & 75 & 88 & 96 & 95 & 67.4 \\
$\mathbf{9 . 5 0} \mathbf{~ m m}$ & 68 & 63 & 74 & 79 & 83 & 52.3 \\
$\mathbf{4 . 7 5} \mathbf{~ m m}$ & 47 & 40 & 47 & 47 & 57 & 28.5 \\
$\mathbf{2 . 3 6} \mathbf{~ m m}$ & 32 & 25 & 35 & 37 & 43 & 16.5 \\
$\mathbf{1 . 1 8} \mathbf{~ m m}$ & 22 & 17 & 26 & 30 & 35.5 & 10.5 \\
$\mathbf{6 0 0} \boldsymbol{\mu m}$ & 15 & 12 & 20 & 25 & 26.5 & 7.6 \\
$\mathbf{3 0 0} \boldsymbol{\mu m}$ & 10 & 8 & 13 & 15 & 12.2 & 6.1 \\
$\mathbf{1 5 0} \boldsymbol{\mu m}$ & 7 & 6 & 8 & 9 & 5.3 & 5.4 \\
$\mathbf{7 5} \boldsymbol{\mu m}$ & 5.0 & 5.0 & 5.0 & 5.0 & 4.6 & 5.0 \\
\hline
\end{tabular}

\section{Effect of VMA on Asphalt Concrete Performance}

Kandhal and Chakraborty (1996) evaluated the use of VMA as a design criteria for Superpave asphalt concrete mixtures. The literature review completed "did not indicate the existence of any significant rational data correlating the durability of HMA pavements with the minimum VMA specified for mix design."

VMA criteria were developed as an indicator to the field performance, if the mixture was either deficient in asphalt binder, or in VTM, the VMA value would reflect this. The use of volumetric properties as a predictive tool to determine the durability of asphalt concrete has presented excessive air voids or VFA and a low amount of VMA suggest future durability problems with the material. Low air voids, or excessive VFA may indicate the pavement will have rutting problems (Coree and Hislop, 1998).

Nukunya et al. (2001) researched the effects of VMA on the performance of coarse and fine-graded mixes. They found that VMA predicted different responses for each gradation. It was found that the low VMA predicted poor performance in fine-graded mixtures. That finegraded mixture was more susceptible to accelerated binder oxidization, than coarse-graded mixes. Alternatively, high VMA predicted poor performance in coarse-graded mixtures. Coarsegraded mixtures were more susceptible to rutting than the fine-graded mixtures. The conclusion was that the rate of rutting resistance for both coarse and fine-graded mixes is different. The coarse graded mixes being influenced greater by change in VMA.

Christensen and Bonaquist (2006) evaluated the rutting resistivity of Superpave mixtures using models generated using data from MnRoad, NCAT, WesTrack Project, and laboratory analysis. The models indicate that the rutting rate of Superpave mixtures is less when the 
mixture has lower VMA. Figure 1 indicates that mixtures with constant design air voids, and inplace voids, an increase in VMA will increase the rutting rate of the mix.

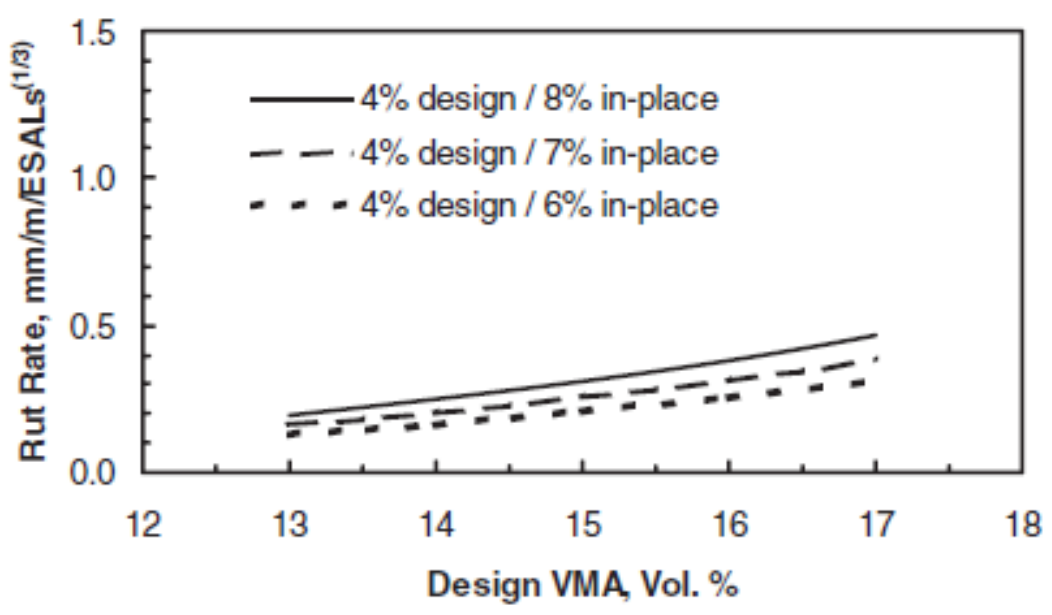

Figure 1.Rut Rate vs. Design VMA

Figure 2 shows the predicted rutting rate of the Superpave mixture increases with design VMA regardless of $\mathrm{FM}_{300}$. $\mathrm{FM}_{300}$ is defined as the summation of the percentages passing the 75-micron (No. 200), 150-micron (No. 100) and 300-micron (No. 50) sieves. Rutting rate increases with VMA regardless of $\mathrm{FM}_{300}$.

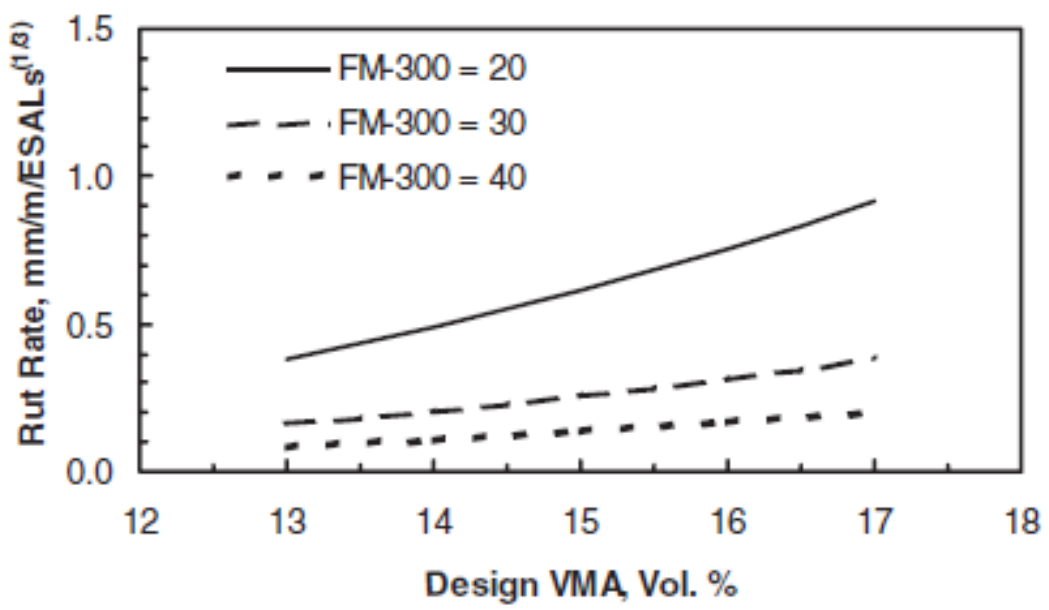

Figure 2.Rut Rate vs. Design VMA FM 300

Christensen and Bonaquist (2006), found that the fatigue life of asphalt concrete increased with the increase of design VMA regardless of design VTM, as shown in Figure 3. 


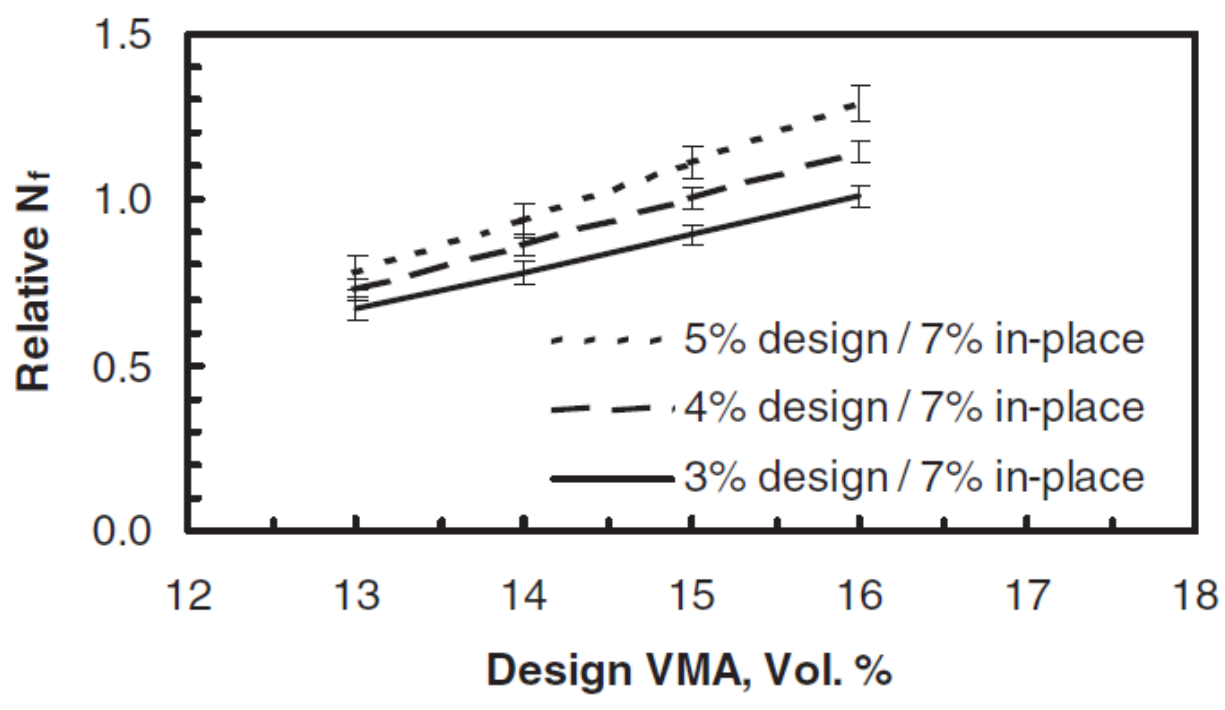

Figure 3. Fatigue life vs. Design VMA

\section{Compaction Effort}

Compaction effort is the term used to describe the number of gyrations, vertical force, and the tilt angle in the SGC (Zaniewski and Adamah, 2009). With the reduction of compaction effort, per Table 2 and Table 3, Zaniewski and Adamah (2009) found the asphalt content required to achieve $4.0 \%$ VTM increased by $0.5 \%$ and $0.4 \%$ for $19 \mathrm{~mm}$, and $37.5 \mathrm{~mm}$ base mix, respectively, for a design traffic of $3.0 \times 10^{6}$ to $30 \times 10^{6}$ ESALS.

\section{Locking Point}

The locking point concept is a technique used to determine the compaction of specimen in the SGC. The locking point is used to determine when the aggregate particles have achieved a dense configuration and further compaction will weaken the integrity of the aggregates. The locking point maximizes the strength of the aggregate structure within the mix, while also ensuring adequate space for asphalt binder to resist rutting and premature aging (Brown, 2005).

The definition of locking point has evolved over time. All methods are based on examining the change in height versus gyration level. The current definition was defined by Vavrik (2000), as the first of three gyrations at at the same height that are preceded by two sets of two gyrations that are measured at the same height (Vavrik, 2000). Table 13 demonstrates an example of the 2-2-3 locking point concept, as see in the table; the $74^{\text {th }}$ gyration indicates that the mixture has achieved a dense configuration. 
Table 13. Example of Locking Point from SGC height output

\begin{tabular}{|c|c|c|c|c|c|c|c|c|c|}
\hline & $\mathbf{0}$ & $\mathbf{1}$ & $\mathbf{2}$ & $\mathbf{4}$ & $\mathbf{5}$ & $\mathbf{6}$ & $\mathbf{7}$ & $\mathbf{8}$ & $\mathbf{9}$ \\
\hline $\mathbf{5 0}$ & 119.2 & $119.1^{*}$ & 119.0 & 118.9 & 118.8 & 118.7 & 118.6 & 118.5 & 118.5 \\
\hline $\mathbf{6 0}$ & 118.4 & 118.3 & 118.2 & 118.1 & 118.0 & 117.9 & 117.8 & 117.7 & 117.6 \\
\hline $\mathbf{7 0}$ & 117.6 & 117.5 & 117.5 & $\underline{\mathbf{1 1 7 . 4}}^{\text {LP }}$ & 117.4 & 117.4 & 117.3 & 117.3 & 117.2 \\
\hline
\end{tabular}

*Number of gyrations: $50+1=51$

\section{Compaction Slope (k)}

The compaction slope, $\mathrm{k}$, was determined by using the following equations.

$$
\begin{gathered}
k=\frac{\% G_{m m N_{\text {Des }}}-\% G_{m m N_{\text {ini }}}}{\log \left(N_{\text {Des }}\right)-\log \left(N_{\text {ini }}\right)} * 100 \\
\% G_{m m N_{\text {Des }}}=\frac{G_{m b}}{G_{m m}} \\
\% G_{m m N_{\text {ini }}}=\frac{G_{m b}}{G_{m m}}\left(\frac{H_{\text {Des }}}{H_{\text {ini }}}\right)
\end{gathered}
$$

\section{Where:}

$\% \mathrm{G}_{\mathrm{mmNDes}}$ is the percent of the maximum theoretical specific gravity at the design

gyrations;

$\% \mathrm{G}_{\mathrm{mmNini}}$ is the percent of the maximum theoretical specific gravity after initial gyrations;

$\mathrm{N}_{\text {des }}$ : Design number of gyrations for the compacted sample;

$\mathrm{N}_{\text {ini; }}$ Initial number of gyrations for the compacted sample;

$\mathrm{H}_{\text {Des: }}$ : Height of compacted sample after design number of gyrations; and

$\mathrm{H}_{\text {ini: }}$ Height of compacted sample after initial number of gyrations.

Vavrik (2000) found mixtures with higher compaction slopes are typically associated with poor mixtures. The increased compaction slope indicates a high densification of mixture in the field; high strength mixtures generally do not have high compaction slopes.

Levia and West (2008) compared the effects of asphalt content, and aggregate ratios on the interlocking of aggregate particles in asphalt concrete and the impact on the compatibility of mixtures in the field. They found mixtures with higher asphalt contents have higher compaction slopes for the same gradation. Fine gradations and mixtures with rounded aggregates have lower compaction slopes. The mixtures with higher compaction slopes generally have lower permanent shear strains and increased shear stiffness. 


\section{Indirect Tensile Strength}

The indirect tensile (IDT) strength test is a test to determine the performance characteristics of asphalt concrete mixtures. The equipment is available to most agencies. The IDT strength test is performed by loading a cylindrical asphalt specimen with a vertical force, as should in Figure 4.
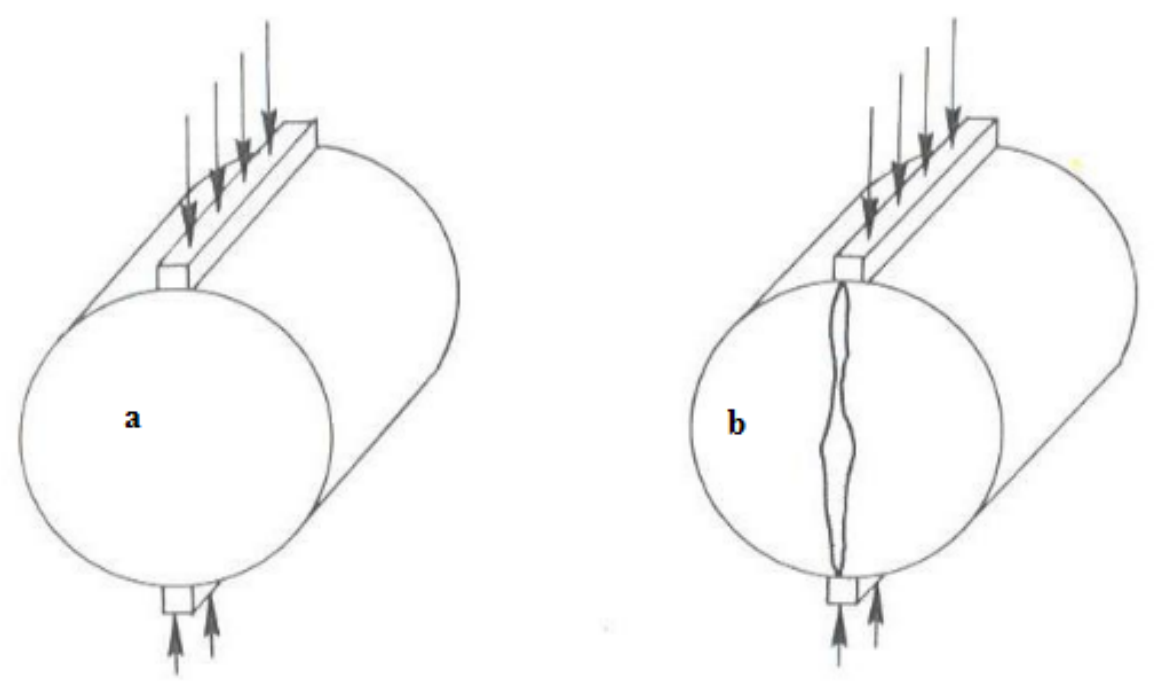

Figure 4. IDT strength test, prior to failure, and failed specimen

The curved loading strips on the top, and bottom of the specimen apply a compression force. The interaction of the stresses causes a tension failure along the vertical diametral plane as shown on Figure 4(b). The peak load that specimen can withstand is recorded and used in the following equation to determine the IDT strength of the specimen.

$$
\sigma_{x}=\frac{2 P}{\pi d t}
$$

Where: $\sigma_{\mathrm{x}}$ : Horizontal tensile strength at the center of the specimen;

P: Peak applied load;

$\mathrm{d}$ : diameter of the specimen (inches); and

$\mathrm{t}$ : Thickness of the specimen (inches).

The IDT strength is used as an indicator for the mixtures performance with respect to rutting, thermal cracking, and fatigue cracking (Christenson and Bonaquist, 2000). The test is considered a quick test, with low loads, that can adequately present the properties of the mixture (Christenson and Bonaquist, 2002). The second generation of high temperature IDT strength testing provides recommended requirements for IDT strength as a fuction of traffic level (Christenson and Bonaquist, 2007). IDT strength was presented as a good indicator of the 
rut depth of asphalt concrete testing compared to the Asphalt Pavement Analyzer (APA) (Zaniewski and Srinivasan, 2003). As shown in Figure 5.

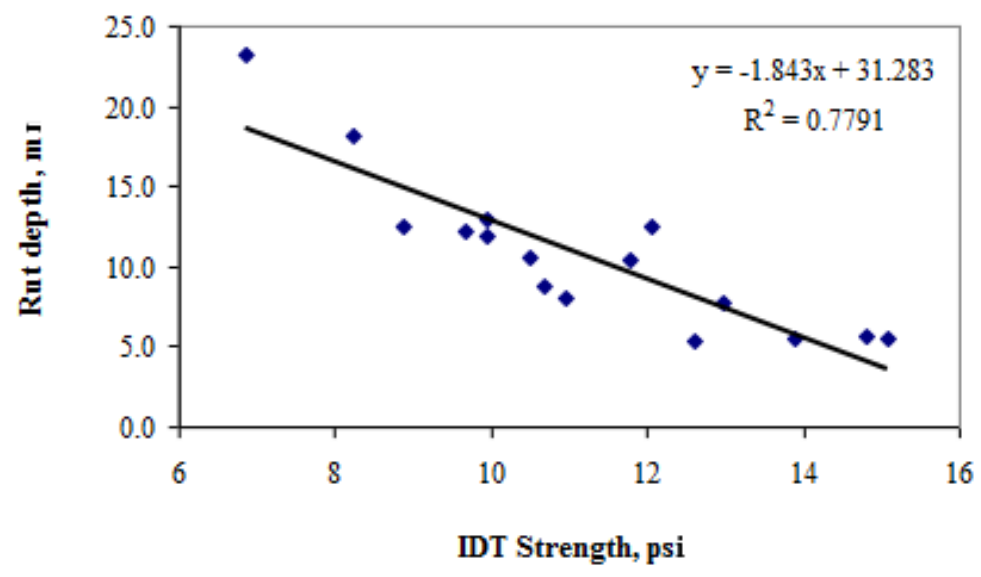

Figure 5. Rut Depth vs. IDT Strength

Wen and Bsuhal (2013) found that using asphalt mixture performance tester (AMPT), with the IDT jig attachment could help predict fatigue life. Using the fracture energy, the area under the stress-strain plot of a loaded specimen up to the peak stress, they could predict the fatigue life of the asphalt concrete with good confidence. The fracture energy is found mathematically by taking the integral of the function that presents the curvature of the line. AMPT uses digital instrumentation to capture this data. Figure 6 presents the results of the fracture energy versus the predicted fatigue life using AMPT.

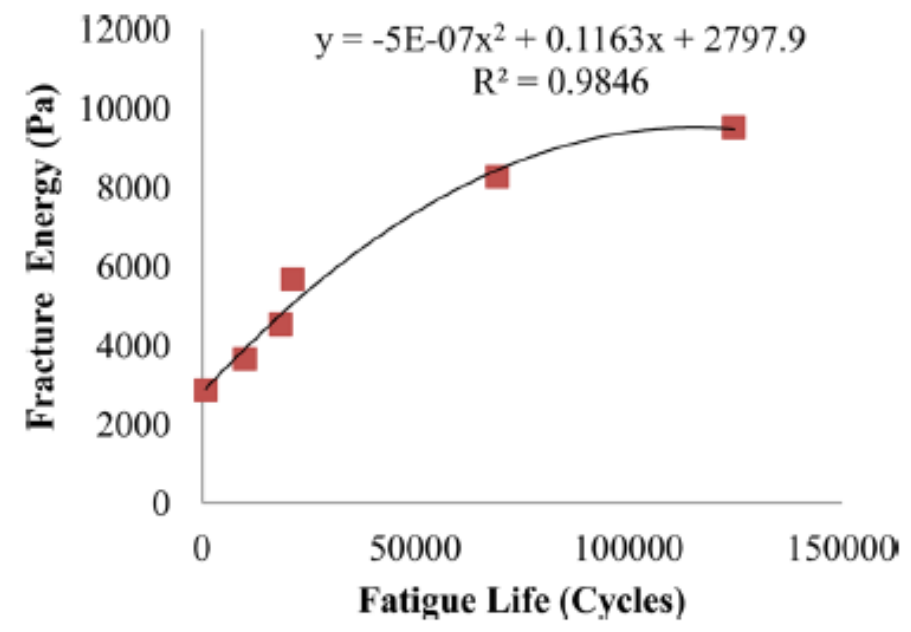

Figure 6. IDT Fracture Energy vs. Fatigue Life (Cycles) 


\section{Film Thickness}

Film thickness is used to describe the thickness of the asphalt film surrounding aggregate particles in an asphalt concrete mixture; it is often referred to as either the apparent film thickness (AFT), or the average film thickness.

Kandhal et al. (1998) published their findings on factors that affect the durability of asphalt mixtures. The report emphasizes the need to optimize the film of asphalt binder that coats the aggregate particles rather than use a broad requirement such as a minimum VMA for a given NMAS. Their analysis determined that high permeability, high air voids, and thin asphalt coats on the aggregate all lead to excessive binder aging and decrease the durability of the mixture in the field. They recommended that an asphalt coating of 8 microns be used to ensure pavement durability.

Testing completed by Christensen and Bonaquist (2006) was analyzed to understand the correlation between the performance of asphalt pavements and the AFT. The basic equation is (Christenson and Bonaquist, 2006):

$$
A F T=\frac{V_{a s p}}{S A * W}(1,000)
$$

Where:

AFT: Average Film Thickness, microns;

$\mathrm{V}_{\text {asp }}$ : Effective volume of asphalt, liters;

SA: Computed surface area of aggregate, $\mathrm{m}^{2} / \mathrm{kg}$; and

W: Mass of aggregate, kg

\section{Aggregate Surface Area}

An alternative to the use of VMA criteria is the use of asphalt film thickness coating aggregate to determine a durable mix design. This concept was introduced in by Richardson (1905) with his determination that the amount of asphalt:

"in any mixture should be sufficient to thickly coat every particle of mineral matter and fill the voids in the sand... without making the resulting asphalt surfaces too susceptible to temperature changes."

Richardson found asphalt mixtures needed a minimum asphalt content that would allow the samples to be stable, and resistant to fatigue cracking. Asphalt concrete that was deficient in binder would become brittle, and become highly susceptible to thermal cracking. 
Richardson found that the proper asphalt content was different for various mineral aggregates, many ranging from $9 \%$ to $14 \%$. Fine mixtures require a larger amount of asphalt than a coarse mixture using the same source mineral aggregate. Richardson expressed that as the diameter of an aggregate particle became smaller, the surface area in square centimeters per gram of mass increase rapidly (Richardson 1905). Table 14 presents Richardson's findings.

Table 14. Surface area for one gram of uniform sand

\begin{tabular}{|c|c|c|c|}
\hline \multicolumn{3}{|c|}{ One Gram of Uniform Sand } \\
\hline Mesh Sieve & $\begin{array}{c}\text { Opening } \\
(\mathrm{mm})\end{array}$ & $\begin{array}{c}\text { Number of } \\
\text { Particles }\end{array}$ & $\begin{array}{c}\text { Surface Area } \\
\left(\mathrm{cm}^{2}\right)\end{array}$ \\
\hline 10 & 1.5 & 213 & 15 \\
\hline 20 & 0.84 & 1,216 & 27 \\
\hline 30 & 0.58 & 3,694 & 39.4 \\
\hline 40 & 0.4 & 11,261 & 56.6 \\
\hline 50 & 0.26 & 41,005 & 87.1 \\
\hline 80 & 0.2 & 90,066 & 113.2 \\
\hline 100 & 0.13 & 328,032 & 174.2 \\
\hline 200 & 0.075 & $1,407,320$ & 283 \\
\hline
\end{tabular}

In 1918, Edwards, an engineer working to improve methods of designing Portland cement concrete mixes, evaluated the use of surface area to design mixes (Hveem 1936). Edwards worked to estimate the both the volume, and mass of each aggregate particle and assign a surface area factor to estimate the specific surface area of aggregates. Hveem published Edward's work regarding the determination of the surface area constant for particles that passed the \#200 sieve (Hveem 1936).

Surface area is a function of the gradation of the blended stockpiles, creating unique surface area factors for each gradation. The gradation is found using AASHTO T27 Sieve Analysis of Fine and Coarse Aggregates; the mass retained on each sieve is used to determine the percentage of the aggregate passing each sieve.

Surface area is computed using Equation 9 (Roberts et al., 2009): 


$$
S A=\sum\left(S F_{i} * P_{i}\right)
$$

Where:

SA: Surface Area of gradation;

$\mathrm{SF}_{\mathrm{i}}$ : Surface Factor for sieve i; and

$P_{i}$ : Cumulative percent passing sieve $i$, in decimal notation.

Surface area calculations are based on the assumption that the diameter of the aggregate particles is equivalent to the size or the opening of the sieve that a particle passed though, Edward's assumed that the particles were spheres with smooth sides. Table 15 contains the surface area factors used by Hveem, adopted from Edwards work, Hveem's initial estimates in 1936, and those by Zaniewski and Reyes $D_{\text {average }}$ method (Zaniewski and Reyes, 2003).

Table 15. Surface Area Factors, based on Percent Passing

\begin{tabular}{|c|c|c|c|c|c|c|c|c|}
\hline Sieve Size & $>4.75 \mathrm{~mm}$ & $4.75 \mathrm{~mm}$ & $2.36 \mathrm{~mm}$ & $1.16 \mathrm{~mm}$ & $600 \mu \mathrm{m}$ & $300 \mu \mathrm{m}$ & $150 \mu \mathrm{m}$ & $75 \mu \mathrm{m}$ \\
\hline $\begin{array}{c}\text { Surface } \\
\text { Area Factor } \\
\left(\mathrm{ft}^{2} / \mathrm{lb}\right)\end{array}$ & 2 & 2 & 4 & 8 & 14 & 30 & 60 & 160 \\
\hline $\begin{array}{c}\text { Surface } \\
\text { Area Factor } \\
\left(\mathrm{m}^{2} / \mathrm{kg}\right)\end{array}$ & 0.41 & 0.41 & 0.82 & 1.64 & 2.87 & 6.14 & 12.29 & 32.77 \\
\hline $\begin{array}{c}\text { Hveem } \\
1936 \\
\left(\mathrm{ft}^{2} / \mathrm{lb}\right)\end{array}$ & 2 & 4 & 8 & 16 & 30 & 60 & 120 & 200 \\
\hline $\begin{array}{c}\text { Hveem } \\
1936 \\
\left(\mathrm{~m}^{2} / \mathrm{kg}\right)\end{array}$ & 0.41 & 0.82 & 1.64 & 3.28 & 6.14 & 12.29 & 24.58 & 40.96 \\
\hline $\begin{array}{c}\text { Zaniewski } \\
\text { and Reyes } \\
\mathrm{D}_{\text {avg }}\left(\mathrm{ft}^{2} / \mathrm{lb}\right)\end{array}$ & 1.6 & 3.1 & 6.3 & 12.4 & 24.6 & 49.1 & 98.3 & 294.8 \\
\hline $\begin{array}{c}\text { Zaniewski } \\
\text { and Reyes } \\
\mathrm{D}_{\text {avg }} \\
\left(\mathrm{m}^{2} / \mathrm{kg}\right)^{1}\end{array}$ & 0.32 & 0.64 & 1.28 & 2.54 & 5.03 & 10.06 & 20.13 & 60.38 \\
\hline
\end{tabular}

Note $^{1}$ : Zaniewski and Reyes $\mathrm{D}_{\text {avg }}$ method uses percent retained on the sieve 
The surface area of the material minus No. 200 sieve is important because of the large specific area of the mineral particles. Zaniewski and Reyes (2003) used the Blaine Air Permeability Apparatus, Figure 7, to measure the surface area of the material passing the No. 200 sieve $(75 \mu \mathrm{m})$. The measured surface area for materials smaller than 75 microns are larger than the value , $32.77 \mathrm{~m}^{2} / \mathrm{kg}$ estimated by Hveem, Zaniewski and Reyes' results are presented in Table 16.

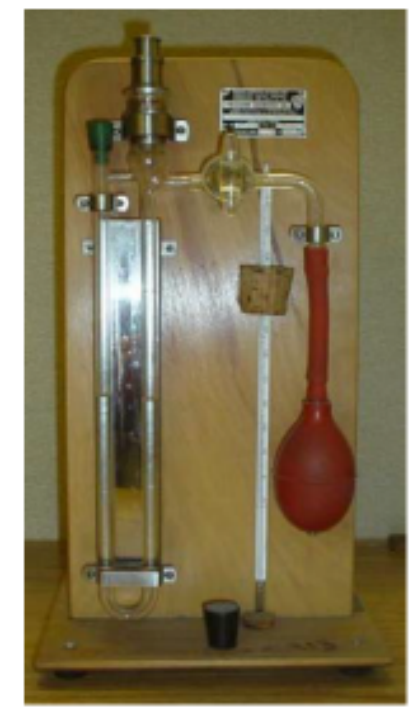

Figure 7. Air Permeability Apparatus

Zaniewski and Reyes (2003) also recommended the use of percent retained on individual sieves to calculate the surface area rather than using the cumulative percent passing by Hveem. It is presented as a more defendable and logical practice because percent passing method can be flawed because the percent passing each sieve is a function of the mass retained on all prior sieves.

Table 16. Specific area for material less than 75 microns

\begin{tabular}{|l|c|}
\hline Aggregate Source & $\begin{array}{c}\text { Average Tested } \\
\text { Surface Area } \\
\left(\mathrm{m}^{2} / \mathrm{kg}\right)\end{array}$ \\
\hline Summersville & 458 \\
\hline Beaver Boxley (A) & 435 \\
\hline Beaver Boxley (B) & 289 \\
\hline APAC Sand & 478 \\
\hline APAC \#10 & 437 \\
\hline New Enterprise & 615 \\
\hline Natural Sand & 118 \\
\hline
\end{tabular}


Christensen and Bonaquist (2006) correlated data between the summation of the percent passing the 75-, 150-, and $300 \mu \mathrm{m}$ sieves $\left(\mathrm{FM}_{300}\right)$ and the aggregate specific surface area calculation. Also correlation between the percent passing the 75 microns sieve $\left(P_{75}\right)$ and the aggregate specific surface area (Christensen and Bonaquist, 2006) was completed. The method for calculating the aggregate specific surface area was not outline, however it is assumed to be constant for all mixes. The research showed that the $\mathrm{FM}_{300}$ is a better indication of surface area than the percent material passing the $75 \mu \mathrm{m}$ sieve. This report demonstrates that a confident prediction of surface area comes from the materials smaller than 300 microns.

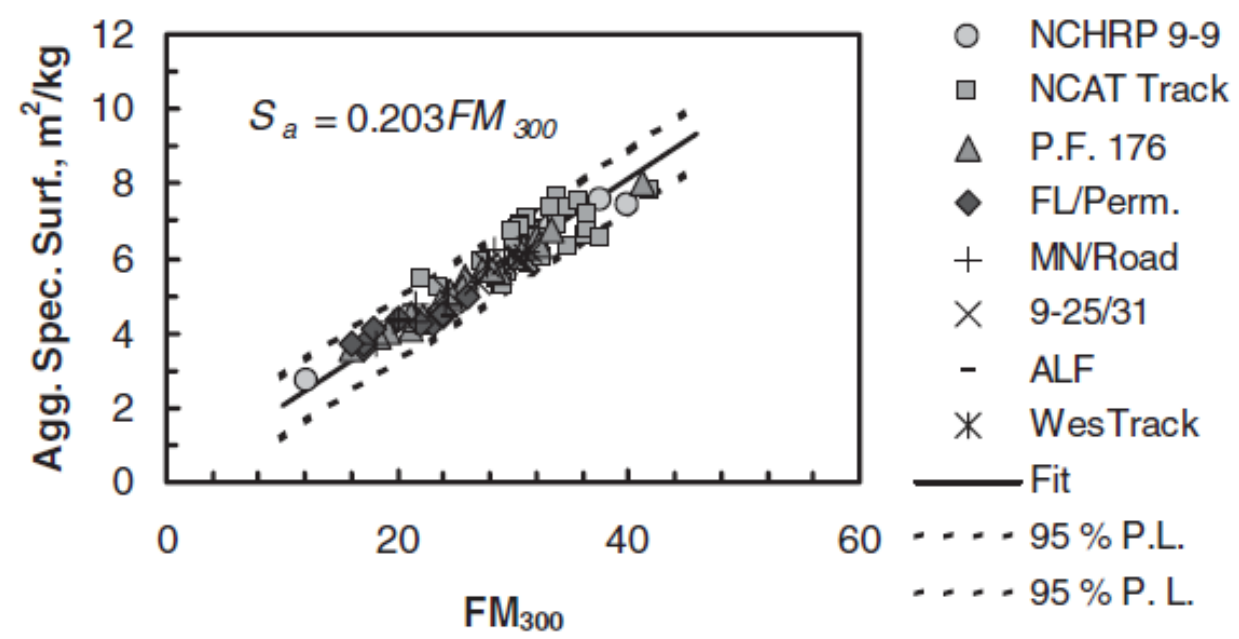

Figure 8. Surface Area vs $\mathrm{FM}_{300}$

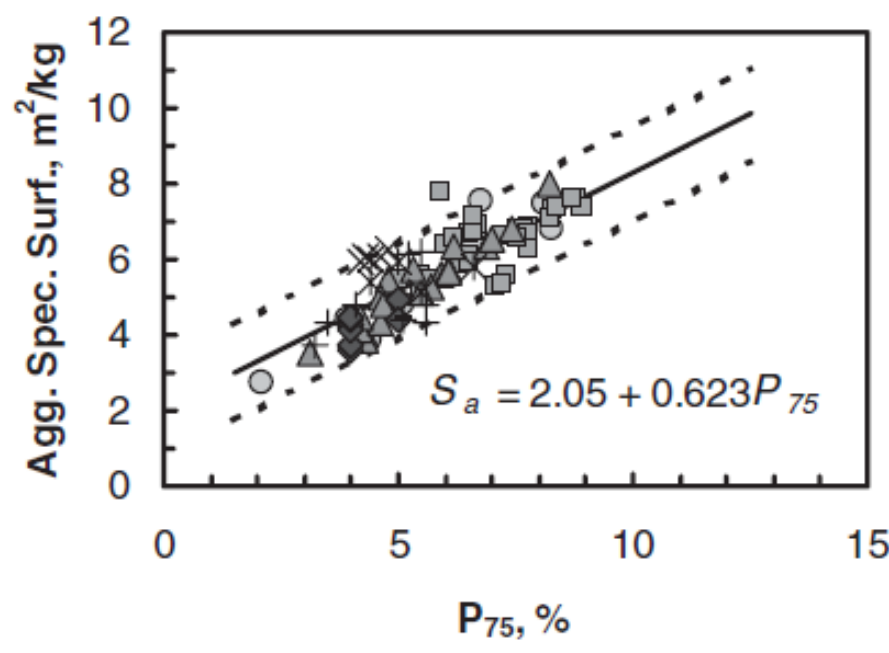

O NCHRP 9-9

口 NCAT Track

$\triangle$ P.F. 176

$\diamond$ FL/Perm.

$+\quad$ MNRoad

$\times \quad 9-25 / 31$

- ALF

* WesTrack

Figure 9. Surface Area vs. $\mathbf{P}_{75}$

Bessette, Logan P. 24 


\section{Summary of Literature Review}

The review of the literature has demonstrated that there are currently alternative design methods to finding the design asphalt content for asphalt concrete. The VMA recommendations outlined by McLeod in the 1950's for the Marshall mix design is based on specific assumptions regarding specific gravity of the aggregates, and that the aggregate was not crushed. The variation in aggregate types, either natural or crushed products, and the specific gravities of aggregates raise the question of whether there is a better method to determine the design asphalt content.

The literature review indicates that the theory of minimum VMA requirements was to ensure minimum asphalt content into a mixture to ensure a durable mix. Christensen and Bonaquist (2006) showed that asphalt durability is related to the AFT that coats the aggregate, therefore, instead of VMA requirements being based on a minimum asphalt content it should be based on the asphalt content that gives the minimum AFT (Christensen and Bonaquist, 2006). This modification allows coarse graded mixes, which have lower surface areas, to meet the volumetric requirements without using excessive asphalt (Kandhal et al., 1998).

The reduction or increase of compaction effort imparted by the SGC can alter the volumetric parameter VMA in asphalt concrete. Additionally, the change in compaction effort affects the percent asphalt required for a mixture to achieve $4.0 \%$ VTM.

As demonstrated by Huber and Schuler (1992), the previous assumption that moving away from the maximum density line increases the VMA is not accurate for all gradations. Additionally, Huber and Schuler showed that the type of aggregate can affect the VMA without changing gradation or asphalt content; crushed limestone create a higher VMA than gravel.

Christensen and Bonaquist (2006) found the AFT and asphalt concrete performance are not straightforward relationships, and that the use of specifying criteria for AFT is not recommended. Zaniewski and Reyes (2003) presented that the measured surface area of aggregate particles passing the $75 \mu \mathrm{m}$ sieve is much larger than that estimated by Hveem in 1936.

Specific surface area of aggregate can be used to determine the volume, and mass of asphalt required to coat aggregate particles regardless of the bulk specific gravity of the aggregate. The selection of design asphalt content by surface area is completed using an ATF between 6.0 to 8.0 microns have the demonstrated to be the most resistant to rutting.

Zaniewski and Srinivasan (2003) found that the IDT strength of compacted Superpave specimen could be correlated to rutting resistance. Christenson and Bonaquist (2007) presented that the minimum requirements for high temperature IDT strength could be changed 
as a function of the travel level. Mixes with higher IDT strength have greater resistance to rutting. Wen and Bsuhal (2013) found fatigue life could be predicted from the fracture energy of the compacted mixture. Mixes that had large areas under the stress-strain diagram when completing the IDT strength test, could withstand greater fatigue cycles in the AMPT. 


\section{CHAPTER 3 RESEARCH METHODOLOGY}

\section{Introduction}

This research evaluated the effects of changing the aggregate gradation, and compaction effort on VMA. The current specifications that are recommended by both the Asphalt Institute and the American Association of State and Highway Transportation Officials, are based on volumetric analysis of asphalt pavements, the components VFA, VTM, and VMA are given design ranges to control the durability and performance of the pavements used in West Virginia, and the United States. However, because VMA is often the most difficult parameter to satisfy it was the focus of this research.

The Superpave $9.5 \mathrm{~mm}$ mix design was supplied from J.F. Allen Company in Elkins, WV. All aggregate were crushed limestone. The contractors design binder content was $6.2 \%$ at 80 gyrations. The research approach involved:

- Obtain aggregate and binder from J.F. Allen Company

- Sieving aggregate on all U.S. customary sieves, $12.5 \mathrm{~mm}, 9.5 \mathrm{~mm}$, No. 4, No. 8, No. 16, No. 30, No. 50, No. 100, and No. 200.

- Wash aggregate to remove fines, and oven dry to constant mass, place in bins for storage, bag house fines were used to supplement the amount of No. 200 material needed in the mixes.

- Blend aggregates to create the three gradations.

- Create specimens for compaction in SGC, and maximum theoretical specific gravity.

- Complete volumetric analysis in accordance with WVDOH specifications.

- Test samples for IDT strength, and compute the force-deformation fracture energy as captured from the IDT strength curve.

- Complete statistical analysis of data collected.

\section{Experiment Design}

The experiment was evaluated with three factors; compaction effort, aggregate gradation, and asphalt content. The compaction efforts were 80 gyrations and 100 gyrations. The aggregate gradations were coarse, design, and fine-graded.

For the experimental design it was desirable to use consistent levels of percent binder for all combinations of compaction level and gradation. The contractor's design binder content was $6.2 \%$ for 80 gyrations. Based on previous experience, it was anticipated that this was $0.4 \%$ greater than would be needed for the same gradation at 100 gyrations. The binder adjustment for gradation would suggest the binder would be greater for the fine blend and lower for the 
coarse gradation. Considering these factors, it was decided to "center" the percent binder in the experiment at $6.0 \%$ The other binder levels were set at $+/-0.5 \%$ and $+/-1.0 \%$., i.e. the percent binder levels used in the experiment were 5.0\%, 5.5\%, 6.0\%, 6.5\% and 7.0\%. Table 17 presents the testing matrix used for this research. Three replicate samples were produced for each combination of factors and levels. Analysis of Variance (ANOVA) was used to evaluate the significance of the factors. When the samples were determined to be statistically different, the Tukey-Kramer Honest Significant Difference test was used to determine which variable were different. A total of 90 compacted specimens, and 45 maximum theoretical specific gravity samples were prepared and tested.

Table 17. Testing matrix

\begin{tabular}{|c|c|c|c|c|c|c|}
\hline \multirow{3}{*}{$\begin{array}{c}\text { NMAS } \\
\text { Compaction Effort } \\
\text { Gradation }\end{array}$} & \multicolumn{6}{|c|}{$9.5 \mathrm{~mm}$} \\
\hline & \multicolumn{3}{|c|}{80 Gyration } & \multicolumn{3}{|c|}{100 Gyrations } \\
\hline & Coarse & Contactor & Fine & Coarse & Contactor & Fine \\
\hline \multicolumn{7}{|l|}{ Asphalt Content } \\
\hline $5.0 \%$ & 1 & 2 & 3 & 16 & 17 & 18 \\
\hline $5.5 \%$ & 4 & 5 & 6 & 19 & 20 & 21 \\
\hline $6.0 \%$ & 7 & 8 & 9 & 22 & 23 & 24 \\
\hline $6.5 \%$ & 10 & 11 & 12 & 25 & 26 & 27 \\
\hline $7.0 \%$ & 13 & 14 & 15 & 28 & 29 & 30 \\
\hline
\end{tabular}

\section{Gradations}

The aggregate blend received from J.F. Allen Company was used as the starting point for creating aggregate gradations. The fine and coarse gradations were created by satisfying the following criteria,

- Gradation could be achieved by blending contractor stockpiles

- Gradation was within control points of WVDOH 9.5mm NMAS specifications

- Gradations created maximum separation of coarse and fine mixes

- Remain approximately $5 \%$ away from control points for practicality.

Figure 10 present the gradation curves for the $9.5 \mathrm{~mm}$ mixes that were created, summary table for the aggregate blending are in the appendix. 


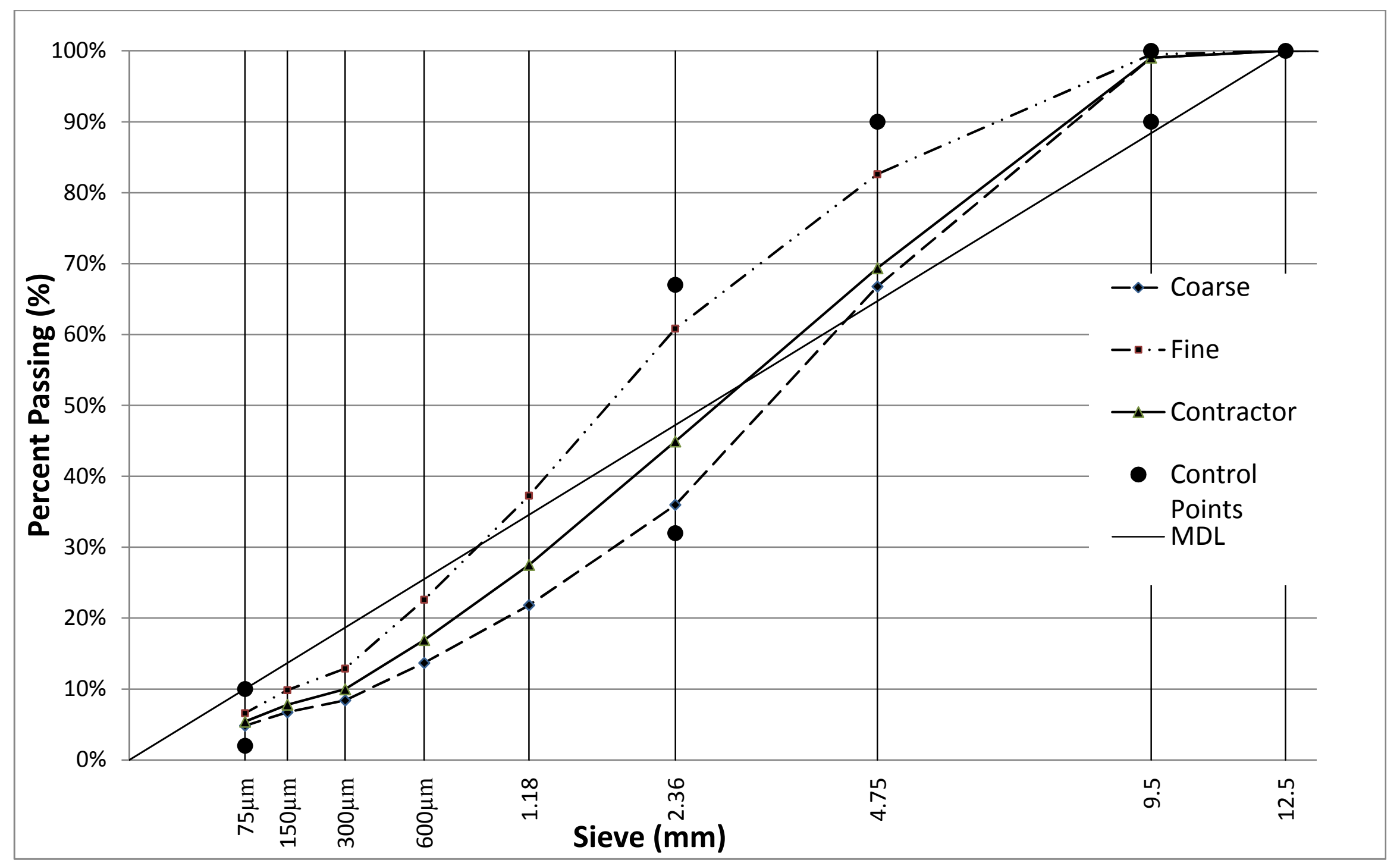

Figure 10. 9.5mm Aggregate Gradations 


\section{Sample Creation}

Weigh out tables were created for each gradation to determine the mass of aggregate from each stockpile to use in the mix. The aggregate, binder, and mixing tools were heated to the mixing temperature of $157^{\circ} \mathrm{C}$. Once at the design mixing temperature the aggregate was added to the mixing bucket. A small crater was created in the center of the hot aggregate and the correct mass of binder was poured into the creator. The aggregate and binder were then mixed together in the bucket mixer until all aggregate particles were covered with binder. The amount of material in each batch was sufficient to make 2 compacted, and one maximum specific gravity samples.

Upon completion of mixing, the mix was placed in the oven to condition at the compaction temperature of $145^{\circ} \mathrm{C}$ for two hours with stirring after one hour. Once the mix had conditioned for two hours, it was poured into a SGC mold that was heated to the compaction temperature. The mold with the mixture was placed in the SGC and compacted to either 80, or 100 gyrations. After compaction the specimen was allowed to cool to room temperature before completion of the volumetric analysis. The specimens created for the maximum theoretical specific gravity samples were created in the same procedure as the compacted specimen, but after the two hour conditioning time it was spread out on a non-absorbing surface to cool to room temperature.

\section{Analysis}

The volumetric analysis used AASHTO T166, Bulk Specific Gravity of Compacted Hot Mix Asphalt (HMA) using Saturated Surface Dry Specimens, T209, and Theoretical Maximum Specific Gravity and Density of Hot Mix Asphalt (HMA), T269, Percent Air Voids in Compacted Dense and Open Asphalt Mixtures, using the following equations:

$$
\begin{gathered}
V T M=\left(\frac{G_{m m}-G_{m b}}{G_{m m}}\right) * 100 \\
V M A=\left(100-\frac{G_{m b} P_{s}}{G_{s b}}\right) \\
V F A=\left(\frac{V M A-V T M}{V M A}\right) * 100
\end{gathered}
$$

Where,

$\mathrm{G}_{\mathrm{mm}}=$ Maximum theoretical gravity of mixture;

$\mathrm{G}_{\mathrm{sb}}=$ Bulk specific gravity of aggregate; 
$\mathrm{P}_{\mathrm{s}}=$ Percent stone, and,

$\mathrm{G}_{\mathrm{mb}}=$ Bulk specific gravity

\section{IDT Strength Testing}

The IDT strength of the asphalt specimen were found by testing the SGC pills. The pills ranged from $110 \mathrm{~mm}$ to $120 \mathrm{~mm}$ in height and had diameter of $150 \mathrm{~mm}$. Prior to testing the pills, they were submerged in a $60^{\circ} \mathrm{C}$ water bath for 1 hour and 15 minutes. The temperature of $60^{\circ} \mathrm{C}$ was used because it is the standard temperature for Marshall stability testing, and the time of saturation was increased to account for the increased volume of the Superpave specimem. The Marshall stability apparatus that was used for testing applied a constant deformation rate of $50 \mathrm{~mm} / \mathrm{min}$. The strength of each sample was computed using Equation 7.

\section{Fracture Energy}

The fracture energy for each specimen was calculated by importing the load vs. deformation curve from the IDT test into AutoCad and completing a set of data manipulations. The order of operations was as follows:

- Import laboratory curve into AutoCad and ensure proper scale.

- Find point of peak load and draw line perpendicular to the abscissa.

- Use "Spline" command to outline the lab curve from point $(0,0)$ to peak load.

- Use "area" command by "polyline" to calculate the area under the load deformation curve.

\section{Locking Point and Compaction Slope}

The locking point, and compaction slope of each mixture was determined for each mixture. The 2-2-3 locking point was used all mixes, the compaction slope was calculated using Equations 2, 3, and 4.

\section{Statistical Analysis}

After the laboratory tests where completed, a variety of statistical analysis methods were used to determine the significance of the results. The Analysis of Variance (ANOVA), linear regression, and the Tukey Kramer Honest Significant Difference test (HSD) were used. The background regarding the statistical methods follows.

\section{ANOVA}

The one way ANOVA analysis was used to determine if there was a significant difference between groups of data. This is a statistical method for comparing several sample means, and 
assumes the null hypothesis $\left(\mathrm{H}_{\mathrm{o}}\right)$ that all means are equal, and the alternative hypothesis $\left(\mathrm{H}_{\mathrm{a}}\right)$ that not all means are equal (Moore et al., 2012).

$$
H_{0}: \mu_{1}=\mu_{2}=\ldots=\mu_{i}
$$

$\mathrm{H}_{\mathrm{a}}:$ not all $\mu_{\mathrm{i}}$ are equal

Where:

$$
\begin{aligned}
& \mu_{1}: \text { mean of sample } 1 ; \\
& \mu_{2}: \text { mean of sample } 2 ; \text { and } \\
& \mu_{i}: \text { mean of the } i^{\text {th }} \text { sample. }
\end{aligned}
$$

An assumption for the ANOVA analysis is the group varied by a single factor, an example of this was: "At 80 gyrations, and 5\% binder, how do the IDT strengths of coarse, fine, and contractor graded mixes compare?" The null hypothesis will be rejected if the F-statistic, a function of the degrees of freedom in the numerator and denominator, is larger than F-critical at the $95 \%$ confidence interval. If the F-statistic is less than F-critical, the null hypothesis is accepted.

\section{Tukey Kramer Honest Significant Difference (HSD)}

The Tukey Kramer HSD is a method of multiple comparison used in conjunction with ANOVA to determine if two means are equal when the F-test rejects the null hypothesis (Dowdy et al., 2004). The test compares means over a confidence interval by means of 15

$$
\left|y_{i}-y_{j}\right| \geq q_{\propto, a, a(n-1)} \sqrt{\frac{M S_{E}}{n}}
$$

Where:

$$
\begin{aligned}
& Y_{i}=\text { average of group } i ; \\
& Y_{j}=\text { average of group } j ;
\end{aligned}
$$

$\mathrm{q}_{\alpha, \mathrm{a}, \mathrm{a}(\mathrm{n}-1)}=\mathrm{q}$-statistic as a function of degrees of freedom in numerator, denominator and confidence interval.

$\mathrm{MS}_{\mathrm{e}}=$ mean square of error, $\mathrm{n}=$ number of samples.

\section{Linear Regression}

A linear regression line is a straight line that predicts how dependent variable y changes as independent $x$ changes. This is accomplished by fitting a line with slope $b_{1}$ and intercept $b_{0}$ to the data. The equation for the line is presented as:

$$
y=b_{o}+b_{1} x
$$


Using Equation 16, a response value for $y$ can be plotted for any value of $x$. The quality of prediction is indicated by $R^{2}$, the fraction of variation. $A n R^{2}=1.00$ indicates that the regression line exactly predicts the value of $y$ for any change in $x$.

Where:

$$
R^{2}=\frac{\sum\left(\hat{y}_{i}-\bar{y}_{i}\right)^{2}}{\sum\left(y_{i}-\bar{y}_{i}\right)^{2}}
$$

$\sum\left(\hat{y}_{i}-\bar{y}_{i}\right)^{2}=$ variance of predicted values $\hat{y} ;$ and

$\sum\left(y_{i}-\bar{y}_{i}\right)^{2}=$ variance of observed values $\mathrm{y}$.

\section{Summary of Research Methodology}

To properly evaluate the effect of aggregate gradation, compaction effort, and asphalt content on VMA the following steps were required.

- Blend of stockpiles to create three gradations that exhibit high surface area, moderate surface area, and low surface area.

- Create specimens with 5.0\%, 5.5\%, 6.0\%, 6.5\% and 7.0\% asphalt content.

- Compute the volumetric properties in accordance with the West Virginia Department of Highways Material Procedures.

- Test samples for IDT strength and compute the fracture energy.

- Development of analysis procedures for determining relationships between compaction effort, aggregate gradation, and volumetric properties. 


\section{CHAPTER 4 RESULTS AND ANALYSIS}

The samples created were evaluated for volumetric properties, locking point, compaction slope, IDT strength, and fracture energy. The design binder content for each mix was determined for both 80 , and 100 gyrations. Once the volumetric properties were determined, the specimens were tested for IDT strength after curing for 24-hours. The relationships between volumetric properties, compaction effort, asphalt film thickness, fracture energy and IDT strength were evaluated.

\section{Mix Properties}

The first analysis performed on the data was to evaluate the data to determine the design binder content and associated properties as summarized in Tables 19 and 20. The volumetric plots in the appendix were used to determine $\mathrm{P}_{\mathrm{b}}$ at $4.0 \%$ VTM for each mix. Then the other volumetric properties were selected at their respective value of $\mathrm{P}_{\mathrm{b}}$ dependent on the combination of gradation and compaction. The results obtained from the research data area compared to the WVDOH criteria for $9.5 \mathrm{~mm}$ mixes.

The volumetric parameters and other performance indicators at the design binder contents are presented in Table 18. Figures showing the properties are presented in the appendices.

For both compaction levels the design binder content for the contractor gradation is less than the design binder content for the fine and coarse gradations. This is a reasonable result as the gradation curves for the fine and coarse gradations are further away from the maximum density line than the contractor design blend, especially for the aggregates passing the No. 16 sieve.

Table 18. Volumetric Properties at 4.0\% VTM, 80 Gyrations

\begin{tabular}{|c|c|c|c|c|}
\hline & \multicolumn{4}{|c|}{$\mathbf{8 0}$ Gyrations } \\
\hline & Coarse & Fine & Contractor & Criteria \\
\hline $\mathbf{P}_{\mathbf{b}}$ & $7.0 \%$ & $6.8 \%$ & $6.4 \%$ & - \\
\hline VTM & $4.0 \%$ & $4.0 \%$ & $4.0 \%$ & $15.5 \%$ \\
\hline VMA & $18.2 \%$ & $17.2 \%$ & $16.8 \%$ & $74 \%-80 \%$ \\
\hline VFA & $78 \%$ & $78 \%$ & $75 \%$ & - \\
\hline $\mathbf{P}_{\text {be }}$ & $6.3 \%$ & $5.7 \%$ & $5.6 \%$ & $0.6-1.2$ \\
\hline $\mathbf{d} / \mathbf{P}_{\text {be }}$ & 0.76 & 1.15 & 0.96 & \\
\hline
\end{tabular}


Table 19. Volumetric Parameters at 4\% VTM, 100 Gyrations

\begin{tabular}{|c|c|c|c|c|}
\hline & \multicolumn{4}{|c|}{100 Gyrations } \\
\hline & Coarse & Fine & Contractor & Criteria \\
\hline $\mathbf{P}_{\mathbf{b}}$ & $6.8 \%$ & $6.6 \%$ & $6.1 \%$ & - \\
\hline VTM & $4.0 \%$ & $4.0 \%$ & $4.0 \%$ & $4.0 \%$ \\
\hline VMA & $18.0 \%$ & $16.7 \%$ & $16.1 \%$ & $15.5 \%$ \\
\hline VFA & $78 \%$ & $76 \%$ & $75 \%$ & $74 \%-80 \%$ \\
\hline $\mathbf{P}_{\mathbf{b e}}$ & $6.1 \%$ & $5.5 \%$ & $5.3 \%$ & - \\
\hline $\mathbf{d} / \mathbf{P}_{\mathbf{b e}}$ & 0.79 & 1.2 & 1.02 & $0.6-1.2$ \\
\hline
\end{tabular}

Table 20 provides additional mix properties that were interpolated from the data collected from the asphalt contents around the respective design binder content, as indicated in Table 18 and Table 19. The coarse, and fine mixtures have less IDT strength than the contractors gradation. As the gradation moves from coarse to fine the compaction slope decreases. As anticipated the coarse gradation had the highest ATF.

Table 20. Mix Properties at Design Binder Content*

\begin{tabular}{|c|c|c|c|c|}
\hline & \multicolumn{3}{|c|}{ Gradation } \\
\hline & & Coarse & Fine & Contractor \\
\hline \multirow{3}{*}{$\begin{array}{c}80 \\
\text { Gyrations }\end{array}$} & $T_{f}$ (microns) & 14.2 & 9.08 & 11.0 \\
\hline & $\begin{array}{c}\text { Compaction } \\
\text { Slope (k) }\end{array}$ & 10.6 & 9.6 & 10.0 \\
\hline & IDT (psi) & 15.1 & 16.2 & 17.5 \\
\hline \multirow{3}{*}{$\begin{array}{c}100 \\
\text { Gyrations }\end{array}$} & $T_{f}$ (microns) & 13.7 & 8.8 & 10.3 \\
\hline & $\begin{array}{c}\text { Compaction } \\
\text { Slope (k) }\end{array}$ & 9.9 & 9.3 & 9.4 \\
\hline & IDT (psi) & 12.2 & 15.5 & 15.7 \\
\hline
\end{tabular}

*Average for 3 Samples

- The 80 gyration mixes required more design binder than the 100 gyration mixes.

- The coarse, and fine gradations had higher VMA than the contractor gradation due to the increased distance from the maximum density line. 
- The contractor gradation had the largest change in VMA when changing from 80to 100 gyrations.

- The coarse graded, 80 and 100 gyration mix had a VMA that was greater than the WVDOH recommendation stating that mixes with VMA more than $2 \%$ higher than the specification are susceptible to rutting and have tendency to shove under the roller.

The 100 gyration mixture produced lower VMA than the 80 gyration. As anticipated the coarse and fine gradations, which are far away from the maximum density line, achieve the highest the VMA. The contractor gradation has the largest change in VMA when changing the compaction level from 100 to 80 gyrations.

According to the literature, the percent binder required to achieve $4 \%$ VTM at $\mathrm{N}_{\text {design }}$ is less when using higher compaction effort. The fine and coarse gradations both required $0.2 \%$ less binder when changing the compaction level from 80 to 100 gyrations; the contractor gradation required $0.3 \%$ less binder.

The VMA change was less than seen by Huber and Anderson (2004). When reducing the gyration by 20 , the change in VMA was $0.2 \%, 0.5 \%$, and $0.7 \%$ for the coarse, fine, and contractor gradations, respectively. This is less than the $1.0 \%$ change reported by Huber and Anderson (2004) when decreasing $\mathrm{N}_{\text {design }}$ by 25 gyrations.

\section{Surface Area and Film Thickness}

The specific surface area of the gradations were found using two methods; the Hveem method using cumulative percent passing, Zaniewski and Reyes (2004) $D_{\text {avg }}$ method with individual percent retained. The surface area calculation using the $P_{200}$ constants determined by Zaniewski and Reyes (2004) was not used for this research. Table 21 shows the Hveem method resulted in higher surface areas than the $D_{\text {average }}$ method for each gradation. For consistency with the literature the Hveem method was used for all following analysis.

Table 21. Calculated Surface Areas

\begin{tabular}{|c|c|c|}
\cline { 2 - 3 } \multicolumn{1}{c|}{} & \multicolumn{2}{c|}{ Method } \\
\cline { 2 - 3 } \multicolumn{1}{c|}{} & Hveem & $\mathrm{D}_{\text {avg }}$ \\
\hline Gradation & \multicolumn{2}{|c|}{$\left(\mathrm{m}^{2} / \mathrm{kg}\right)$} \\
\hline Coarse & 4.65 & 4.42 \\
\hline Fine & 6.66 & 6.29 \\
\hline Contractor & 5.33 & 5.05 \\
\hline
\end{tabular}


Figure 11 demonstrates the differences in calculated surface area between the methods.

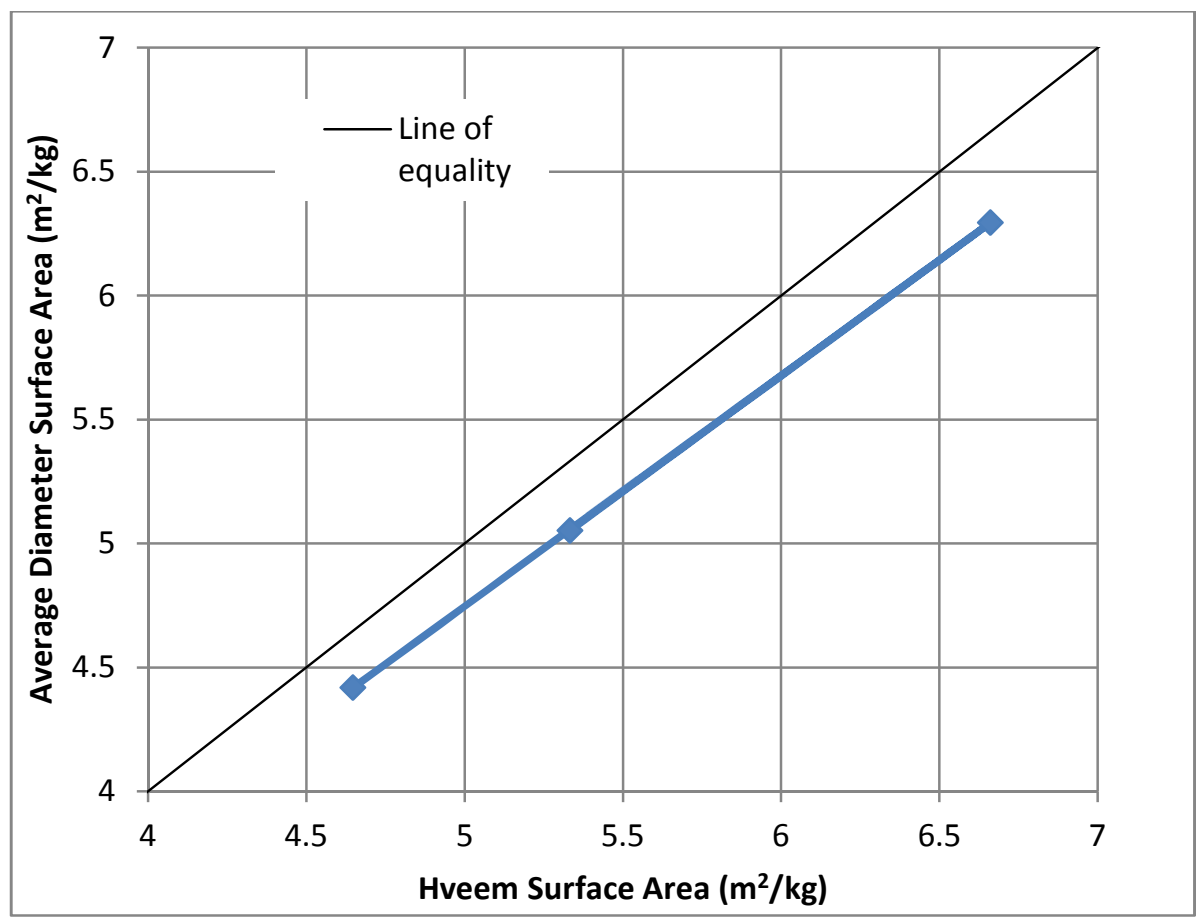

Figure 11. Calculated Surface Area, $D_{\text {avg }}$ vs. Hveem

\section{Film Thickness}

The film thickness was calculated using Equation 6. The mixtures had film thickness between 6.4 microns (Fine gradation, 5.0\% binder) and 14.9 microns (Coarse Gradation, 7.0\% binder) when using the Hveem method of surface area calculation. There was not an optimum asphalt film thickness to be applied to all gradation. Kandhal et al. (1998) recommended film thickness should be in the range of 9 to 10 microns

\section{Indirect Tensile Strength}

Zaniewski and Srinivasan (2003) correlated IDT strength and APA results to allow the use of IDT as an indicator of rutting potential, shown in Figure 5. Using an APA limit of $8 \mathrm{~mm}$ (Brown et al., 2001) an IDT strength greater than 12 psi indicates a suitable mix with respect to rutting.

Figure 12 and 13 shows that the IDT strength of the specimen increase with film thickness for each gradation at both compaction levels. The coarse gradation presented the lowest IDT strength although it had the largest film thickness. The contractor gradation created the highest IDT strengths. 


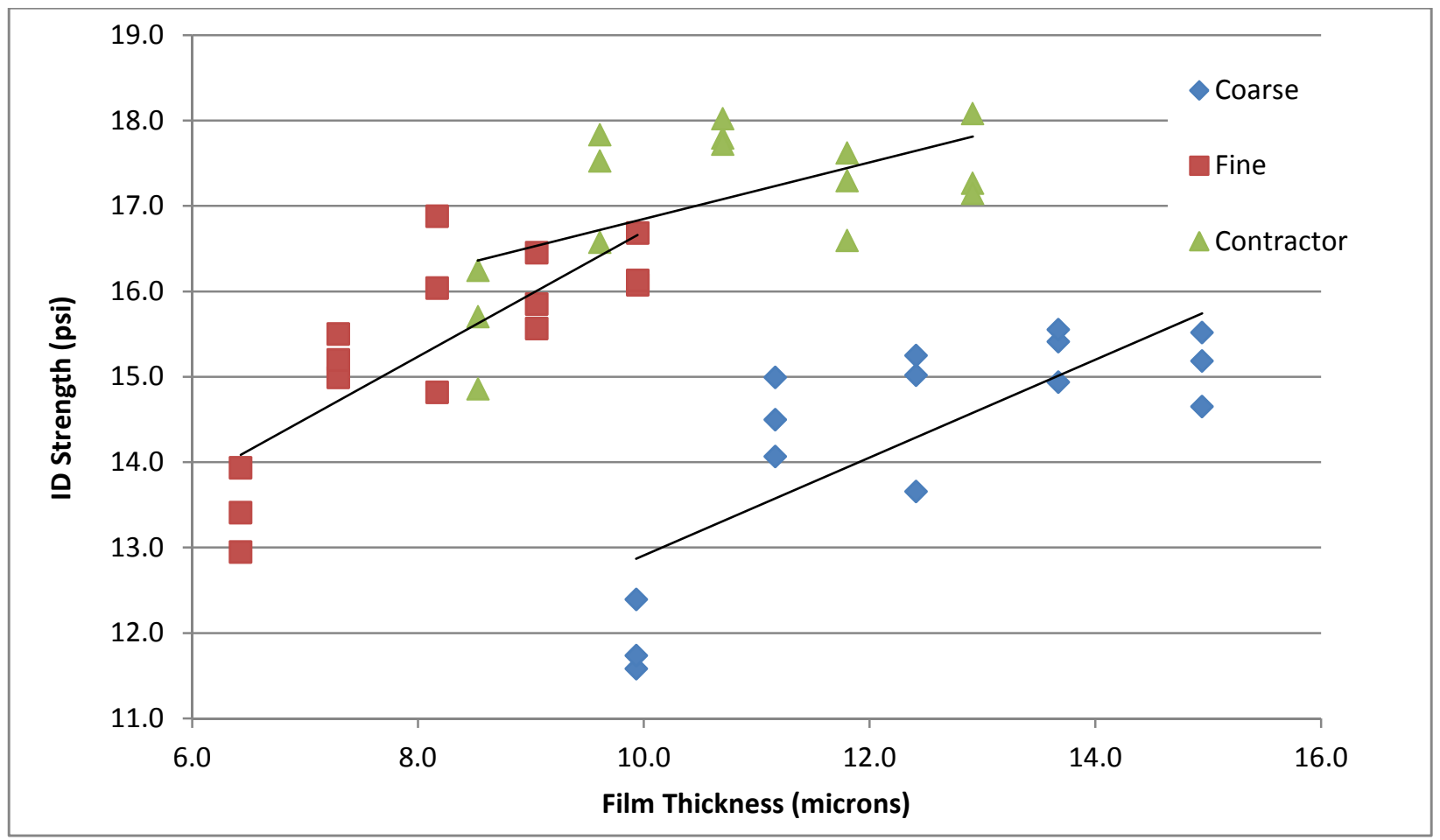

Figure 12. Relationship between IDT strength and film thickness at 80 gyrations

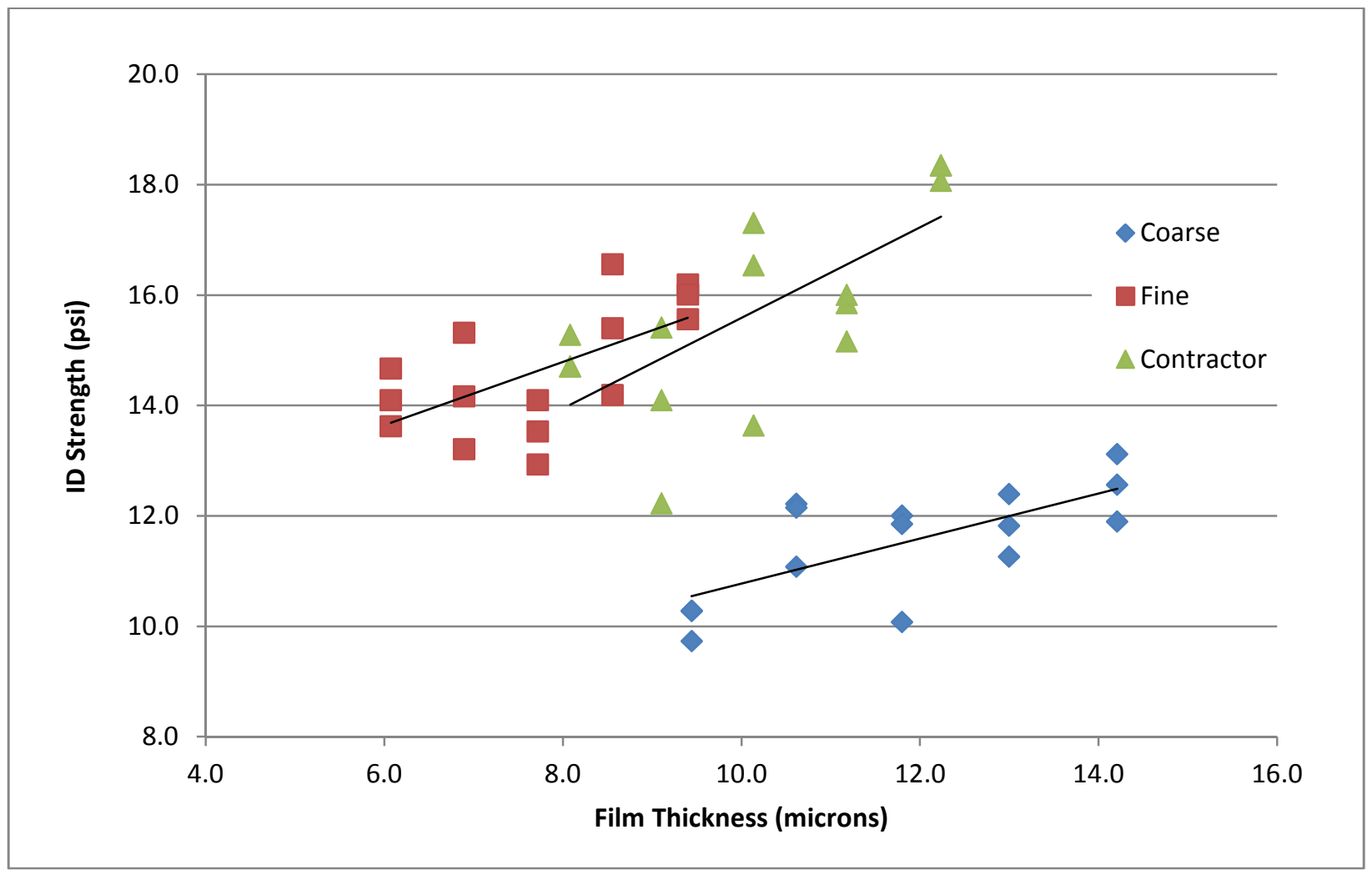

Figure 13. Relationship between IDT strength and film thickness at 100 gyrations 


\section{Fracture Energy}

Fracture energy, as calculated by Wen and Bsuhal (2013) was accomplished by finding the area under the stress-strain diagram of an asphalt specimen loaded using the AMPT with IDT jig. They found that fracture energy can be used to calculate the number of fatigue cycles a specimen could endure with good confidence, Figure 6.

To simulate the Wen and Bsuhal method, the area under the load-deformation diagram from the IDT test was calculated for all specimens. Each graph was digitized, and then imported into AutoDesk ${ }^{\circledR}$ AutoCad, as presented in Figure 14. A spline polyline was fit to the curve of each specimen, and then the area function was used to find the fracture energy (lb-inch).

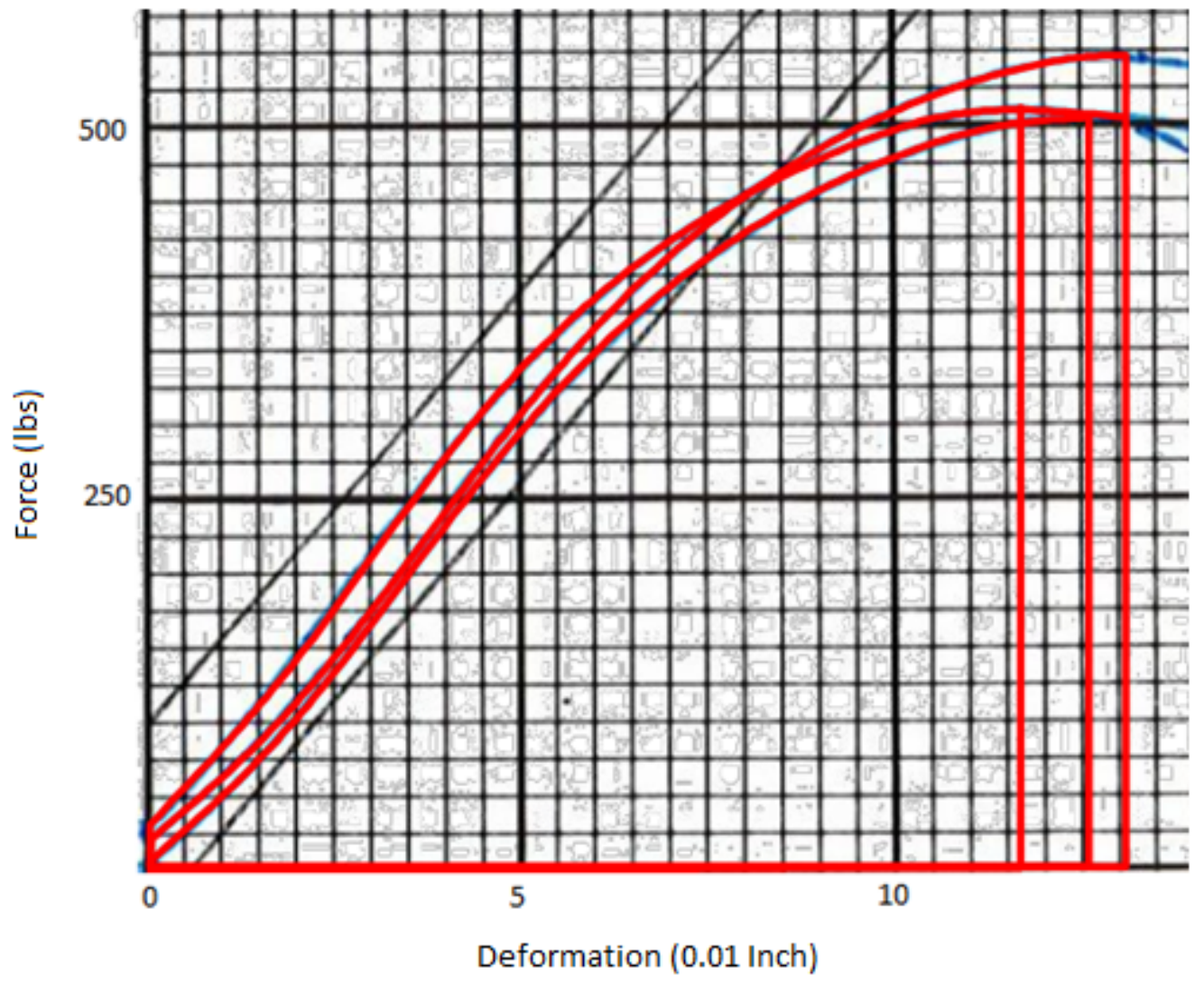

Figure 14. Example Fracture Energy from IDT Load Diagram

The calculated fracture energy was used to compare the estimated fatigue life of the 80 and 100 gyration samples. The fracture energy for the 80 gyration samples were on average $32 \%$ greater than the 100 gyration samples. Table 22 presents the fracture energy (Ib-in), IDT strength (psi), and percent difference for all samples. 
The IDT strength and fracture energy data are shown on Figure 15. The coefficient of determination, $\mathrm{R}^{2}$ of the trendline is 0.61 . The coarse, 80 gyration samples have fracture energy that is similar to the contractors 80 gyration mixes, although having lower IDT strength.

According to Wen and Bsuhal (2013), this indicates the two mixes will have similar fatigue life, while the larger AFT of the coarse mixture will resist oxidization better than the fine, and contractor mix. 
Figure 15. Fracture Energy vs. IDT Strength

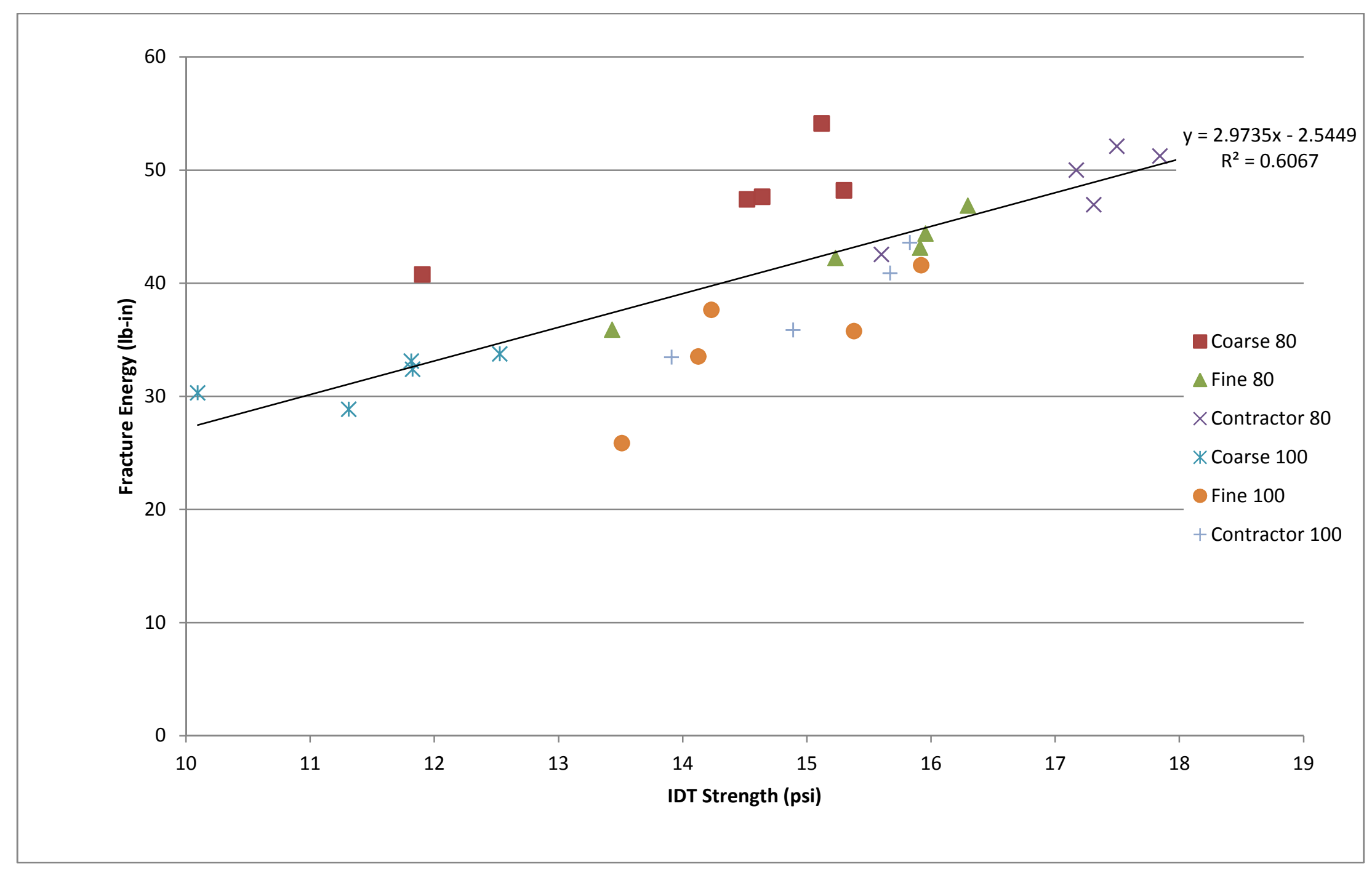

Bessette, Logan P. 41 
Table 22. IDT Strength and Fracture Energy

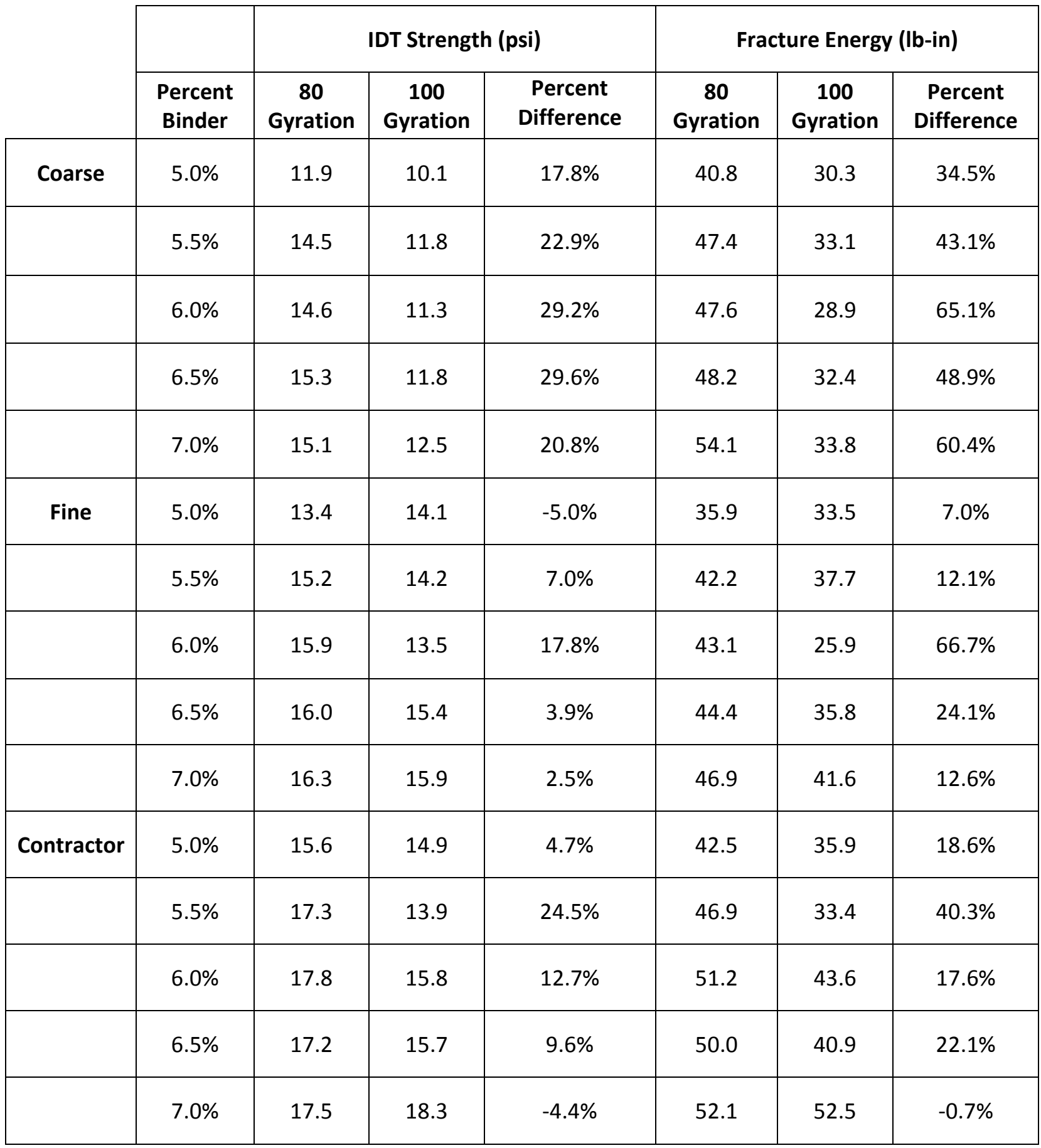

\section{Locking Point}

The 2-2-3 locking point was not achieved for any mix at 80 gyrations. The average number of gyration to achieve locking point was determined from the 3 compacted specimens at each unique gradation and binder content. Table 23 presents these data. Cells that do not contain 
data had at least one specimen that did not achieve locking point, all fine graded mixes had a minimum of one specimen failing to lock out within 100 gyrations. The failure to achieve lock out by the fine mix indicates that the aggregate structure of the asphalt concrete is not in a dense configuration.

Table 23. Gyrations to achieve locking point

\begin{tabular}{|c|c|c|c|}
\hline & \multicolumn{3}{|c|}{ Gradation } \\
\hline Percent Binder & Coarse & Fine & Design \\
\hline $5.0 \%$ & 85 & - & 94 \\
\hline $5.5 \%$ & 90 & - & 95 \\
\hline $6.0 \%$ & - & - & 92 \\
\hline $6.5 \%$ & 93 & - & - \\
\hline $7.0 \%$ & 91 & - & - \\
\hline
\end{tabular}

The fine gradation mixture did not lock out in accordance with the 2-2-3, this mixture also had the lowest asphalt film thickness, and lowest compaction slope. The locking point data are in the appendices.

Figure 16 shows compaction slope $(\mathrm{k})$ is influenced by film thickness, the thicker asphalt coating the steeper the compaction slope. Vavrik (2000) found mixes with high compaction slopes generally have poor performance because of rapid densification in field construction. The coarse graded mixture had the highest compaction slope, and the lowest IDT strength of the specimens tested. 


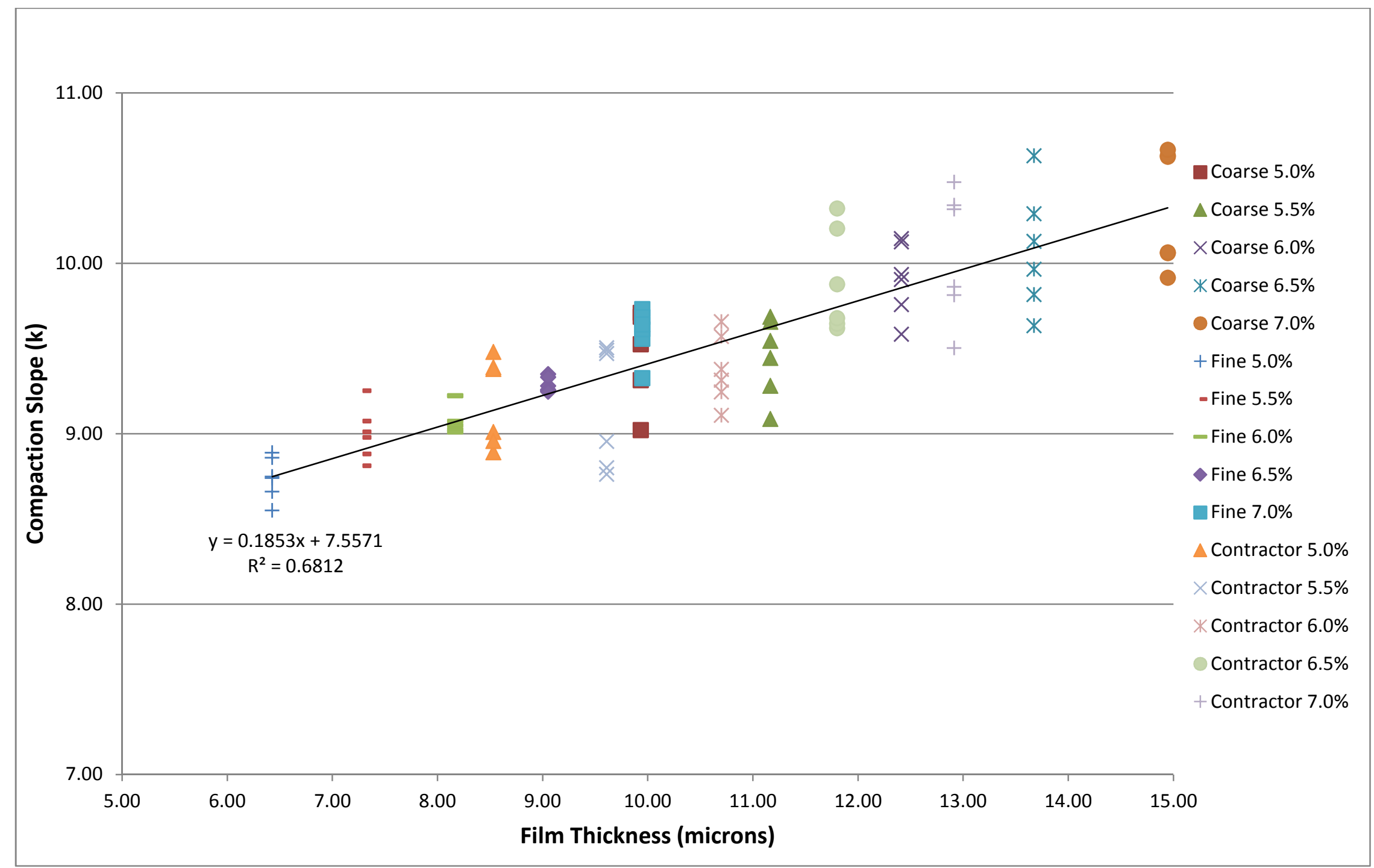

Figure 16. Compaction slope vs. Film thickness 
Comparison between the dust-to-effective binder ratio, and the dust-to-film thickness ratio (percent dust to film thickness in microns) was completed as part of this research. Under WVDOH specifications, the dust-to-effective binder ratio must be 0.6-1.2 for fine graded mixes, or 0.8-1.6 for coarse graded mixes. The film thickness was calculated using the effective asphalt binder and the surface area of the aggregate calculated by the Hveem method.

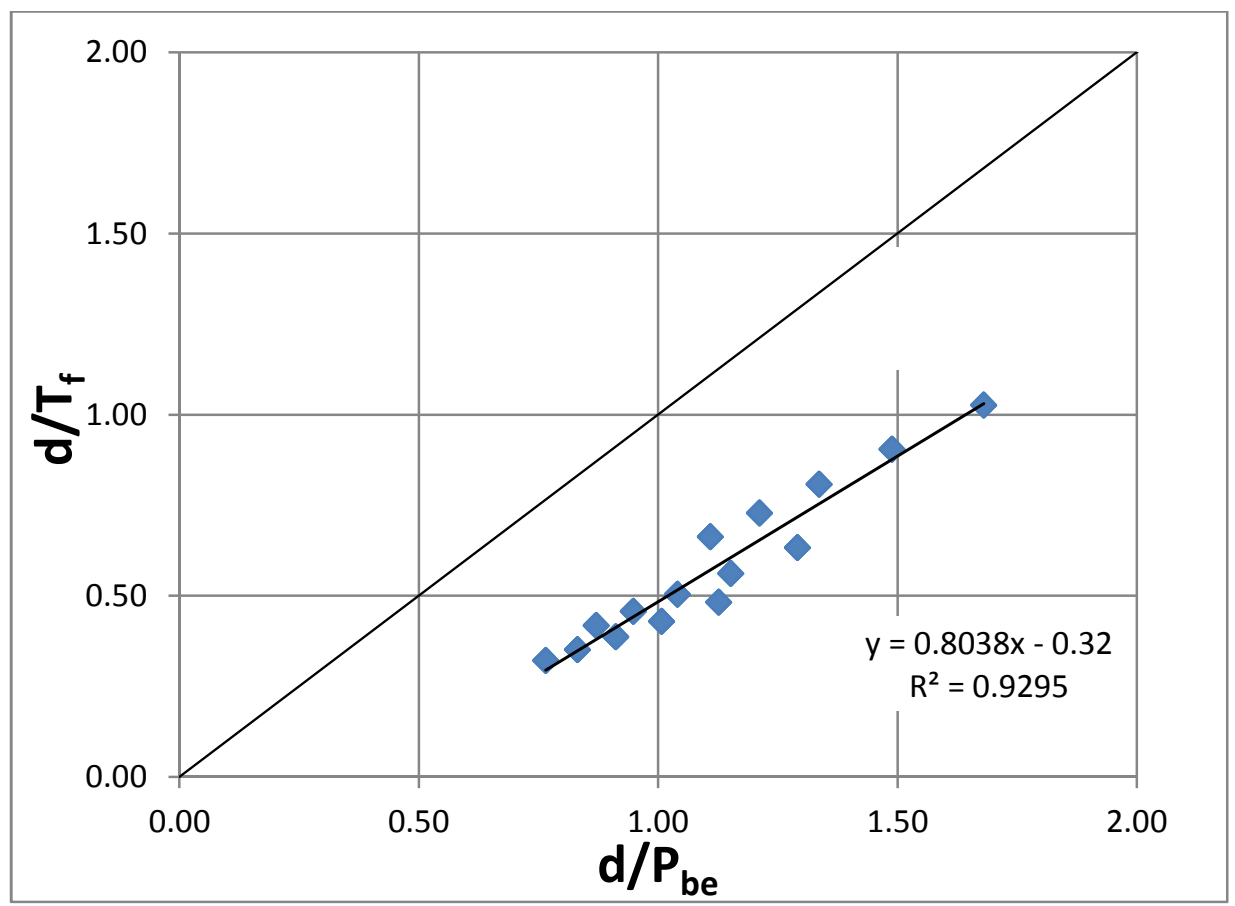

Figure 17. Dust-to-film thickness ratio vs. dust-to-effective binder ratio

Figure 17 shows that there is a relationship between the dust-to-film thickness ratio and the dust-to-effective binder ratio. As seen in the figure, the dust to effective binder ratio has a larger range than the dust to film thickness ratio.

\section{Comparison of IDT Strength and Compaction Effort}

Analysis of the effect of compaction effort on the IDT strength was completed for each of the gradations. Figures 18, 19, and 20 show the IDT strength of the mixes compacted to 80 gyrations was higher than that of the 100 gyration mixes. This trend was consistent for each gradation level 


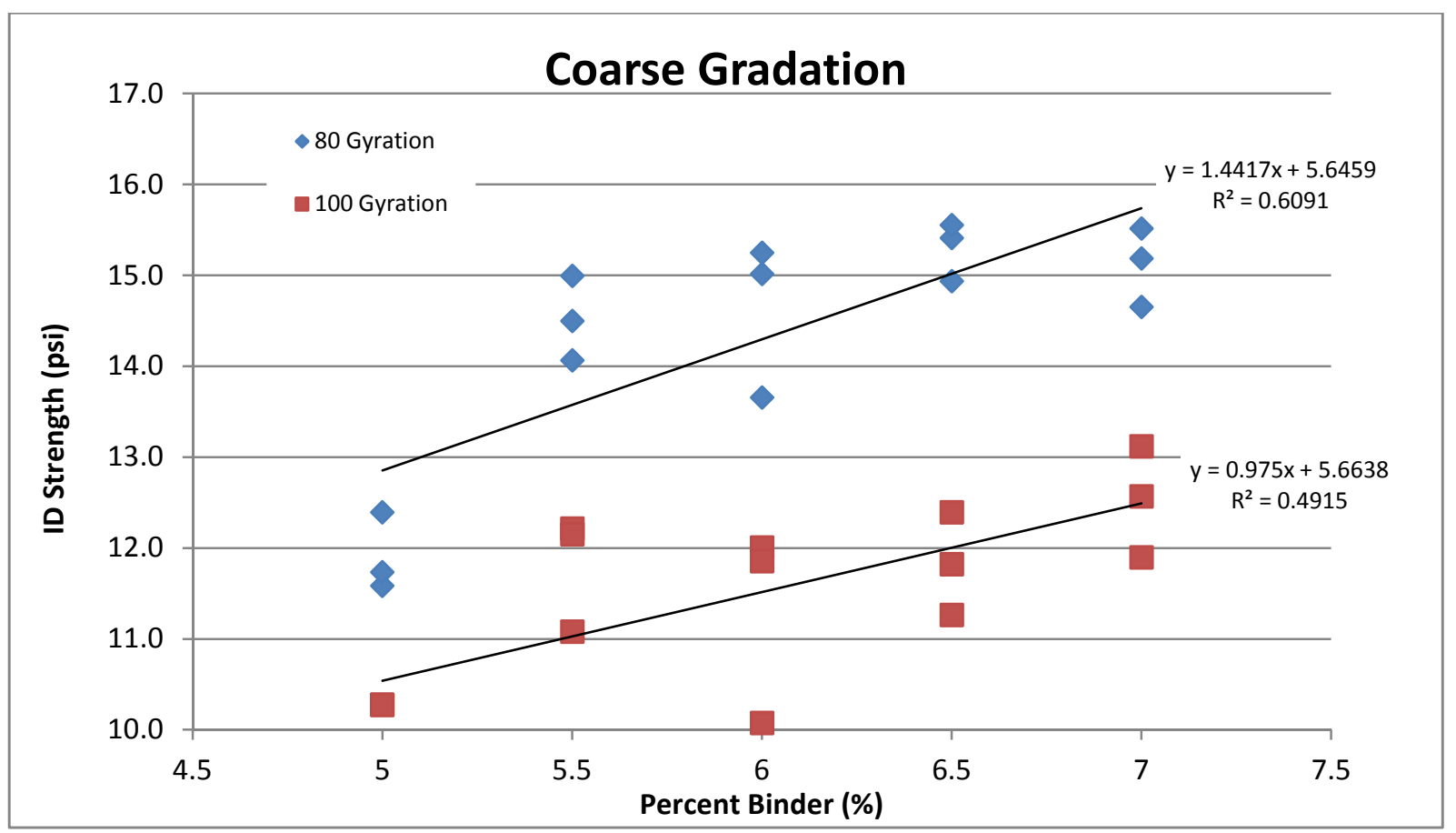

Figure 18. IDT Strength vs. percent binder for Coarse gradation

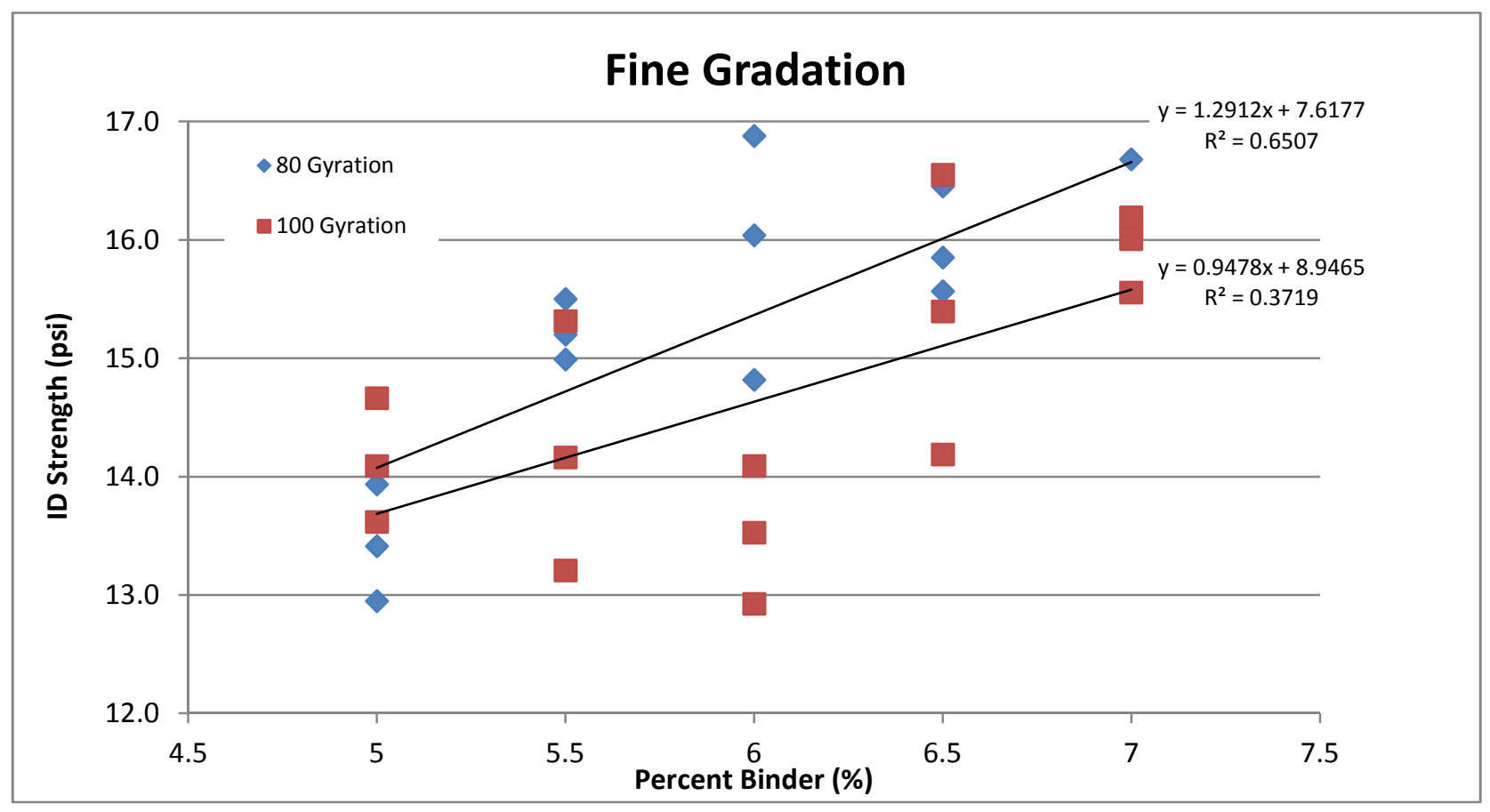

Figure 19. IDT Strength vs. Percent binder, Fine gradation 


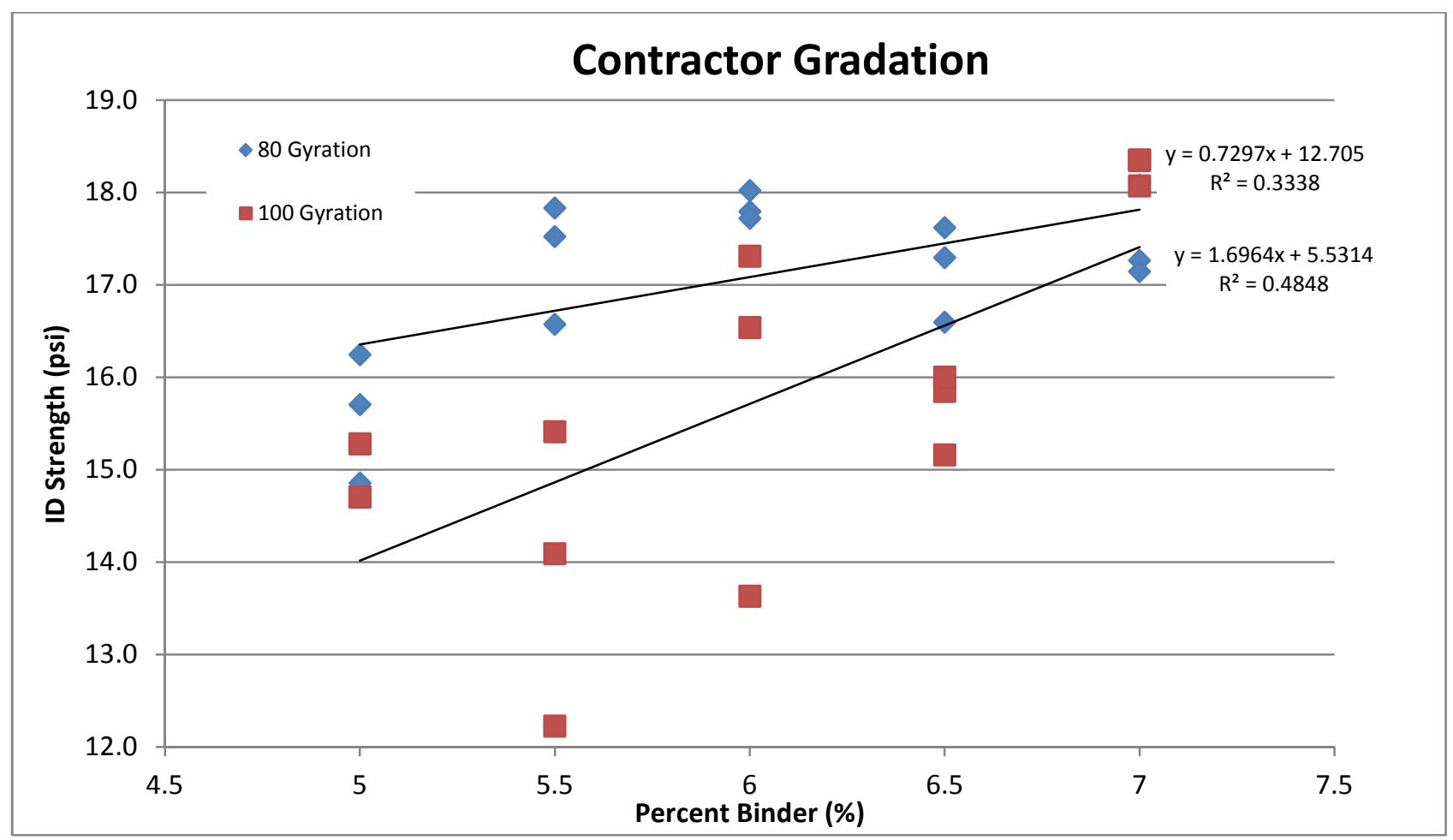

Figure 20. IDT Strength vs. Percent binder, Contractor gradation

\section{ANOVA Summary}

\section{Comparison of Gyrations}

The Analysis of Variance was used to determine if there was a statistical difference between the IDT strength determined for the 80 and 100 gyration mixes with a significance level of $\mathrm{P}=0.05$, indicating a $95 \%$ confidence interval. As indicated in the research approach, a $p$-value less than 0.05 indicate that the means are not equal, and there is insufficient evidence to reject the null hypothesis.

The Tukey-Kramer honest significant difference (HSD) analysis was used to determine if one gradation was significantly different than the others once the ANOVA analysis had found there was a significant difference amongst the group. The analysis tables for IDT strength at 100 gyrations are shown in Table 24 and Table 25, and Table 26 and Table 27 for 80 gyrations. 
Table 24. IDT Strength for 100 Gyrations

Anova: Single

Factor

SUMMARY

\begin{tabular}{lcccc}
\hline \multicolumn{1}{c}{ Groups } & Count & Sum & Average & Variance \\
\hline Coarse 1 & 15 & 172.71 & 11.514 & 1.036 \\
Fine 2 & 15 & 219.49 & 14.633 & 1.294 \\
Contractor 3 & 15 & 235.64 & 15.709 & 3.180 \\
\hline
\end{tabular}

\begin{tabular}{|c|c|c|c|c|c|c|}
\hline Source of Variation & SS & $d f$ & $M S$ & $F$ & P-value & F crit \\
\hline Between Groups & 142.47 & 2 & 71.23 & 38.78 & $2.87 \mathrm{E}-10$ & 3.219942 \\
\hline Within Groups & 77.144 & 42 & 1.837 & & & \\
\hline Total & 219.61 & 44 & & & & \\
\hline
\end{tabular}

Table 25. Tukey-Kramer Multiple Comparisons, 100 Gyrations

\begin{tabular}{lr} 
Coarse Gradation 1 & 11.51 \\
n Group 1 & 15 \\
Fine Gradation 2 & 14.63 \\
n Group 2 & 15 \\
Contractor Gradation 3 & 15.71 \\
n Group 3 & 15 \\
MSe & 1.84 \\
Q Statistic & 3.44 \\
\hline Comparison of Group 1 to Group 2 \\
Absolute Difference & 3.1191 \\
Standard Error of Difference & 0.3499 \\
Critical Range & 1.2038 \\
Means of Groups 1 and 2 are & Different \\
\hline Comparison of Group 1 to Group 3 & \\
Absolute Difference & 4.1959 \\
Standard Error of Difference & 0.3499 \\
Critical Range & 1.2038 \\
Means of Groups 1 and 3 are & Different \\
\hline Comparison of Group 2 to Group 3 & \\
Absolute Difference & 1.0768 \\
Standard Error of Difference & 0.3499 \\
Critical Range & 1.2038 \\
Means of Groups 2 and 3 are & Not Different \\
\hline
\end{tabular}




\section{Table 26. IDT Strength for 80 Gyrations}

Anova: Single

Factor

SUMMARY

\begin{tabular}{lrccr}
\hline \multicolumn{1}{c}{ Groups } & Count & Sum & Average & Variance \\
\hline Coarse & 15 & 214.4406 & 14.29604 & 1.828064 \\
Fine & 15 & 230.4736 & 15.36491 & 1.372532 \\
Design & 15 & 256.2513 & 17.08342 & 0.8546 \\
\hline
\end{tabular}

ANOVA

\begin{tabular}{lcrcccc}
\hline Source of Variation & SS & $d f$ & MS & $F$ & P-value & F crit \\
\hline Between Groups & 59.32617 & 2 & 29.66309 & 21.9445 & $2.99 \mathrm{E}-07$ & 3.219942 \\
Within Groups & 56.77276 & 42 & 1.351732 & & & \\
Total & 116.0989 & 44 & & & & \\
\hline
\end{tabular}

Table 27. Tukey-Kramer Multiple Comparisons 80 Gyrations

Coarse Gradation 1

14.30

n Group 1

Fine Gradation $2 \quad 15.36$

n Group 2

Contractor Gradation $3 \quad 17.08$

n Group 3

MSe $\quad 1.35$

Q Statistic $\quad 3.44$

Comparison of Group 1 to Group 2

Absolute Difference $\quad 1.0689$

Standard Error of Difference $\quad 0.3002$

Critical Range $\quad 1.0327$

Means of Groups 1 and 2 are Different

Comparison of Group 1 to Group 3

Absolute Difference $\quad 2.7874$

Standard Error of Difference $\quad 0.3002$

Critical Range $\quad 1.0327$

Means of Groups 1 and 3 are Different

Comparison of Group 2 to Group 3

Absolute Difference $\quad 1.7185$

Standard Error of Difference $\quad 0.3002$

Critical Range $\quad 1.0327$

Means of Groups 2 and 3 are Different 
The Tukey-Kramer HSD analysis was also used to analyze each gradation at 80 gyrations, it was determined that the IDT strength of each gradation was significantly different.

ANOVA was used to determine if the VMA calculated from 80 , and 100 gyrations was equal. It was found that the 80 , and 100 gyration mixes did not produce VMA that was statistically significant. The $p$-value was 0.1854 , the entire ANOVA summary table is presented in Table 28.

\section{Table 28. ANOVA Table for Gyrations}

Anova: Single

Factor

SUMMARY

\begin{tabular}{lrccc}
\hline \multicolumn{1}{c}{ Groups } & Count & Sum & Average & Variance \\
\hline 80 Gyrations & 45 & 779.9207 & 17.33157 & 0.672554 \\
100 Gyrations & 45 & 769.3985 & 17.09774 & 0.708834 \\
\hline
\end{tabular}

ANOVA

\begin{tabular}{lcrrrrc}
\hline Source of Variation & SS & $d f$ & \multicolumn{1}{c}{ MS } & $F$ & P-value & F crit \\
\hline Between Groups & 1.23019001 & 1 & 1.23019 & 1.781092 & 0.185458 & 3.949321 \\
Within Groups & 60.7810899 & 88 & 0.690694 & & & \\
& & & & & & \\
Total & 62.0112799 & 89 & & & & \\
\hline
\end{tabular}

\section{Comparison of Gradation}

After determining there was insufficient evidence to reject the null hypothesis that the mean VMA for $\mathbf{8 0}$ and $\mathbf{1 0 0}$ gyration mixes were equal, it was assumed that all variance in the data was due to randomness. With this assumption all coarse, fine, and contractor data was pooled together for 80 and 100 gyrations. ANOVA was used to determine the VMA created by the three gradations were statistically different, the $p$-value was approximately zero.

Table 29 presents the ANOVA summary. The Tukey-Kramer HSD was used to determine if the VMA of any two gradations was equal, it was found that the VMA for each gradation is statistically different from the others as presented in Table 30. 
Table 29. ANOVA for Gradations

SUMMARY

\begin{tabular}{lrrrr}
\hline \multicolumn{1}{c}{ Groups } & \multicolumn{1}{c}{ Count } & \multicolumn{1}{c}{ Sum } & \multicolumn{1}{c}{ Average } & Variance \\
\hline Coarse & 30 & 545.89 & 18.20 & 0.188 \\
Fine & 30 & 512.91 & 17.10 & 0.066 \\
Contractor & 30 & 490.52 & 16.35 & 0.101 \\
\hline
\end{tabular}

\begin{tabular}{|c|c|c|c|c|c|c|}
\hline Source of Variation & SS & $d f$ & MS & $F$ & P-value & F crit \\
\hline Between Groups & 51.713 & 2 & 25.856 & 218.429 & $1.21 \mathrm{E}-34$ & 3.101 \\
\hline Within Groups & 10.299 & 87 & 0.1184 & & & \\
\hline Total & 62.011 & 89 & & & & \\
\hline
\end{tabular}

Table 30. Tukey-Kramer Gradation Comparison

Tukey-Kramer Multiple Comparisons

\begin{tabular}{lr} 
Coarse 1 & 18.20 \\
n Group 1 & 30 \\
Fine 2 & 17.10 \\
n Group 2 & 30 \\
Contractor 3 & 16.35 \\
n Group 3 & 30 \\
MSW & 0.1184 \\
Q Statistic & 3.71 \\
\hline Comparison of Group 1 to Group 2 & \\
Absolute Difference & 1.099360 \\
Standard Error of Difference & 0.062823 \\
Critical Range & 0.233071 \\
Means of Groups 1 and 2 are & Different \\
\hline Comparison of Group 1 to Group 3 & \\
Absolute Difference & 1.845517 \\
Standard Error of Difference & 0.062823 \\
Critical Range & 0.233071 \\
Means of Groups 1 and 3 are & Different \\
\hline Comparison of Group 2 to Group 3 & \\
Absolute Difference & 0.746157 \\
Standard Error of Difference & 0.062823 \\
Critical Range & 0.233071 \\
Means of Groups 2 and 3 are & Different \\
\hline
\end{tabular}




\section{Summary of Results}

The change in gradation did create significant differences in the VMA results for the mixtures. The coarse and fine gradations, with increased distance from the MDL, created higher VMA than the design aggregate structure. This was anticipated from survey of the literature.

The calculation of surface area for the $D_{\text {avg }}$ and Hveem method created similar results, increasing the asphalt film thickness surrounding the aggregate particles creates an increase compaction slope. The increased asphalt film thickness acts as a lubricant between aggregate particles and allows for the particles to slide past each other and achieve a dense aggregate configuration. The increased film thickness created increase IDT strength for all gradations regardless of gyrations.

IDT strength was used by Zaniewski and Srinivisan (2003) to predict the rutting depth of asphalt pavements in the APA. Increased IDT strength was correlated to increased resistance to rutting. Wen and Bsuhal (2013) found that increased fracture energy is correlated with increased fatigue life in asphalt pavements. This research found that IDT strength is not directly correlated to fracture energy. The coarse graded mixture had the lowest IDT strength but had greater fracture energy than all other mixes at the respective design binder content. At 80 gyrations each mix created a statistically different IDT strength. At 100 gyrations the coarse gradation created a statistically different IDT strength than the fine and contractor gradations.

The fine graded mixture did not reach locking point at any asphalt content. This is indicative of mixture that has not reached a dense configuration. Locking point is correlated with increased compaction slope, although previous research has indicated mixes with high compaction slopes are difficult to compact in the field. 


\section{CHAPTER 5 CONCLUSION AND RECOMMENDATIONS}

This research was based on the hypothesis that the reduction in design gyrations from 100 to 80 gyrations would create a significant difference on the volumetric parameter, VMA. Three separate gradations were used to simulate the range of possible gradations in the production of asphalt concrete. The literature survey presented that a reduction in design gyrations would have no effect on VMA once the design binder content was achieved at the desired gyration level. The mix design, aggregate and PG64-22 asphalt binder was provided by the J.F. Allen Company.

The compaction slope for all samples was calculated using the output from the SGC. The samples were tested in accordance with West Virginia Departments of Highway specifications. Upon completion of volumetric analysis the samples were tested for IDT strength using the Marshall stabilometer apparatus with the IDT loading heads. The IDT strength was measured at $140^{\circ} \mathrm{F}\left(60^{\circ} \mathrm{C}\right)$ after conditioning for one hour and fifteen minutes. The elevated temperature was used to simulate the conditions used for stability and flow testing that originated with the Marshall method.

The load-deflection curve that was created during the IDT test was imported into AutoCad, the area under the curve was computed to represent the fracture energy for sample.

Upon completion of the material testing, and statistical analysis indicated the reduction in the number of design gyrations from 100 to 80 did not produce statistical difference in VMA. The samples created with $\mathrm{N}_{\text {design }}$ of 80 gyrations did have higher values of VMA although they were not significant. The specimens created with $\mathrm{N}_{\text {design }}$ of 100 gyrations achieve $4 \%$ VTM with lower binder content than the 80 gyration specimens. The 80 gyration mixes has more IDT strength than those with 100 gyrations.

It is emphasized that although the change in VMA upon reducing the compaction effort was not significant, a change in $0.3 \%$ for the design binder content is important to both state agencies and contractors.

The change in aggregate gradation created significant difference for both the 80 and 100 gyration mixes. The coarse graded, and fine graded mixture, which were farthest from the maximum density line, created the highest VMA. The design graded mixture presented the lowest VMA, although it had the highest IDT strength.

The coarse graded mixture had the highest compaction slope, and largest asphalt film thickness, and the lowest dust to film thickness ratio. The high compaction slope could indicate a tender mixture that would shove under field compaction. The increased asphalt film 
surrounding the aggregate particles acted as a lubricant and assisted with the densification of the mixture as anticipated from literature. This mixture created the weakest mixtures in terms of IDT strength. The fracture energy of the coarse mix was greater than all other mixtures, indicating an increased fatigue life.

The fine graded mixture had the lowest compaction slope, the thinnest asphalt film thickness and the highest dust to film thickness ratio. The surface area of the mixture was the largest of the three tested. The thin asphalt film allowed friction between aggregate particles and therefore hindered the densification of the mixture. The IDT strength of the specimens were higher than those with the coarse gradation.

The design grade mixture presented intermediate compaction slope and film thickness in comparison to the other gradations. The design gradation mixes created the highest IDT strengths of all mixture. This mixture was the closest to the maximum density line, and created the lowest VMA of all specimens tested.

The $D_{\text {average }}$ method, and Hveem method for estimating the surface area of aggregate particles produced similar results for all three gradations. The $D_{\text {average }}$ method with Zaniewski and Reyes measure minus No. 200 sieve material value created large surface areas for each gradation. The three methods used are for the estimation of the surface area, and are not measured values. Because these values are used only for estimation, it is recommended that the Hveem method be used because of it is currently more widely adopted than the $D_{\text {average }}$ method.

\section{Recommendations for Further Research}

The samples created in the West Virginia University Asphalt Technology Laboratory were created using a mix design from a single asphalt concrete producer in West Virginia. The samples were created using limestone aggregate from a single quarry, only $9.5 \mathrm{~mm}$ mixes were evaluated. Additional aggregate types and mix types should be evaluated.

All samples were tested for IDT strength at an elevated temperature of $140^{\circ} \mathrm{F}\left(60^{\circ} \mathrm{C}\right)$ to simulate the temperatures when the pavement is susceptible to rutting. Research should be completed using a combination of APA, IDT, and AMPT to determine the correlation of the performance properties of rutting resistance, and fatigue life to the laboratory analysis completed by the IDT test. The IDT strength can serve as an indicator of rutting resistance, and fracture energy predicting fatigue life. The ability to use the IDT test as a low cost alternative to AMPT is a valuable tool for government agencies and industry professionals. 


\section{REFERENCES}

Abdullah, W., Obaidat, M.T., and Abu Sa'da, N.M., "Influence of Aggregate Type and Gradation on Voids of Asphalt Concrete Pavement". Journal of Materials in Civil Engineering, American Society of Civil Engineers. Vol. 2, No. 2. Reston, Virginia. 1998

Brown, D., Superpave Enters the Modern Ear. Better Roads, Vol. 75, Number 9. 2005.

Coree, B, and Hislop, W., "The Difficult Nature of Minimum VMA: A Historical Perspective." lowa State University. November 1998.

Chadbourn, B.A., Skok, E.L., Newcomb, D., Crow, B., and Spindler, S., "The Effects of Voids in Mineral Aggregate (VMA) on Hot-mix Asphalt Pavements". University of Minnesota, Report No. MN/RC-2000-13, Minneapolis, MN. 1999

Christensen, W.D., Bonaquist, R., and Jack, D.P., "Evaluation of Triaxial Strength as a Simple Test for Asphalt Concrete Rut Resistance", Final Report, Pennsylvania Department of Transportation. 2000.

Christensen, W.D., and Bonaquist, R., "Practical Approaches to Hot-Mix Asphalt Mix Design and Production Quality Control Testing", Transportation Research Board of the National Academies. Transportation Research Circular. No. E-C-124. 2007.

Christensen, W.D., and Bonaquist, R., "Use of Strength Tests for Evaluating the Rut Resistance of Asphalt Concrete", Journal of the Association of Asphalt Paving Technologists. Vol. 71. 2002.

Christensen, W.D., and Bonaquist, R., "Volumetric Requirements for Superpave Mix Design". NCHRP 567. Washington D.C., Transportation Research Board, 2006.

Dowdy, S., Weardon, S., and Chilko, D., "Statistics for Research", $3^{\text {rd }}$ Edition. Hoboken, New Jersey. John Wiley and Sons, Inc. 2004.

Hinrichsen, J.A., and Heggen, J., "Minimum Voids in the Mineral Aggregate in Hot-Mix Asphalt Based on Gradation and Volumetric Properties". Transportation Research Record, No. 1545, Washington, D.C., 1996. 
Huber, G.A., and Anderson, R., "Superpave Design Compaction Effort: Validity of using Density at the End of Service Life as Parameter to Define N-Design", Journal of the Association of Asphalt Paving Technologists, Vol. 73, 2004.

Huber, G.A., and Shuler, T.S., "Providing Sufficient Void Space for Asphalt Cement: Relationship of Mineral Aggregate Voids and Aggregate Gradation. ASTM STP 1147, American Society for Testing and Materials, Philadelphia, Pennsylvania 1992.

Hudson, S., and Davis R., Relationship of Aggregate Voidage to Gradation. Proceedings, Association of Asphalt Paving Technologists, Vol. 34, 1965.

Hveem, F.N., The Surface Area Method as Used in the Design of Bituminous Mixtures, State of California, California Department of Public Works, Divison of Highways. 1936.

Hveem, F.N., Gradation of Mineral Aggregates in Dense Graded Bituminous Mixtures. State of California, California Department of Public Works, Divison of Highways. 1941.

Kandhal, P., and Chakraborty S., Evaluation of Voids in the Mineral Aggregate for HMA Paving Mixtures. NCAT Report No. 96-4, National Center for Asphalt Technology. March 1996.

Kandhal, P., Foo, K., and Mallick, R., "A Critical Review of Voids in Mineral Aggregate Requirements in Superpave". Transportation Research Record, No. 1609, Washington, D.C., 1998.

Leiva, F., and West R., "Analysis of Hot-mix Asphalt Lab Compactability using Lab Compaction Parameters and Mix Characteristics." Transportation Research Record; Journal of the Transportation Research Board. 2057.1 (2008): 89-98.

McLeod, N.W., "Void Requirements for Dense-Graded Bituminous Paving Mixtures." Symposium on Bituminous Paving Mixtures. American Society of Testing and Materials, STP-252. January 1959.

Moore, D., McCabe, G., and Craig, B. Introduction to the Practice of Statistics. 7th. New York, New York: W.H. Freeman and Company, 2012. 
Nukunya, B., Roque, R., "Effect of Aggregate Structure on Rutting Potential of Densegraded Asphalt Mixtures." Transportation Research Record, No. 1789, Washington, D.C. 2002.

Powell,B., and Brown,E., "Superpave Mix Design: Verifying Gradations in the $\mathrm{N}_{\text {Design }}$ Table". NCHRP 573. Washington D.C., Transportation Research Board, 2007.

Richardson, The Modern Asphalt Pavement. First Edition. New York: Chapman \& Hall Limited, 1905.

Roberts, F., Kandhal, P., Brown, E.R., Lee, D., and Kennedy, W.,Hot Mix Asphalt Materials, Mixture Design, and Construction. Third Edition. Lanham Maryland: NAPA, 2009.

The Asphalt Institute Asphalt Handbook. Manual Series Number 4 (MS-4), $7^{\text {th }}$ Edition., Lexington, Kentucky. 2007

The Asphalt Institute,"Mix Design Methods for Asphalt Concrete and Other Hot Mix Types", Manual Series No. 2, 1969 Edition, College Park, Maryland 1969.

United States. Department of the Army Corps of Engineers. Investigation of the Design and Control of Asphalt Paving Mixtures.. Vicksburg, Mississippi: Technical Memorandum No. 3-254, 1948.

Vavrik, W., "Asphalt Mixture Design Concepts to Develop Aggregate Interlock." University of Illinois, Doctoral Dissertation, 2000.

Wen, H., and Sushanta B., "A Laboratory Study to Predict the Rutting and Fatigue Behavior of Asphalt Concrete using the Indirect Tensile Test." Journal of Testing and Evaluation. 41.2 (2013).

West Virginia Department of Transportation. "Materials Procedure 401.02.22: Guide to Designing Hot Mix Asphalt using the Marshall Design Method." Charleston, West Virginia. May 2011

West Virginia Department of Transportation. "Materials Procedure 401.02.28: Guide to Designing Hot Mix Asphalt using the SuperPave Volumetric Design Method." Charleston, West Virginia. May 2011 
Zaniewski, J.P.,and Adamah, C., "Effect of Compaction Effort on SuperPave Base Course Materials." Report to the West Virginia Department of Highways, 2009.

Zaniewski, J.P., and Hornbeck,N., "Effect of Compaction Effort on SuperPave Surface Course Materials." Report to the West Virginia Department of Highways, 2008.

Zaniewski, J.P., and Reyes, C., "Evaluation of the Effect of Fines on Asphalt Concrete." Report to the West Virginia Department of Highways, June, 2003.

Zaniewski, J.P., and Srinivasan, G., "Evaluation of Indirect Tensile Strength to Identify Asphalt Concrete Rutting Potential." Report to the West Virginia Department of Highways, 2004. 


\section{APPENDIX}

Table A 1. Stockpile Gradations and Specific Gravities

\begin{tabular}{|c|c|c|c|c|}
\hline & Elkins \#8 & Elkins \#9 & Elkins Sand & $\begin{array}{c}\text { Baghouse } \\
\text { Fines }\end{array}$ \\
\hline Sieve Size $(\mathrm{mm})$ & \multicolumn{4}{|c|}{ Percent Passing } \\
\hline $50\left(2^{\prime \prime}\right)$ & 100 & 100 & 100 & 100 \\
\hline $37.5\left(11 / 2^{\prime \prime}\right)$ & 100 & 100 & 100 & 100 \\
\hline 25 (1") & 100 & 100 & 100 & 100 \\
\hline 19 (3/4") & 100 & 100 & 100 & 100 \\
\hline $12.5\left(1 / 2^{\prime \prime}\right)$ & 100 & 100 & 100 & 100 \\
\hline 9.5 (3/8") & 98 & 100 & 100 & 100 \\
\hline 4.75 (No. 4) & 29 & 78 & 100 & 100 \\
\hline 2.36 (No. 8) & 4 & 10 & 84 & 100 \\
\hline 1.18 (No. 16) & 2 & 4 & 51 & 100 \\
\hline .600 (No. 30) & 2 & 3 & 30 & 100 \\
\hline .300 (No. 50) & 2 & 3 & 12 & 100 \\
\hline 0.75 (No. 200) & 1.3 & 2.7 & 7.4 & 94.4 \\
\hline Gsa & 2.720 & 2.712 & 2.735 & 2.708 \\
\hline Gsb & 2.662 & 2.649 & 2.611 & 2.708 \\
\hline
\end{tabular}




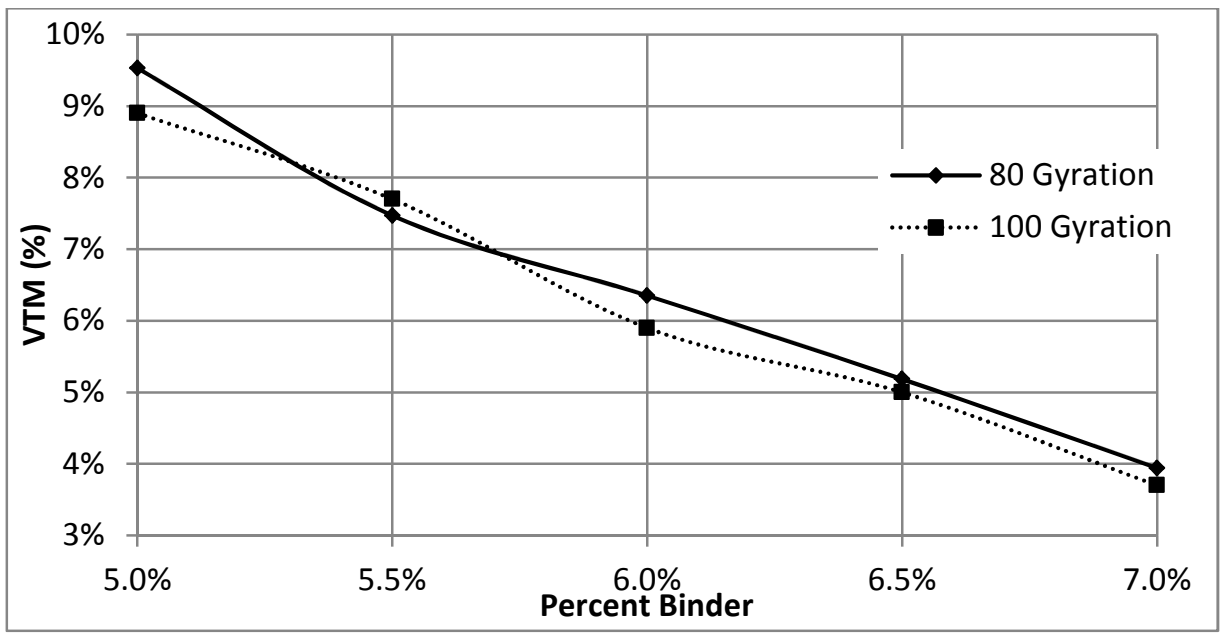

Figure 21. Coarse Gradation, VTM (\%) vs. Percent Binder

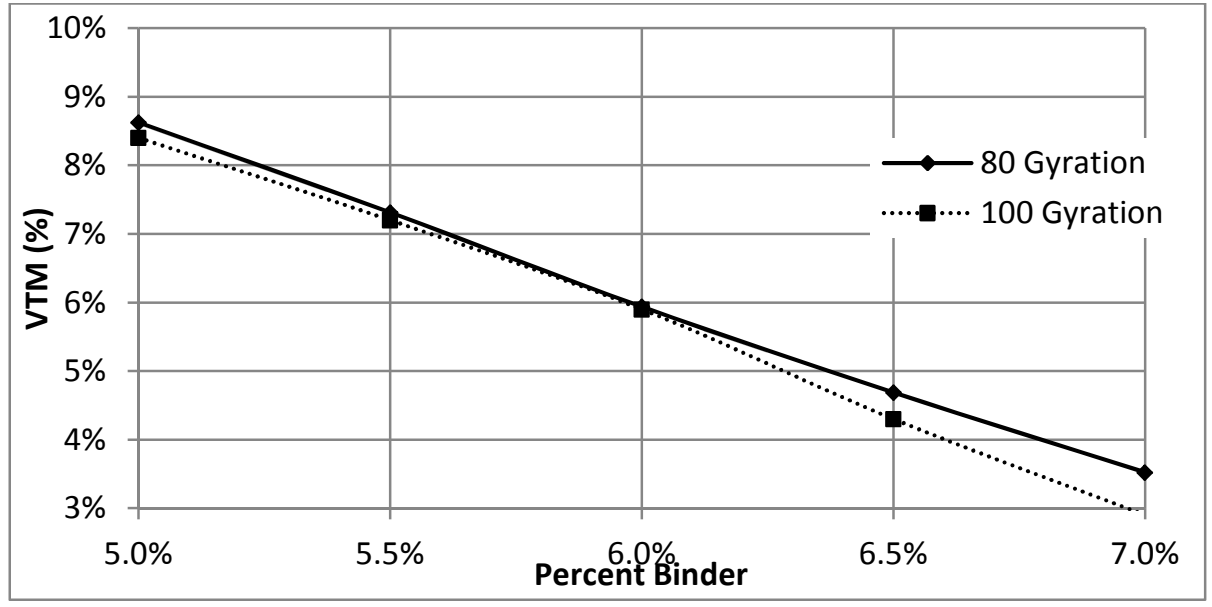

Figure 22. Fine Gradation, VTM (\%) vs. Percent Binder

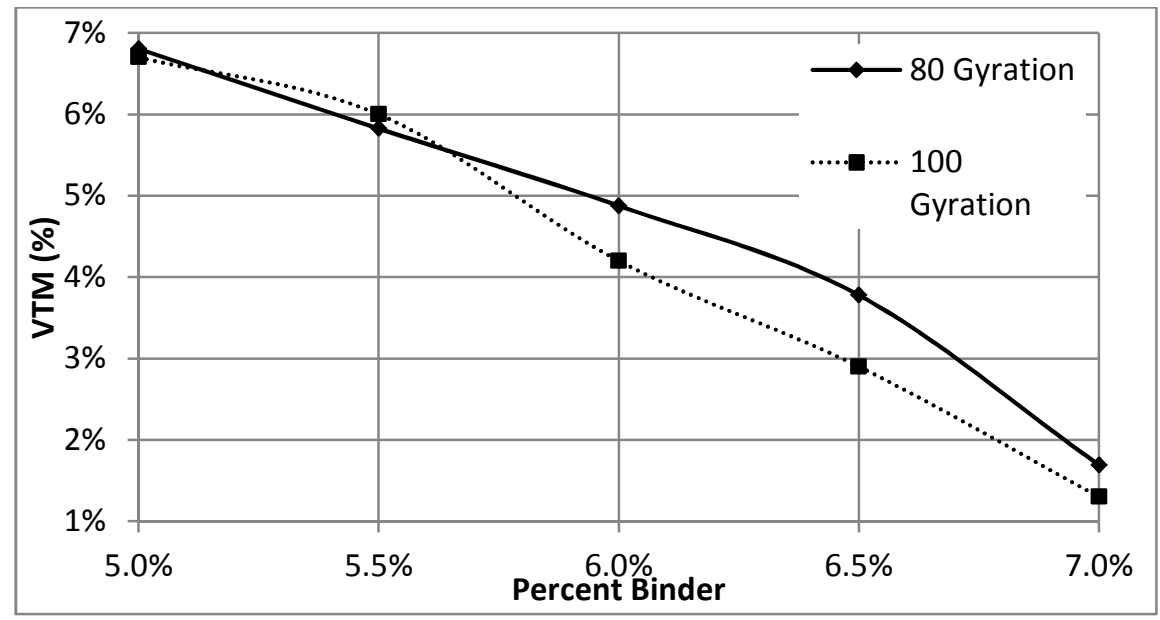

Figure 23. Contractor Gradation, VTM(\%) vs. Percent Binder 


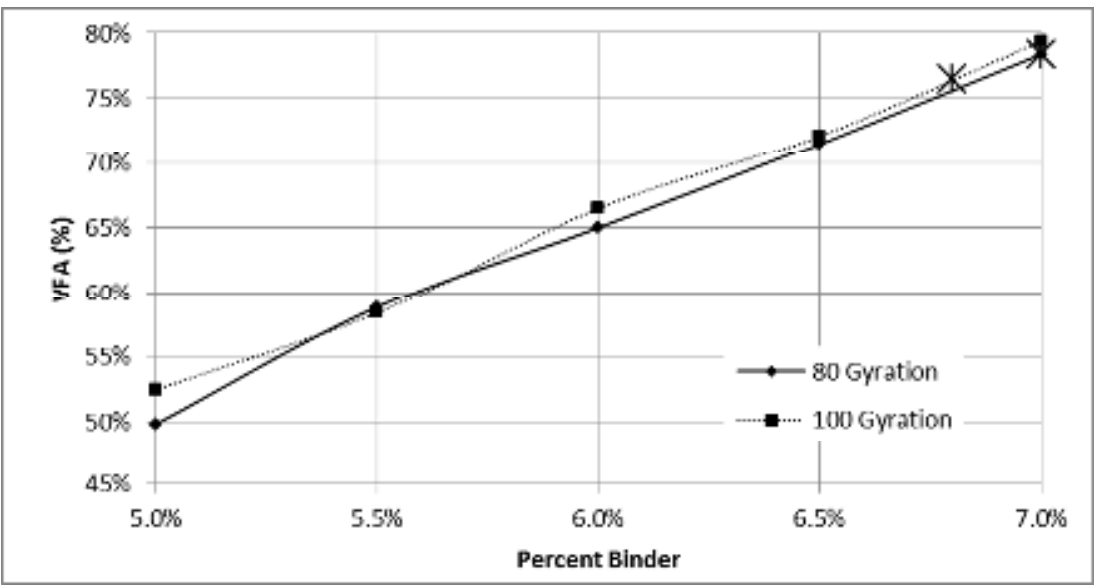

Figure 24. Coarse Gradation, VFA vs. Percent Binder

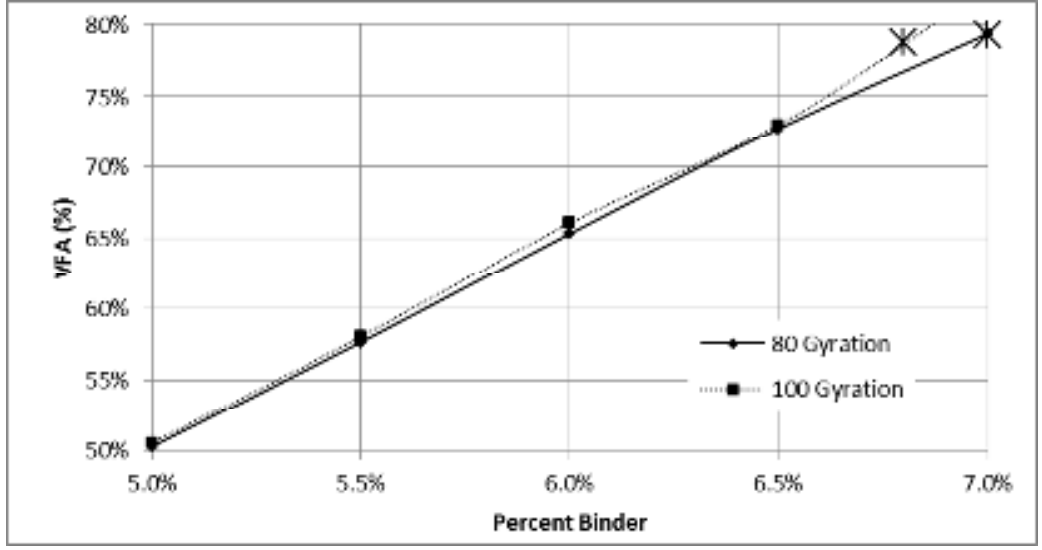

Figure 25. Fine Gradation, VFA vs. Percent Binder

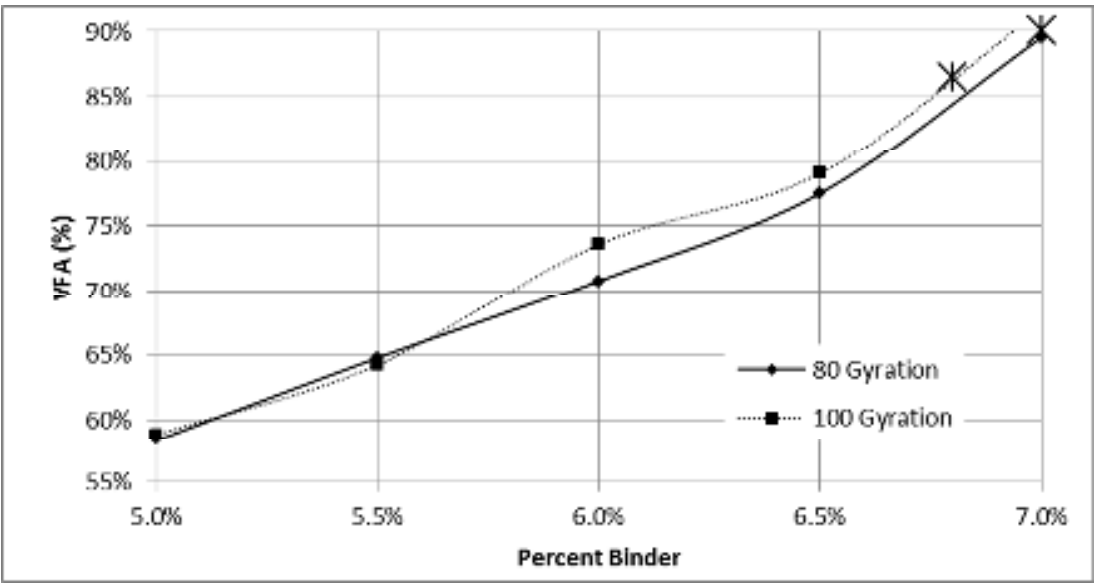

Figure 26. Contractor Gradation, VFA vs. Percent Binder 


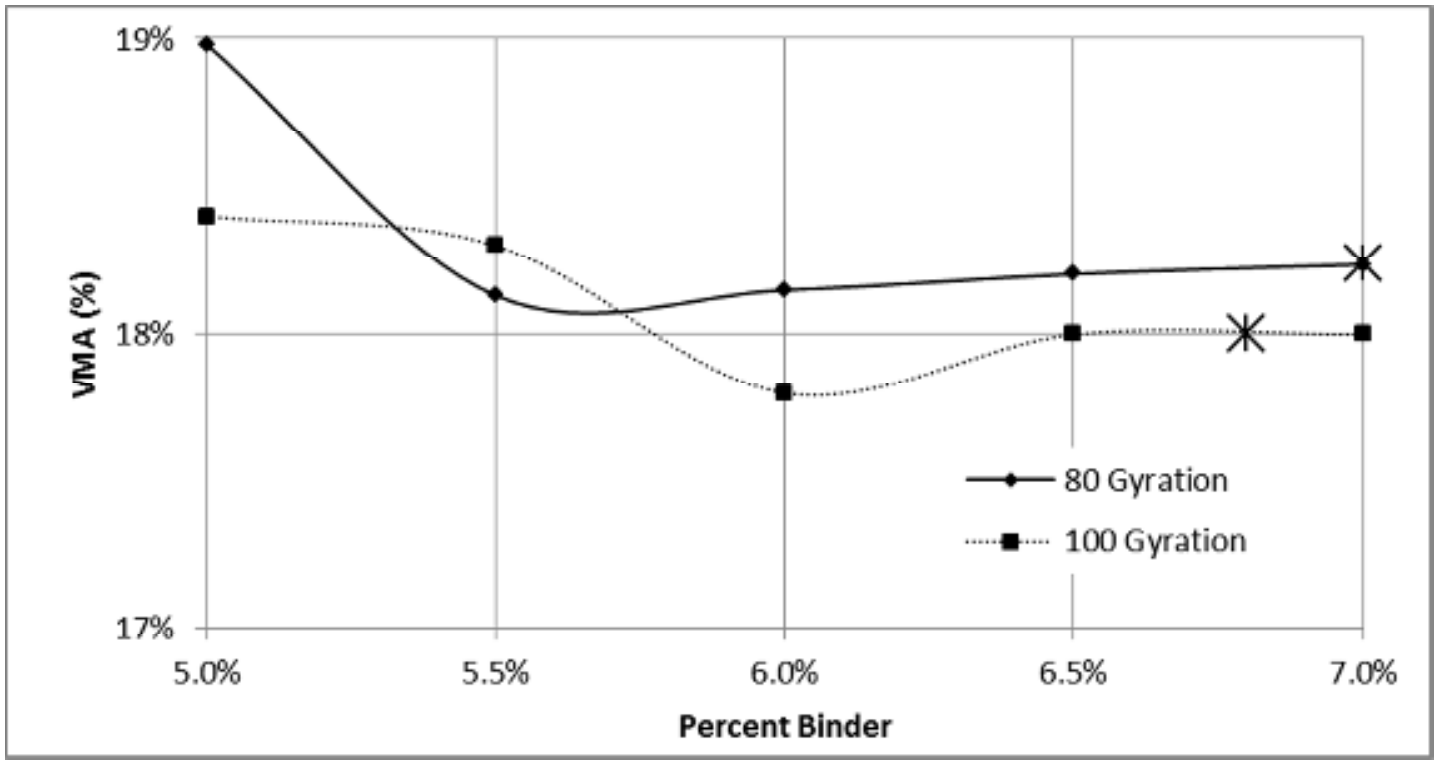

Figure 27. Coarse Gradation, VMA vs. Percent Binder

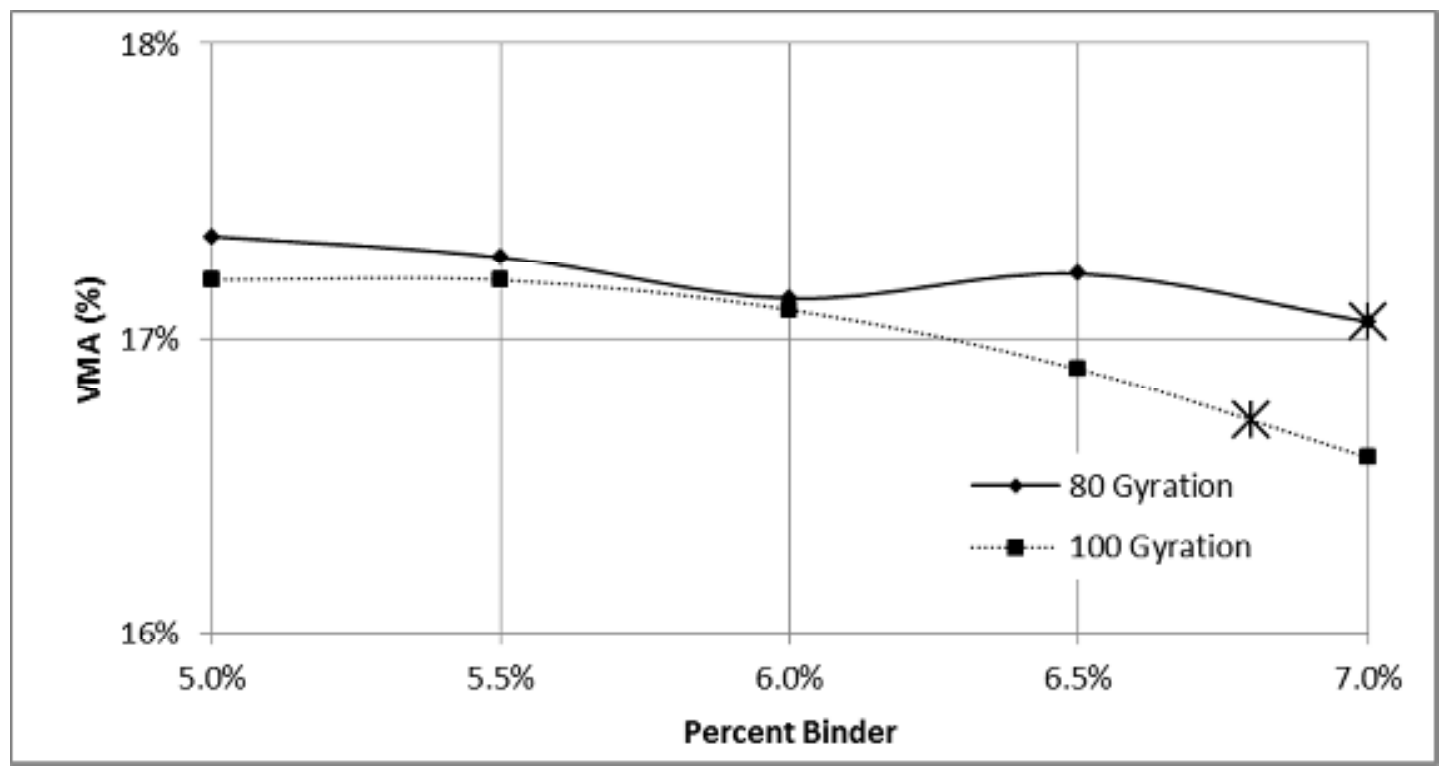

Figure 28. Fine Gradation, VMA vs. Percent Binder 


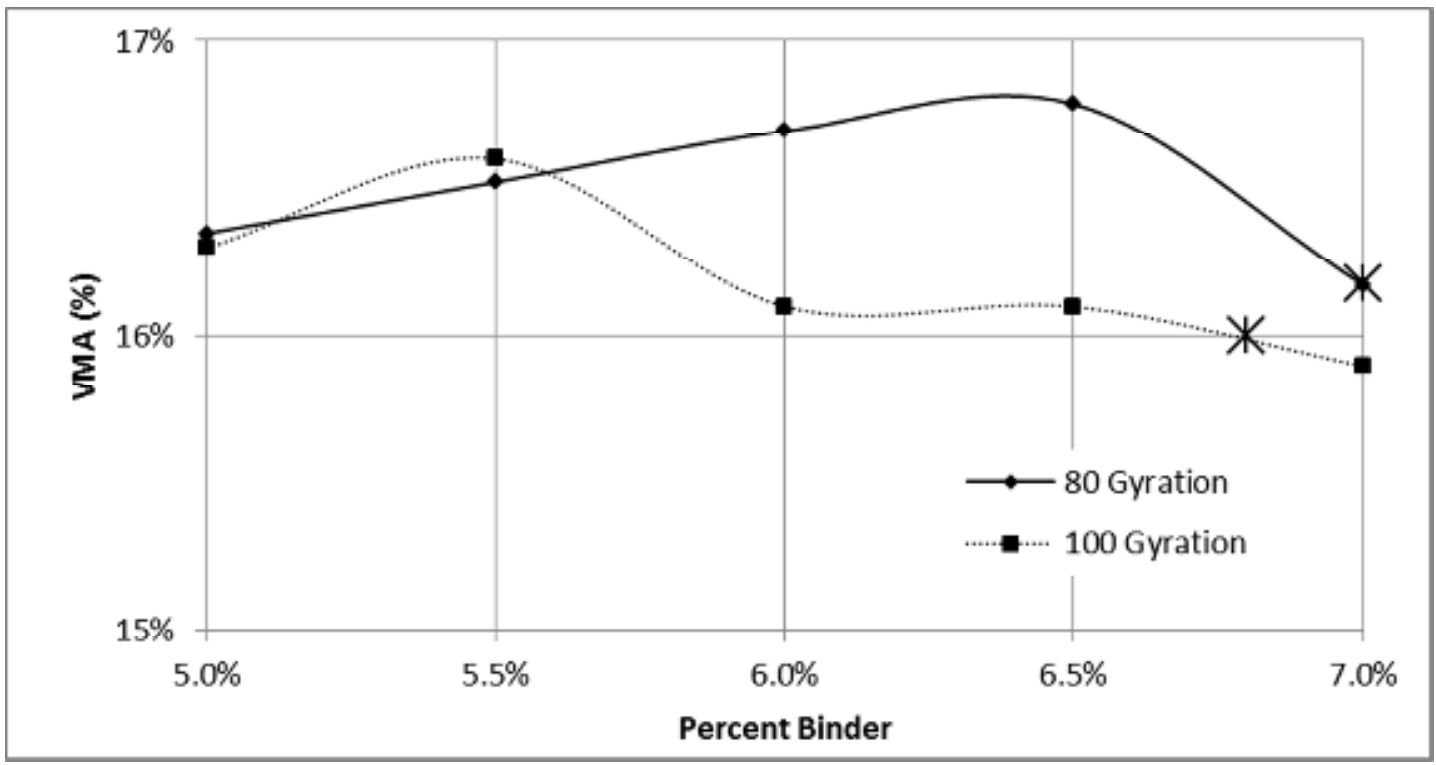

Figure 29. Contractor Gradation, VMA vs. Percent Binder 
Table A 2. Properties of Mixes Tested

\begin{tabular}{|c|c|c|c|c|}
\hline Mix Number & VTM (\%) & $\begin{array}{l}\text { IDT Strength } \\
\text { (psi) }\end{array}$ & $\begin{array}{l}\text { k, Compaction } \\
\text { Slope }\end{array}$ & $\begin{array}{c}\mathrm{T}_{\mathrm{F}} \text {, Film } \\
\text { Thickness } \\
\text { (microns) }\end{array}$ \\
\hline 1 & $9.9 \%$ & 11.6 & 9.7 & 9.9 \\
\hline 2 & $10.4 \%$ & 11.7 & 9.5 & 9.9 \\
\hline 3 & $11.3 \%$ & 12.4 & 9.7 & 9.9 \\
\hline 4 & $8.4 \%$ & 14.1 & 9.7 & 11.2 \\
\hline 5 & $8.6 \%$ & 15.0 & 9.7 & 11.2 \\
\hline 6 & $7.6 \%$ & 14.5 & 9.4 & 11.2 \\
\hline 7 & $6.6 \%$ & 13.7 & 10.1 & 12.4 \\
\hline 8 & $6.9 \%$ & 15.0 & 10.1 & 12.4 \\
\hline 9 & $6.7 \%$ & 15.2 & 9.6 & 12.4 \\
\hline 10 & $6.0 \%$ & 14.9 & 10.1 & 13.7 \\
\hline 11 & $5.0 \%$ & 15.4 & 10.3 & 13.7 \\
\hline 12 & $4.0 \%$ & 15.6 & 10.6 & 13.7 \\
\hline 13 & $4.1 \%$ & 15.5 & 10.6 & 14.9 \\
\hline 14 & $4.2 \%$ & 14.7 & 10.6 & 14.9 \\
\hline 15 & $4.1 \%$ & 15.2 & 10.7 & 14.9 \\
\hline 16 & $9.5 \%$ & 13.9 & 8.7 & 6.4 \\
\hline 17 & $9.5 \%$ & 12.9 & 8.9 & 6.4 \\
\hline 18 & $9.3 \%$ & 13.4 & 8.7 & 6.4 \\
\hline 19 & $7.8 \%$ & 15.0 & 9.1 & 7.3 \\
\hline 20 & $7.7 \%$ & 15.2 & 9.0 & 7.3 \\
\hline 21 & $8.1 \%$ & 15.5 & 9.3 & 7.3 \\
\hline 22 & $6.8 \%$ & 16.9 & 9.0 & 8.2 \\
\hline 23 & $6.1 \%$ & 16.0 & 9.2 & 8.2 \\
\hline 24 & $6.1 \%$ & 14.8 & 9.1 & 8.2 \\
\hline 25 & $5.0 \%$ & 16.5 & 9.4 & 9.1 \\
\hline 26 & $5.0 \%$ & 15.9 & 9.3 & 9.1 \\
\hline 27 & $4.8 \%$ & 15.6 & 9.3 & 9.1 \\
\hline 28 & $3.9 \%$ & 16.1 & 9.6 & 9.9 \\
\hline 29 & $3.5 \%$ & 16.7 & 9.7 & 9.9 \\
\hline 30 & $3.5 \%$ & 16.1 & 9.7 & 9.9 \\
\hline 31 & $7.4 \%$ & 16.2 & 9.4 & 8.5 \\
\hline 32 & $7.4 \%$ & 15.7 & 9.5 & 8.5 \\
\hline 33 & $7.1 \%$ & 14.9 & 9.4 & 8.5 \\
\hline 34 & $6.2 \%$ & 16.6 & 9.5 & 9.6 \\
\hline 35 & $6.2 \%$ & 17.8 & 9.5 & 9.6 \\
\hline 36 & $6.1 \%$ & 17.5 & 9.5 & 9.6 \\
\hline
\end{tabular}

Bessette, Logan P. 64 


\begin{tabular}{|c|c|c|c|c|}
\hline Mix Number & VTM (\%) & $\begin{array}{l}\text { IDT Strength } \\
\text { (psi) }\end{array}$ & $\begin{array}{l}\text { k, Compaction } \\
\text { Slope }\end{array}$ & $\begin{array}{c}\mathrm{T}_{\mathrm{F}}, \text { Film } \\
\text { Thickness } \\
\text { (microns) }\end{array}$ \\
\hline 38 & $5.1 \%$ & 17.7 & 9.6 & 10.7 \\
\hline 39 & $5.1 \%$ & 18.0 & 9.2 & 10.7 \\
\hline 40 & $4.1 \%$ & 16.6 & 9.9 & 11.8 \\
\hline 41 & $3.7 \%$ & 17.6 & 10.2 & 11.8 \\
\hline 42 & $4.0 \%$ & 17.3 & 10.3 & 11.8 \\
\hline 43 & $1.8 \%$ & 18.1 & 10.3 & 12.9 \\
\hline 44 & $1.7 \%$ & 17.3 & 10.5 & 12.9 \\
\hline 45 & $1.7 \%$ & 17.1 & 10.3 & 12.9 \\
\hline 46 & $8.7 \%$ & 10.3 & 9.3 & 9.93 \\
\hline 47 & $9.0 \%$ & 9.7 & 9.0 & 9.93 \\
\hline 48 & $9.0 \%$ & 10.3 & 8.0 & 9.93 \\
\hline 49 & $7.6 \%$ & 11.1 & 9.5 & 11.17 \\
\hline 50 & $7.8 \%$ & 12.2 & 9.3 & 11.17 \\
\hline 51 & $7.8 \%$ & 12.1 & 9.1 & 11.17 \\
\hline 52 & $6.0 \%$ & 12.0 & 9.9 & 12.41 \\
\hline 53 & $6.0 \%$ & 10.1 & 9.9 & 12.41 \\
\hline 54 & $5.8 \%$ & 11.9 & 9.8 & 12.41 \\
\hline 55 & $5.0 \%$ & 11.8 & 9.6 & 13.67 \\
\hline 56 & $4.9 \%$ & 11.3 & 10.0 & 13.67 \\
\hline 57 & $5.1 \%$ & 12.4 & 9.8 & 13.67 \\
\hline 58 & $3.7 \%$ & 11.9 & 10.1 & 14.95 \\
\hline 59 & $3.6 \%$ & 12.6 & 10.1 & 14.95 \\
\hline 60 & $3.6 \%$ & 13.1 & 9.9 & 14.95 \\
\hline 61 & $8.5 \%$ & 13.6 & 8.7 & 6.43 \\
\hline 62 & $8.4 \%$ & 14.1 & 8.6 & 6.43 \\
\hline 63 & $8.4 \%$ & 14.7 & 8.9 & 6.43 \\
\hline 64 & $7.2 \%$ & 13.2 & 8.8 & 7.29 \\
\hline 65 & $7.2 \%$ & 15.3 & 9.0 & 7.29 \\
\hline 66 & $7.2 \%$ & 14.2 & 8.9 & 7.29 \\
\hline 67 & $5.8 \%$ & 13.5 & 9.2 & 8.17 \\
\hline 68 & $5.8 \%$ & 14.1 & 9.0 & 8.17 \\
\hline 69 & $6.1 \%$ & 12.9 & 9.0 & 8.17 \\
\hline 70 & $4.6 \%$ & 16.6 & 9.3 & 9.05 \\
\hline 71 & $4.2 \%$ & 15.4 & 9.3 & 9.05 \\
\hline 72 & $4.1 \%$ & 14.2 & 9.2 & 9.05 \\
\hline 73 & $2.9 \%$ & 16.2 & 9.6 & 9.95 \\
\hline 74 & $2.8 \%$ & 16.0 & 9.6 & 9.95 \\
\hline 75 & $3.1 \%$ & 15.6 & 9.3 & 9.95 \\
\hline
\end{tabular}

Bessette, Logan P. 65 


\begin{tabular}{|c|c|c|c|c|}
\hline Mix Number & VTM (\%) & $\begin{array}{c}\text { IDT Strength } \\
(\mathrm{psi})\end{array}$ & $\begin{array}{c}\mathrm{k} \text {, Compaction } \\
\text { Slope }\end{array}$ & $\begin{array}{c}\mathrm{T}_{\mathrm{F}}, \text { Film } \\
\text { Thickness } \\
\text { (microns) }\end{array}$ \\
\hline 77 & $6.8 \%$ & 14.7 & 8.9 & 8.53 \\
\hline 78 & $6.7 \%$ & 14.7 & 9.0 & 8.53 \\
\hline 79 & $6.0 \%$ & 14.1 & 9.0 & 9.61 \\
\hline 80 & $5.9 \%$ & 15.4 & 8.8 & 9.61 \\
\hline 81 & $6.1 \%$ & 12.2 & 8.8 & 9.61 \\
\hline 82 & $4.3 \%$ & 13.6 & 9.3 & 10.70 \\
\hline 83 & $4.2 \%$ & 17.3 & 9.4 & 10.70 \\
\hline 84 & $4.2 \%$ & 16.5 & 9.1 & 10.70 \\
\hline 85 & $3.5 \%$ & 15.8 & 9.6 & 11.80 \\
\hline 86 & $2.8 \%$ & 16.0 & 9.6 & 11.80 \\
\hline 87 & $2.5 \%$ & 15.2 & 9.7 & 11.80 \\
\hline 88 & $1.3 \%$ & 18.1 & 9.9 & 12.91 \\
\hline 89 & $1.3 \%$ & 18.3 & 9.8 & 12.91 \\
\hline 90 & $1.4 \%$ & 18.4 & 9.5 & 12.91 \\
\hline
\end{tabular}

Note $^{1}$ : Mix combinations given in Table 17

Note $^{2}$ : Calculated using Zaniewski and Reyes $D_{\text {avg }}$ 
Table A 3. Coarse Gradation Aggregate Blending

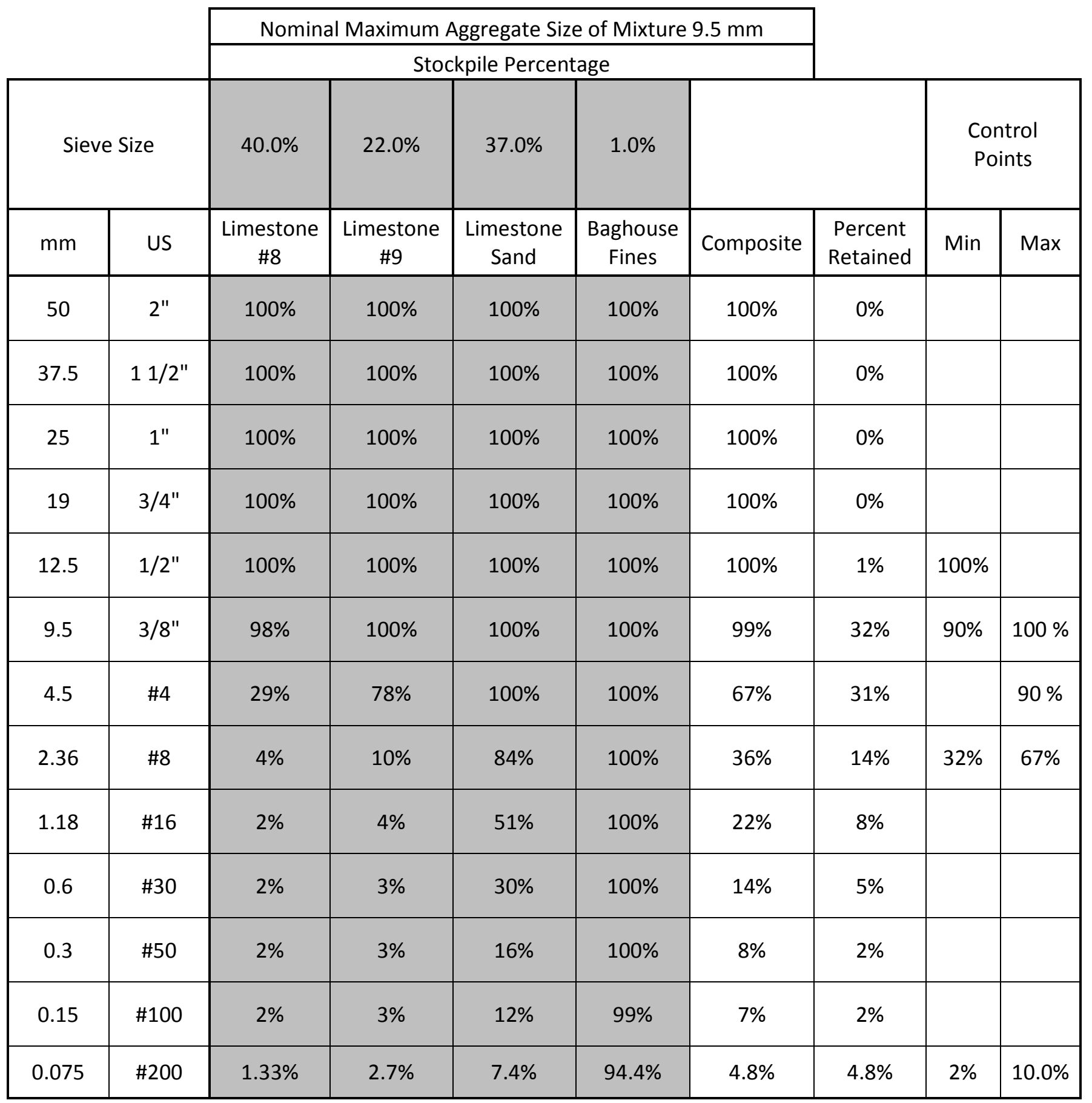


Table A 4. Fine Gradation Aggregate Blending

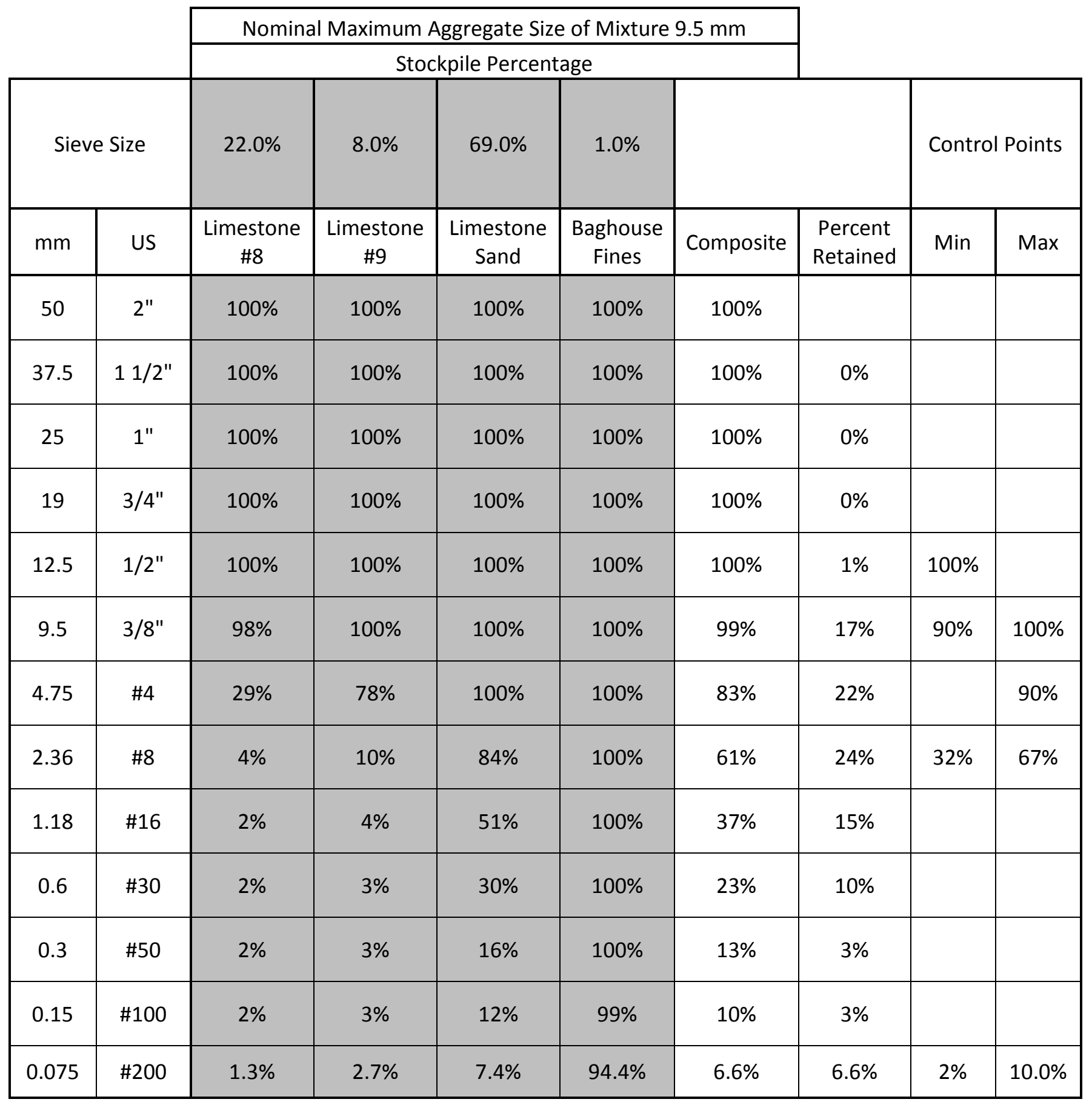


Table A 5. Contractor Gradation Aggregate Blending

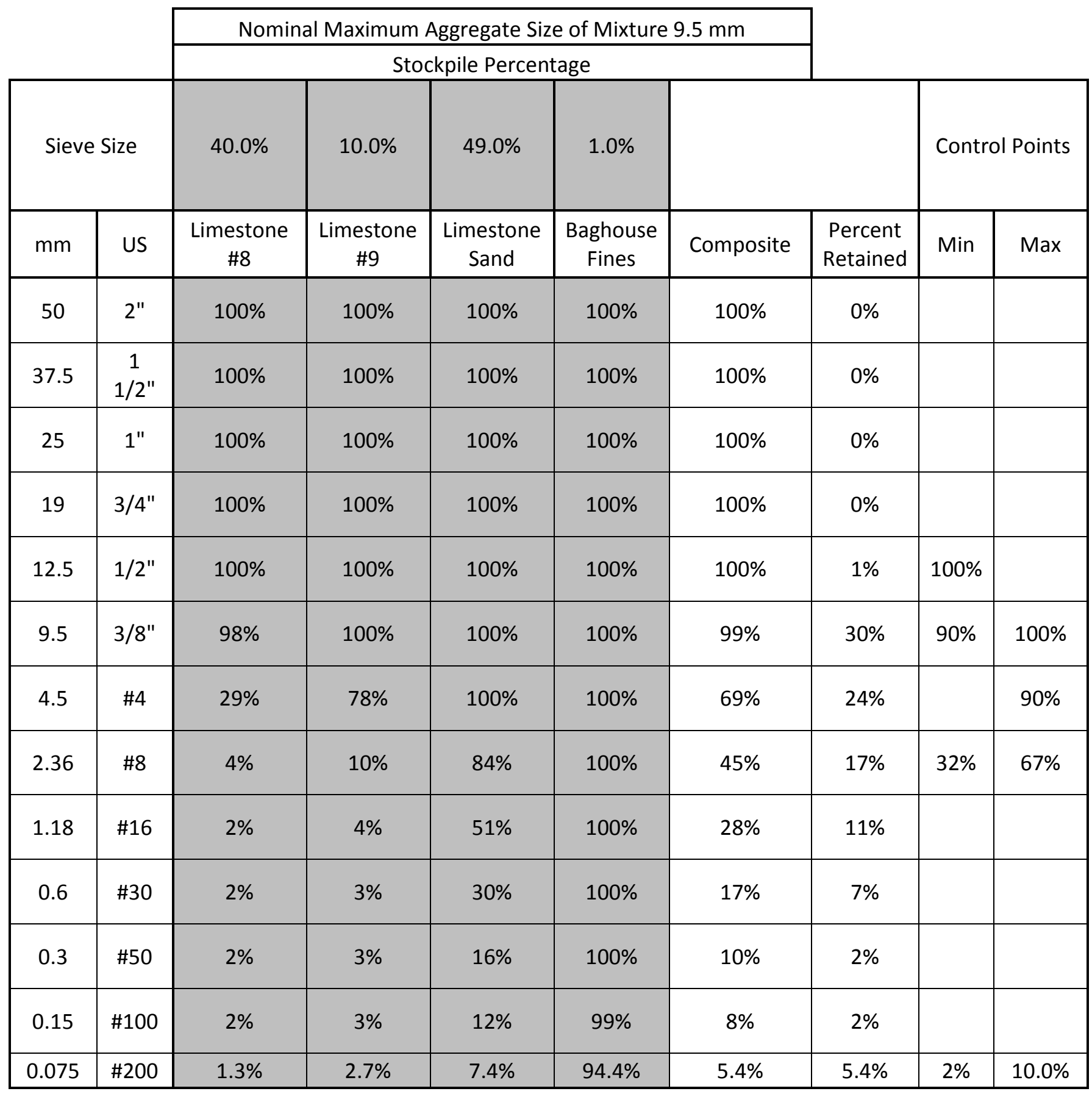


Table A 6. 80 Gyration Tukey Kramer Comparisons

Anova: Single

Factor

SUMMARY

\begin{tabular}{lrccr}
\hline \multicolumn{1}{c}{ Groups } & \multicolumn{1}{c}{ Count } & Sum & Average & Variance \\
\hline Coarse & 15 & 214.4406 & 14.29604 & 1.828064 \\
Fine & 15 & 230.4736 & 15.36491 & 1.372532 \\
Design & 15 & 256.2513 & 17.08342 & 0.8546 \\
\hline
\end{tabular}

\begin{tabular}{|c|c|c|c|c|c|c|}
\hline Source of Variation & SS & $d f$ & $M S$ & $F$ & P-value & F crit \\
\hline Between Groups & 59.32617 & 2 & 29.66309 & 21.9445 & 2.99E-07 & 3.219942 \\
\hline Within Groups & 56.77276 & 42 & 1.351732 & & & \\
\hline Total & 116.0989 & 44 & & & & \\
\hline
\end{tabular}

Tukey-Kramer Multiple Comparisons

\begin{tabular}{lr} 
Mean Group 1 & 14.30 \\
$\mathrm{n}$ Group 1 & 15 \\
Mean Group 2 & 15.36 \\
$\mathrm{n}$ Group 2 & 15 \\
Mean Group 3 & 17.08 \\
$\mathrm{n}$ Group 3 & 15 \\
MSW & 1.35 \\
Q Statistic & 3.44 \\
\hline
\end{tabular}

Comparison of Group 1 to Group 2

Absolute Difference $\quad 1.0689$

Standard Error of Difference $\quad 0.3002$

Critical Range $\quad 1.0327$

Means of Groups 1 and 2 are Different

Comparison of Group 1 to Group 3

Absolute Difference $\quad 2.7874$

Standard Error of Difference $\quad 0.3002$

Critical Range $\quad 1.0327$

Means of Groups 1 and 3 are Different

Comparison of Group 2 to Group 3

Absolute Difference $\quad 1.7185$

Standard Error of Difference $\quad 0.3002$

Critical Range $\quad 1.0327$

Means of Groups 2 and 3 are Different 
Table A 7. Coarse Graded 80 Gyration Samples

\begin{tabular}{|c|c|c|c|c|c|c|c|c|c|c|c|c|c|}
\hline $\begin{array}{l}\text { Sample } \\
\text { Number }\end{array}$ & $\begin{array}{l}\text { Percent } \\
\text { Binder }\end{array}$ & $\begin{array}{c}\text { Mass } \\
\text { of Dry } \\
\text { Sample } \\
\text { (g) }\end{array}$ & $\begin{array}{c}\text { Mass of } \\
\text { Submerged } \\
\text { Sample (g) }\end{array}$ & $\begin{array}{c}\text { Mass of } \\
\text { SSD } \\
\text { Sample } \\
\text { (g) }\end{array}$ & $\begin{array}{c}\text { Absorption } \\
\%\end{array}$ & $\mathrm{G}_{\mathrm{mb}}$ & VTM & VMA & $\mathrm{G}_{\mathrm{se}}$ & $P_{b a}$ & $P_{\text {be }}$ & VFA & $\begin{array}{l}\text { Tensile } \\
\text { Strength } \\
\text { (psi) }\end{array}$ \\
\hline 1 & \multirow{3}{*}{$5.0 \%$} & 4604.6 & 2615.4 & 4647.8 & $0.94 \%$ & 2.266 & $9.9 \%$ & 18.5 & 2.695 & $0.78 \%$ & $4.26 \%$ & $47 \%$ & 11.6 \\
\hline 2 & & 4628.0 & 2630.4 & 4683.1 & $1.19 \%$ & 2.255 & $10.4 \%$ & 18.9 & 2.695 & $0.78 \%$ & $4.26 \%$ & $45 \%$ & 11.7 \\
\hline 3 & & 4637.2 & 2614.3 & 4687.4 & $1.08 \%$ & 2.237 & $11.3 \%$ & 19.5 & 2.695 & $0.78 \%$ & $4.26 \%$ & $42 \%$ & 12.4 \\
\hline 4 & \multirow{3}{*}{$5.5 \%$} & 4622.9 & 2618.3 & 4645.6 & $0.49 \%$ & 2.280 & $8.4 \%$ & 18.4 & 2.695 & $0.78 \%$ & $4.76 \%$ & $54 \%$ & 14.1 \\
\hline 5 & & 4373.8 & 2477.3 & 4398.0 & $0.55 \%$ & 2.277 & $8.6 \%$ & 18.5 & 2.695 & $0.78 \%$ & $4.76 \%$ & $54 \%$ & 15.0 \\
\hline 6 & & 4642.5 & 2644.9 & 4664.4 & $0.47 \%$ & 2.299 & $7.6 \%$ & 17.7 & 2.695 & $0.78 \%$ & $4.76 \%$ & $57 \%$ & 14.5 \\
\hline 7 & \multirow{3}{*}{$6.0 \%$} & 4584.7 & 2601.6 & 4592.3 & $0.17 \%$ & 2.303 & $6.6 \%$ & 18.0 & 2.695 & $0.78 \%$ & $5.27 \%$ & $63 \%$ & 13.7 \\
\hline 8 & & 4636.0 & 2624.5 & 4643.4 & $0.16 \%$ & 2.296 & $6.9 \%$ & 18.3 & 2.695 & $0.78 \%$ & $5.27 \%$ & $62 \%$ & 15.0 \\
\hline 9 & & 4589.2 & 2602.3 & 4596.9 & $0.17 \%$ & 2.301 & $6.7 \%$ & 18.1 & 2.695 & $0.78 \%$ & $5.27 \%$ & $63 \%$ & 15.2 \\
\hline 10 & \multirow{3}{*}{$6.5 \%$} & 4588.0 & 2599.1 & 4594.7 & $0.15 \%$ & 2.299 & $6.0 \%$ & 18.6 & 2.695 & $0.78 \%$ & $5.77 \%$ & $68 \%$ & 14.9 \\
\hline 11 & & 4606.7 & 2627.9 & 4612.0 & $0.12 \%$ & 2.322 & $5.0 \%$ & 17.8 & 2.695 & $0.78 \%$ & $5.77 \%$ & $72 \%$ & 15.4 \\
\hline 12 & & 4620.3 & 2653.8 & 4626.4 & $0.13 \%$ & 2.342 & $4.0 \%$ & 17.1 & 2.695 & $0.78 \%$ & $5.77 \%$ & $76 \%$ & 15.6 \\
\hline 13 & \multirow{3}{*}{$7.0 \%$} & 4615.3 & 2633.1 & 4620.1 & $0.10 \%$ & 2.323 & $4.1 \%$ & 18.2 & 2.695 & $0.78 \%$ & $6.28 \%$ & $78 \%$ & 15.5 \\
\hline 14 & & 4621.2 & 2632.7 & 4623.9 & $0.06 \%$ & 2.321 & $4.2 \%$ & 18.3 & 2.695 & $0.78 \%$ & $6.28 \%$ & $77 \%$ & 14.7 \\
\hline 15 & & 4637.3 & 2643.4 & 4640.3 & $0.06 \%$ & 2.322 & $4.1 \%$ & 18.2 & 2.695 & $0.78 \%$ & $6.28 \%$ & $78 \%$ & 15.2 \\
\hline
\end{tabular}


Table A 8. Fine Graded 80 Gyration Samples

\begin{tabular}{|c|c|c|c|c|c|c|c|c|c|c|c|c|c|}
\hline $\begin{array}{l}\text { Sample } \\
\text { Number }\end{array}$ & $\begin{array}{l}\text { Percent } \\
\text { Binder }\end{array}$ & $\begin{array}{c}\text { Mass } \\
\text { of Dry } \\
\text { Sample } \\
\text { (g) }\end{array}$ & $\begin{array}{c}\text { Mass of } \\
\text { Submerged } \\
\text { Sample (g) }\end{array}$ & $\begin{array}{l}\text { Mass of } \\
\text { SSD } \\
\text { Sample } \\
\text { (g) }\end{array}$ & $\begin{array}{c}\text { Absorption } \\
\%\end{array}$ & $\mathrm{G}_{\mathrm{mb}}$ & VTM & VMA & $\mathrm{G}_{\mathrm{se}}$ & $P_{b a}$ & $P_{\text {be }}$ & VFA & $\begin{array}{l}\text { Tensile } \\
\text { Strength } \\
\text { (psi) }\end{array}$ \\
\hline 16 & \multirow{3}{*}{$5.0 \%$} & 4707.3 & 2666.3 & 4728.2 & $0.44 \%$ & 2.283 & $9.5 \%$ & 17.4 & 2.704 & $1.13 \%$ & $3.93 \%$ & $45 \%$ & 13.9 \\
\hline 17 & & 4637.9 & 2630.8 & 4661.8 & $0.52 \%$ & 2.284 & $9.5 \%$ & 17.4 & 2.704 & $1.13 \%$ & $3.93 \%$ & $45 \%$ & 12.9 \\
\hline 18 & & 4702.3 & 2669.9 & 4725.7 & $0.50 \%$ & 2.287 & $9.3 \%$ & 17.3 & 2.704 & $1.13 \%$ & $3.93 \%$ & $46 \%$ & 13.4 \\
\hline 19 & \multirow{3}{*}{$5.5 \%$} & 4698.8 & 2665.6 & 4708.9 & $0.21 \%$ & 2.300 & $7.8 \%$ & 17.2 & 2.704 & $1.13 \%$ & $4.43 \%$ & $55 \%$ & 15.0 \\
\hline 20 & & 4697.7 & 2671.3 & 4711.7 & $0.30 \%$ & 2.302 & $7.7 \%$ & 17.1 & 2.704 & $1.13 \%$ & $4.43 \%$ & $55 \%$ & 15.2 \\
\hline 21 & & 4684.3 & 2653.4 & 4695.3 & $0.23 \%$ & 2.294 & $8.1 \%$ & 17.4 & 2.704 & $1.13 \%$ & $4.43 \%$ & $54 \%$ & 15.5 \\
\hline 22 & \multirow{3}{*}{$6.0 \%$} & 4695.5 & 2665.4 & 4702.7 & $0.15 \%$ & 2.305 & $6.8 \%$ & 17.5 & 2.704 & $1.13 \%$ & $4.94 \%$ & $61 \%$ & 16.9 \\
\hline 23 & & 4696.1 & 2679 & 4702.8 & $0.14 \%$ & 2.320 & $6.1 \%$ & 16.9 & 2.704 & $1.13 \%$ & $4.94 \%$ & $64 \%$ & 16.0 \\
\hline 24 & & 4710.2 & 2685.6 & 4716.4 & $0.13 \%$ & 2.319 & $6.1 \%$ & 17.0 & 2.704 & $1.13 \%$ & $4.94 \%$ & $64 \%$ & 14.8 \\
\hline 25 & \multirow{3}{*}{$6.5 \%$} & 4712.8 & 2689.1 & 4717.3 & $0.10 \%$ & 2.324 & $5.0 \%$ & 17.3 & 2.704 & $1.13 \%$ & $5.44 \%$ & $71 \%$ & 16.5 \\
\hline 26 & & 4715.1 & 2690 & 4719.2 & $0.09 \%$ & 2.324 & $5.0 \%$ & 17.3 & 2.704 & $1.13 \%$ & $5.44 \%$ & $71 \%$ & 15.9 \\
\hline 27 & & 4701.9 & 2685.6 & 4705.8 & $0.08 \%$ & 2.327 & $4.8 \%$ & 17.1 & 2.704 & $1.13 \%$ & $5.44 \%$ & $72 \%$ & 15.6 \\
\hline 28 & \multirow{3}{*}{$7.0 \%$} & 4710.9 & 2695.8 & 4712.9 & $0.04 \%$ & 2.335 & $3.9 \%$ & 17.3 & 2.704 & $1.13 \%$ & $5.95 \%$ & $77 \%$ & 16.1 \\
\hline 29 & & 4698.5 & 2697 & 4699.7 & $0.03 \%$ & 2.346 & $3.5 \%$ & 16.9 & 2.704 & $1.13 \%$ & $5.95 \%$ & $79 \%$ & 16.7 \\
\hline 30 & & 4682.3 & 2686.4 & 4683.7 & $0.03 \%$ & 2.344 & $3.5 \%$ & 17.0 & 2.704 & $1.13 \%$ & $5.95 \%$ & $79 \%$ & 16.1 \\
\hline
\end{tabular}


Table A 9. Coarse Graded 80 Gyration Samples

\begin{tabular}{|c|c|c|c|c|c|c|c|c|c|c|c|c|c|}
\hline $\begin{array}{l}\text { Sample } \\
\text { Number }\end{array}$ & $\begin{array}{l}\text { Percent } \\
\text { Binder }\end{array}$ & $\begin{array}{c}\text { Mass } \\
\text { of Dry } \\
\text { Sample } \\
\text { (g) }\end{array}$ & $\begin{array}{c}\text { Mass of } \\
\text { Submerged } \\
\text { Sample (g) }\end{array}$ & $\begin{array}{l}\text { Mass of } \\
\text { SSD } \\
\text { Sample } \\
\text { (g) }\end{array}$ & $\begin{array}{c}\text { Absorption } \\
\%\end{array}$ & $\mathrm{G}_{\mathrm{mb}}$ & VTM & VMA & $\mathrm{G}_{\mathrm{se}}$ & $P_{b a}$ & $P_{b e}$ & VFA & $\begin{array}{c}\text { Tensile } \\
\text { Strength } \\
\text { (psi) }\end{array}$ \\
\hline 31 & \multirow{3}{*}{$5.0 \%$} & 4738.4 & 2710.5 & 4754.6 & $0.34 \%$ & 2.318 & $7.4 \%$ & 16.5 & 2.696 & $0.86 \%$ & $4.18 \%$ & $55 \%$ & 16.2 \\
\hline 32 & & 4730.2 & 2704.4 & 4743.3 & $0.28 \%$ & 2.320 & $7.4 \%$ & 16.4 & 2.696 & $0.86 \%$ & $4.18 \%$ & $55 \%$ & 15.7 \\
\hline 33 & & 4707.6 & 2696.2 & 4720.8 & $0.28 \%$ & 2.325 & $7.1 \%$ & 16.2 & 2.696 & $0.86 \%$ & $4.18 \%$ & $56 \%$ & 14.9 \\
\hline 34 & \multirow{3}{*}{$5.5 \%$} & 4735.3 & 2708.4 & 4742.4 & $0.15 \%$ & 2.328 & $6.2 \%$ & 16.5 & 2.696 & $0.86 \%$ & $4.69 \%$ & $62 \%$ & 16.6 \\
\hline 35 & & 4732.2 & 2706.4 & 4739.4 & $0.15 \%$ & 2.328 & $6.2 \%$ & 16.6 & 2.696 & $0.86 \%$ & $4.69 \%$ & $62 \%$ & 17.8 \\
\hline 36 & & 4740.5 & 2712.6 & 4747.2 & $0.14 \%$ & 2.330 & $6.1 \%$ & 16.5 & 2.696 & $0.86 \%$ & $4.69 \%$ & $63 \%$ & 17.5 \\
\hline 37 & \multirow{3}{*}{$6.0 \%$} & 4706.1 & 2694.6 & 4711.3 & $0.11 \%$ & 2.334 & $5.2 \%$ & 16.8 & 2.696 & $0.86 \%$ & $5.19 \%$ & $69 \%$ & 17.8 \\
\hline 38 & & 4700.9 & 2696.5 & 4707.8 & $0.15 \%$ & 2.337 & $5.1 \%$ & 16.7 & 2.696 & $0.86 \%$ & $5.19 \%$ & $70 \%$ & 17.7 \\
\hline 39 & & 4710.2 & 2700.2 & 4715.3 & $0.11 \%$ & 2.337 & $5.1 \%$ & 16.6 & 2.696 & $0.86 \%$ & $5.19 \%$ & $70 \%$ & 18.0 \\
\hline 40 & \multirow{3}{*}{$6.5 \%$} & 4691.7 & 2691.4 & 4694.9 & $0.07 \%$ & 2.342 & $4.1 \%$ & 16.9 & 2.696 & $0.86 \%$ & $5.70 \%$ & $76 \%$ & 16.6 \\
\hline 41 & & 4684.4 & 2694.1 & 4686.8 & $0.05 \%$ & 2.351 & $3.7 \%$ & 16.6 & 2.696 & $0.86 \%$ & $5.70 \%$ & $78 \%$ & 17.6 \\
\hline 42 & & 4690.4 & 2692.9 & 4692.7 & $0.05 \%$ & 2.345 & $4.0 \%$ & 16.8 & 2.696 & $0.86 \%$ & $5.70 \%$ & $76 \%$ & 17.3 \\
\hline 43 & \multirow{3}{*}{$7.0 \%$} & 4682.2 & 2711.6 & 4683.7 & $0.03 \%$ & 2.374 & $1.8 \%$ & 16.2 & 2.696 & $0.86 \%$ & $6.20 \%$ & $89 \%$ & 18.1 \\
\hline 44 & & 4674.0 & 2709.6 & 4675.5 & $0.03 \%$ & 2.378 & $1.7 \%$ & 16.1 & 2.696 & $0.86 \%$ & $6.20 \%$ & $90 \%$ & 17.3 \\
\hline 45 & & 4710.5 & 2729.7 & 4712.1 & $0.03 \%$ & 2.376 & $1.7 \%$ & 16.2 & 2.696 & $0.86 \%$ & $6.20 \%$ & $89 \%$ & 17.1 \\
\hline
\end{tabular}


Table A 10. Coarse Graded 100 Gyration Samples

\begin{tabular}{|c|c|c|c|c|c|c|c|c|c|c|c|c|c|}
\hline $\begin{array}{l}\text { Sample } \\
\text { Number }\end{array}$ & $\begin{array}{c}\text { Percent } \\
\text { Binder }\end{array}$ & $\begin{array}{c}\text { Mass } \\
\text { of Dry } \\
\text { Sample } \\
\text { (g) }\end{array}$ & $\begin{array}{c}\text { Mass of } \\
\text { Submerged } \\
\text { Sample (g) }\end{array}$ & $\begin{array}{l}\text { Mass of } \\
\text { SSD } \\
\text { Sample } \\
\text { (g) }\end{array}$ & $\begin{array}{c}\text { Absorption } \\
\%\end{array}$ & $\mathrm{G}_{\mathrm{mb}}$ & VTM & VMA & $\mathrm{G}_{\mathrm{se}}$ & $P_{b a}$ & $P_{\text {be }}$ & VFA & $\begin{array}{l}\text { Tensile } \\
\text { Strength } \\
\text { (psi) }\end{array}$ \\
\hline 46 & \multirow{3}{*}{$5.0 \%$} & 4658.7 & 2656.2 & 4704.7 & $0.99 \%$ & 2.274 & $8.7 \%$ & 18.2 & 2.695 & $0.8 \%$ & $4.3 \%$ & $52.4 \%$ & 10.3 \\
\hline 47 & & 4644.6 & 2635.8 & 4686.9 & $0.91 \%$ & 2.264 & $9.0 \%$ & 18.5 & 2.695 & $0.8 \%$ & $4.3 \%$ & $51.2 \%$ & 9.7 \\
\hline 48 & & 4658.8 & 2643.2 & 4699.3 & $0.87 \%$ & 2.266 & $9.0 \%$ & 18.5 & 2.695 & $0.8 \%$ & $4.3 \%$ & $51.4 \%$ & 10.3 \\
\hline 49 & \multirow{3}{*}{$5.5 \%$} & 4630.5 & 2630.8 & 4657.4 & $0.58 \%$ & 2.285 & $7.6 \%$ & 18.2 & 2.695 & $0.8 \%$ & $4.8 \%$ & $58.3 \%$ & 11.1 \\
\hline 50 & & 4650.4 & 2637.3 & 4676.2 & $0.55 \%$ & 2.281 & $7.8 \%$ & 18.4 & 2.695 & $0.8 \%$ & $4.8 \%$ & $57.8 \%$ & 12.2 \\
\hline 51 & & 4638.3 & 2627.5 & 4661.4 & $0.50 \%$ & 2.280 & $7.8 \%$ & 18.4 & 2.695 & $0.8 \%$ & $4.8 \%$ & $57.7 \%$ & 12.1 \\
\hline 52 & \multirow{3}{*}{$6.0 \%$} & 4666.7 & 2653.8 & 4674.9 & $0.18 \%$ & 2.309 & $6.0 \%$ & 17.8 & 2.695 & $0.8 \%$ & $5.3 \%$ & $66.5 \%$ & 12.0 \\
\hline 53 & & 4574.7 & 2598.9 & 4581.4 & $0.15 \%$ & 2.308 & $6.0 \%$ & 17.9 & 2.695 & $0.8 \%$ & $5.3 \%$ & $66.2 \%$ & 10.1 \\
\hline 54 & & 4582.6 & 2609.8 & 4590.1 & $0.16 \%$ & 2.314 & $5.8 \%$ & 17.6 & 2.695 & $0.8 \%$ & $5.3 \%$ & $67.3 \%$ & 11.9 \\
\hline 55 & \multirow{3}{*}{$6.5 \%$} & 4655.7 & 2651.2 & 4663.2 & $0.16 \%$ & 2.314 & $5.0 \%$ & 18.1 & 2.695 & $0.8 \%$ & $5.8 \%$ & $72.1 \%$ & 11.8 \\
\hline 56 & & 4617.4 & 2630.9 & 4623.3 & $0.13 \%$ & 2.318 & $4.9 \%$ & 18.0 & 2.695 & $0.8 \%$ & $5.8 \%$ & $72.7 \%$ & 11.3 \\
\hline 57 & & 4603.7 & 2622.8 & 4612.9 & $0.20 \%$ & 2.313 & $5.1 \%$ & 18.1 & 2.695 & $0.8 \%$ & $5.8 \%$ & $72.0 \%$ & 12.4 \\
\hline 58 & \multirow{3}{*}{$7.0 \%$} & 4642.1 & 2652.4 & 4647.1 & $0.11 \%$ & 2.327 & $3.7 \%$ & 18.0 & 2.695 & $0.8 \%$ & $6.3 \%$ & $79.4 \%$ & 11.9 \\
\hline 59 & & 4630.4 & 2645.9 & 4633.5 & $0.07 \%$ & 2.330 & $3.6 \%$ & 18.0 & 2.695 & $0.8 \%$ & $6.3 \%$ & $79.8 \%$ & 12.6 \\
\hline 60 & & 4637.5 & 2650.8 & 4641.2 & $0.08 \%$ & 2.330 & $3.6 \%$ & 18.0 & 2.695 & $0.8 \%$ & $6.3 \%$ & $79.9 \%$ & 13.1 \\
\hline
\end{tabular}


Table A 11. Fine Graded 100 Gyration Samples

\begin{tabular}{|c|c|c|c|c|c|c|c|c|c|c|c|c|c|}
\hline $\begin{array}{l}\text { Sample } \\
\text { Number }\end{array}$ & $\begin{array}{l}\text { Percent } \\
\text { Binder }\end{array}$ & $\begin{array}{c}\text { Mass } \\
\text { of Dry } \\
\text { Sample } \\
\text { (g) }\end{array}$ & $\begin{array}{c}\text { Mass of } \\
\text { Submerged } \\
\text { Sample (g) }\end{array}$ & $\begin{array}{c}\text { Mass of } \\
\text { SSD } \\
\text { Sample } \\
\text { (g) }\end{array}$ & $\begin{array}{c}\text { Absorption } \\
\%\end{array}$ & $\mathrm{G}_{\mathrm{mb}}$ & VTM & VMA & $\mathrm{G}_{\mathrm{se}}$ & $P_{b a}$ & $P_{b e}$ & VFA & $\begin{array}{l}\text { Tensile } \\
\text { Strength } \\
\text { (psi) }\end{array}$ \\
\hline 61 & \multirow{3}{*}{$5.0 \%$} & 4693.4 & 2662.5 & 4715.1 & $0.46 \%$ & 2.287 & $8.5 \%$ & 17.3 & 2.704 & $1.1 \%$ & $3.9 \%$ & $50.5 \%$ & 13.6 \\
\hline 62 & & 4696.1 & 2665 & 4715.5 & $0.41 \%$ & 2.290 & $8.4 \%$ & 17.1 & 2.704 & $1.1 \%$ & $3.9 \%$ & $51.0 \%$ & 14.1 \\
\hline 63 & & 4702.3 & 2670 & 4723.1 & $0.44 \%$ & 2.290 & $8.4 \%$ & 17.1 & 2.704 & $1.1 \%$ & $3.9 \%$ & $51.0 \%$ & 14.7 \\
\hline 64 & \multirow{3}{*}{$5.5 \%$} & 4657.2 & 2644.6 & 4668.3 & $0.24 \%$ & 2.301 & $7.2 \%$ & 17.2 & 2.704 & $1.1 \%$ & $4.4 \%$ & $58.1 \%$ & 13.2 \\
\hline 65 & & 4655.5 & 2643 & 4666.3 & $0.23 \%$ & 2.301 & $7.2 \%$ & 17.2 & 2.704 & $1.1 \%$ & $4.4 \%$ & $58.0 \%$ & 15.3 \\
\hline 66 & & 4662.3 & 2644.8 & 4669.9 & $0.16 \%$ & 2.302 & $7.2 \%$ & 17.2 & 2.704 & $1.1 \%$ & $4.4 \%$ & $58.2 \%$ & 14.2 \\
\hline 67 & \multirow{3}{*}{$6.0 \%$} & 4704.4 & 2679.9 & 4708.2 & $0.08 \%$ & 2.319 & $5.8 \%$ & 17.0 & 2.704 & $1.1 \%$ & $4.9 \%$ & $66.1 \%$ & 13.5 \\
\hline 68 & & 4701.1 & 2676.9 & 4705.8 & $0.10 \%$ & 2.317 & $5.8 \%$ & 17.1 & 2.704 & $1.1 \%$ & $4.9 \%$ & $65.7 \%$ & 14.1 \\
\hline 69 & & 4709.3 & 2676.2 & 4713.6 & $0.09 \%$ & 2.311 & $6.1 \%$ & 17.3 & 2.704 & $1.1 \%$ & $4.9 \%$ & $64.8 \%$ & 12.9 \\
\hline 70 & \multirow{3}{*}{$6.5 \%$} & 4687.5 & 2675.5 & 4690.5 & $0.06 \%$ & 2.326 & $4.6 \%$ & 17.2 & 2.704 & $1.1 \%$ & $5.4 \%$ & $73.0 \%$ & 16.6 \\
\hline 71 & & 4699.6 & 2691.5 & 4702.5 & $0.06 \%$ & 2.337 & $4.2 \%$ & 16.8 & 2.704 & $1.1 \%$ & $5.4 \%$ & $75.0 \%$ & 15.4 \\
\hline 72 & & 4702.9 & 2694.5 & 4705.6 & $0.06 \%$ & 2.338 & $4.1 \%$ & 16.7 & 2.704 & $1.1 \%$ & $5.4 \%$ & $75.3 \%$ & 14.2 \\
\hline 73 & \multirow{3}{*}{$7.0 \%$} & 4652.3 & 2679.9 & 4653.3 & $0.02 \%$ & 2.358 & $2.9 \%$ & 16.5 & 2.704 & $1.1 \%$ & $6.0 \%$ & $82.5 \%$ & 16.2 \\
\hline 74 & & 4702.3 & 2709.2 & 4703.1 & $0.02 \%$ & 2.358 & $2.8 \%$ & 16.5 & 2.704 & $1.1 \%$ & $6.0 \%$ & $82.7 \%$ & 16.0 \\
\hline 75 & & 4697.8 & 2701.9 & 4698.8 & $0.02 \%$ & 2.353 & $3.1 \%$ & 16.7 & 2.704 & $1.1 \%$ & $6.0 \%$ & $81.5 \%$ & 15.6 \\
\hline
\end{tabular}


Table A 12. Design Graded 100 Gyration Samples

\begin{tabular}{|c|c|c|c|c|c|c|c|c|c|c|c|c|c|}
\hline $\begin{array}{l}\text { Sample } \\
\text { Number }\end{array}$ & $\begin{array}{c}\text { Percent } \\
\text { Binder }\end{array}$ & $\begin{array}{c}\text { Mass } \\
\text { of Dry } \\
\text { Sample } \\
\text { (g) }\end{array}$ & $\begin{array}{c}\text { Mass of } \\
\text { Submerged } \\
\text { Sample (g) }\end{array}$ & $\begin{array}{l}\text { Mass of } \\
\text { SSD } \\
\text { Sample } \\
\text { (g) }\end{array}$ & $\begin{array}{c}\text { Absorption } \\
\%\end{array}$ & $\mathrm{G}_{\mathrm{mb}}$ & VTM & VMA & $\mathrm{G}_{\mathrm{se}}$ & $P_{b a}$ & $P_{\text {be }}$ & VFA & $\begin{array}{l}\text { Tensile } \\
\text { Strength } \\
\text { (psi) }\end{array}$ \\
\hline 76 & \multirow{3}{*}{$5.0 \%$} & 4687.2 & 2684.5 & 4701.4 & $0.30 \%$ & 2.324 & $6.7 \%$ & 16.2 & 2.696 & $0.9 \%$ & $4.2 \%$ & $58.8 \%$ & 15.3 \\
\hline 77 & & 4684.6 & 2679.9 & 4697.8 & $0.28 \%$ & 2.322 & $6.8 \%$ & 16.3 & 2.696 & $0.9 \%$ & $4.2 \%$ & $58.4 \%$ & 14.7 \\
\hline 78 & & 4683.6 & 2681.2 & 4696.8 & $0.28 \%$ & 2.324 & $6.7 \%$ & 16.3 & 2.696 & $0.9 \%$ & $4.2 \%$ & $58.8 \%$ & 14.7 \\
\hline 79 & \multirow{3}{*}{$5.5 \%$} & 4693.6 & 2683.7 & 4702.2 & $0.18 \%$ & 2.325 & $6.0 \%$ & 16.6 & 2.696 & $0.9 \%$ & $4.7 \%$ & $64.2 \%$ & 14.1 \\
\hline 80 & & 4690.9 & 2687.3 & 4702.7 & $0.25 \%$ & 2.328 & $5.9 \%$ & 16.6 & 2.696 & $0.9 \%$ & $4.7 \%$ & $64.6 \%$ & 15.4 \\
\hline 81 & & 4705.7 & 2692.3 & 4718 & $0.26 \%$ & 2.323 & $6.1 \%$ & 16.7 & 2.696 & $0.9 \%$ & $4.7 \%$ & $63.8 \%$ & 12.2 \\
\hline 82 & \multirow{3}{*}{$6.0 \%$} & 4690.8 & 2699.8 & 4695 & $0.09 \%$ & 2.351 & $4.3 \%$ & 16.2 & 2.696 & $0.9 \%$ & $5.2 \%$ & $73.6 \%$ & 13.6 \\
\hline 83 & & 4677.2 & 2692.7 & 4681.1 & $0.08 \%$ & 2.352 & $4.2 \%$ & 16.1 & 2.696 & $0.9 \%$ & $5.2 \%$ & $73.8 \%$ & 17.3 \\
\hline 84 & & 4683.4 & 2696.2 & 4687.6 & $0.09 \%$ & 2.352 & $4.2 \%$ & 16.1 & 2.696 & $0.9 \%$ & $5.2 \%$ & $73.7 \%$ & 16.5 \\
\hline 85 & \multirow{3}{*}{$6.5 \%$} & 4683.6 & 2695.7 & 4685.6 & $0.04 \%$ & 2.354 & $3.5 \%$ & 16.5 & 2.696 & $0.9 \%$ & $5.7 \%$ & $79.0 \%$ & 15.8 \\
\hline 86 & & 4671.8 & 2702.1 & 4673.4 & $0.03 \%$ & 2.370 & $2.8 \%$ & 15.9 & 2.696 & $0.9 \%$ & $5.7 \%$ & $82.5 \%$ & 16.0 \\
\hline 87 & & 4628.7 & 2682.3 & 4630.1 & $0.03 \%$ & 2.376 & $2.5 \%$ & 15.7 & 2.696 & $0.9 \%$ & $5.7 \%$ & $83.9 \%$ & 15.2 \\
\hline 88 & \multirow{3}{*}{$7.0 \%$} & 4682.3 & 2719.7 & 4683 & $0.01 \%$ & 2.385 & $1.3 \%$ & 15.9 & 2.696 & $0.9 \%$ & $6.2 \%$ & $91.7 \%$ & 18.1 \\
\hline 89 & & 4667.1 & 2711.3 & 4668.4 & $0.03 \%$ & 2.385 & $1.3 \%$ & 15.9 & 2.696 & $0.9 \%$ & $6.2 \%$ & $91.6 \%$ & 18.3 \\
\hline 90 & & 4672.2 & 2713.3 & 4673.1 & $0.02 \%$ & 2.384 & $1.4 \%$ & 15.9 & 2.696 & $0.9 \%$ & $6.2 \%$ & $91.4 \%$ & 18.4 \\
\hline
\end{tabular}


Table A 13. Maximum Theoretical Specific Gravity Samples

\begin{tabular}{|c|c|c|c|c|c|c|c|c|c|}
\hline Type & Sample & $\begin{array}{c}\text { Percent } \\
\text { Binder } \\
(\%)\end{array}$ & $\begin{array}{l}\text { Mass of } \\
\text { Calibrated } \\
\text { Pycnometer }\end{array}$ & $\begin{array}{c}\text { Mass of } \\
\text { Dry } \\
\text { Sample }\end{array}$ & $\begin{array}{c}\text { Mass of } \\
\text { Calibrated } \\
\text { Pycnometer } \\
\text { and Sample } \\
\text { Submerged }\end{array}$ & $\mathbf{G}_{\mathrm{mm}}$ & $\begin{array}{c}\text { Average } \\
\mathbf{G}_{\mathrm{mm}}\end{array}$ & $\mathbf{G}_{\mathrm{se}}$ & $\begin{array}{c}\text { Average } \\
\mathbf{G}_{\text {se }}\end{array}$ \\
\hline \multirow{15}{*}{ 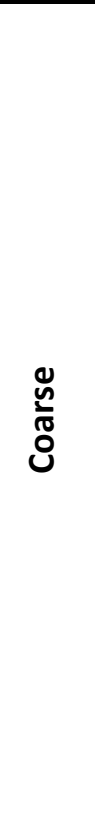 } & 1 & $5.0 \%$ & 1321.7 & 1508.9 & 2224.3 & 2.489 & \multirow{3}{*}{2.490} & 2.692 & \multirow{15}{*}{2.695} \\
\hline & 2 & $5.0 \%$ & 1321.7 & 1512.3 & 2226.8 & 2.491 & & 2.694 & \\
\hline & 3 & $5.0 \%$ & 1321.7 & 1503.7 & 2221.4 & 2.490 & & 2.693 & \\
\hline & 4 & $5.5 \%$ & 1321.7 & 1513.4 & 2222.3 & 2.470 & \multirow{3}{*}{2.473} & 2.692 & \\
\hline & 5 & $5.5 \%$ & 1321.7 & 1517.1 & 2225.5 & 2.474 & & 2.697 & \\
\hline & 6 & $5.5 \%$ & 1321.7 & 1521.6 & 2228.5 & 2.475 & & 2.698 & \\
\hline & 7 & $6.0 \%$ & 1321.7 & 1502.8 & 2212.1 & 2.454 & \multirow{3}{*}{2.456} & 2.695 & \\
\hline & 8 & $6.0 \%$ & 1321.7 & 1507.9 & 2215.8 & 2.457 & & 2.698 & \\
\hline & 9 & $6.0 \%$ & 1321.7 & 1511.2 & 2217.7 & 2.456 & & 2.698 & \\
\hline & 10 & $6.5 \%$ & 1321.7 & 1522.8 & 2220.7 & 2.441 & \multirow{3}{*}{2.437} & 2.702 & \\
\hline & 11 & $6.5 \%$ & 1321.7 & 1515.6 & 2215.7 & 2.438 & & 2.698 & \\
\hline & 12 & $6.5 \%$ & 1321.7 & 1509.4 & 2210.2 & 2.431 & & 2.689 & \\
\hline & 13 & $7.0 \%$ & 1321.7 & 1518.7 & 2211.2 & 2.414 & \multirow{3}{*}{2.417} & 2.689 & \\
\hline & 14 & $7.0 \%$ & 1321.7 & 1499.6 & 2201.6 & 2.420 & & 2.698 & \\
\hline & 15 & $7.0 \%$ & 1321.7 & 1509.4 & 2206.9 & 2.418 & & 2.695 & \\
\hline \multirow{15}{*}{ 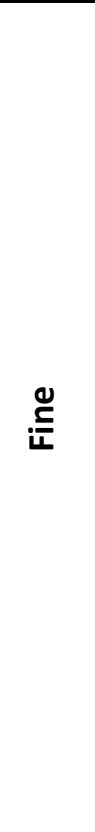 } & 16 & $5.0 \%$ & 1321.7 & 1516.3 & 2231.9 & 2.502 & \multirow{3}{*}{2.500} & 2.708 & \multirow{15}{*}{2.704} \\
\hline & 17 & $5.0 \%$ & 1321.7 & 1505.7 & 2225.1 & 2.500 & & 2.706 & \\
\hline & 18 & $5.0 \%$ & 1321.7 & 1511.2 & 2228.2 & 2.499 & & 2.705 & \\
\hline & 19 & $5.5 \%$ & 1321.7 & 1514.9 & 2225.8 & 2.480 & \multirow{3}{*}{2.480} & 2.705 & \\
\hline & 20 & $5.5 \%$ & 1321.7 & 1513.2 & 2224.1 & 2.477 & & 2.701 & \\
\hline & 21 & $5.5 \%$ & 1321.7 & 1508.3 & 2222.4 & 2.482 & & 2.708 & \\
\hline & 22 & $6.0 \%$ & 1321.7 & 1509.6 & 2218.8 & 2.465 & \multirow{3}{*}{2.461} & 2.709 & \\
\hline & 23 & $6.0 \%$ & 1321.7 & 1506.0 & 2216.8 & 2.465 & & 2.709 & \\
\hline & 24 & $6.0 \%$ & 1321.7 & 1511.9 & 2217.3 & 2.453 & & 2.694 & \\
\hline & 25 & $6.5 \%$ & 1321.7 & 1507.8 & 2211.7 & 2.441 & \multirow{3}{*}{2.439} & 2.701 & \\
\hline & 26 & $6.5 \%$ & 1321.7 & 1515.4 & 2213.4 & 2.430 & & 2.687 & \\
\hline & 27 & $6.5 \%$ & 1321.7 & 1507.4 & 2213.2 & 2.447 & & 2.710 & \\
\hline & 28 & $7.0 \%$ & 1321.7 & 1516.1 & 2212.5 & 2.425 & \multirow{3}{*}{2.427} & 2.704 & \\
\hline & 29 & $7.0 \%$ & 1321.7 & 1513.1 & 2211.0 & 2.426 & & 2.705 & \\
\hline & 30 & $7.0 \%$ & 1321.7 & 1509.7 & 2210.7 & 2.432 & & 2.714 & \\
\hline
\end{tabular}




\begin{tabular}{|c|c|c|c|c|c|c|c|c|c|}
\hline Type & Sample & $\begin{array}{c}\text { Percent } \\
\text { Binder } \\
(\%)\end{array}$ & $\begin{array}{c}\text { Mass of } \\
\text { Calibrated } \\
\text { Pycnometer }\end{array}$ & $\begin{array}{c}\text { Mass of } \\
\text { Dry } \\
\text { Sample }\end{array}$ & $\begin{array}{c}\text { Mass of } \\
\text { Calibrated } \\
\text { Pycnometer } \\
\text { and Sample } \\
\text { Submerged }\end{array}$ & $\mathbf{G}_{\mathrm{mm}}$ & $\begin{array}{c}\text { Average } \\
\mathbf{G}_{\mathrm{mm}}\end{array}$ & $\mathbf{G}_{\mathrm{se}}$ & $\begin{array}{c}\text { Average } \\
\mathbf{G}_{\mathrm{se}}\end{array}$ \\
\hline \multirow{15}{*}{ 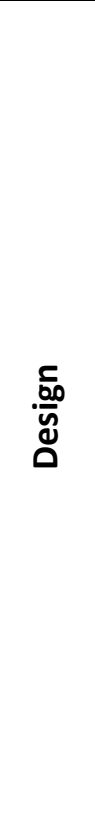 } & 31 & $5.0 \%$ & 1321.8 & 1512.3 & 2226.3 & 2.488 & \multirow{3}{*}{2.491} & 2.691 & \multirow{15}{*}{2.696} \\
\hline & 32 & $5.0 \%$ & 1321.8 & 1514.0 & 2229.4 & 2.497 & & 2.702 & \\
\hline & 33 & $5.0 \%$ & 1321.8 & 1502.3 & 2220.0 & 2.487 & & 2.690 & \\
\hline & 34 & $5.5 \%$ & 1321.8 & 1521.0 & 2228.3 & 2.475 & \multirow{3}{*}{2.473} & 2.699 & \\
\hline & 35 & $5.5 \%$ & 1321.8 & 1511.6 & 2223.1 & 2.477 & & 2.701 & \\
\hline & 36 & $5.5 \%$ & 1321.8 & 1513.5 & 2221.5 & 2.466 & & 2.687 & \\
\hline & 37 & $6.0 \%$ & 1321.8 & 1518.9 & 2223.2 & 2.460 & \multirow{3}{*}{2.456} & 2.702 & \\
\hline & 38 & $6.0 \%$ & 1321.8 & 1503.9 & 2214.4 & 2.460 & & 2.703 & \\
\hline & 39 & $6.0 \%$ & 1321.8 & 1503.8 & 2211.2 & 2.448 & & 2.687 & \\
\hline & 40 & $6.5 \%$ & 1321.5 & 1507.6 & 2211.1 & 2.439 & \multirow{3}{*}{2.438} & 2.700 & \\
\hline & 41 & $6.5 \%$ & 1321.5 & 1519.6 & 2217.4 & 2.436 & & 2.696 & \\
\hline & 42 & $6.5 \%$ & 1321.5 & 1498.4 & 2205.4 & 2.438 & & 2.698 & \\
\hline & 43 & $7.0 \%$ & 1321.5 & 1502.3 & 2200.5 & 2.410 & \multirow{3}{*}{2.417} & 2.685 & \\
\hline & 44 & $7.0 \%$ & 1321.5 & 1514.0 & 2210.2 & 2.421 & & 2.699 & \\
\hline & 45 & $7.0 \%$ & 1321.5 & 1511.7 & 2208.3 & 2.419 & & 2.697 & \\
\hline
\end{tabular}


Bessette, Logan P. 79 